\title{
Das italienische, europäische und internationale Markenrecht und Markenprozessrecht
}

\author{
Christoph Perathoner
}

\section{Einleitung}

Die Marken sind keine Erfindung der Moderne, sie lassen sich bis in die Antike zurückverfolgen. ${ }^{1}$ Der lateinische Begriff marca, der dem germanischen marka gleichzusetzen ist und im Mittelalter vor allem in den germanisch besiedelten Gebieten gebräuchlich war, stand für ein Grenzland, eine Mark eben, aber auch für ein Grenzzeichen, wie beispielsweise einen Grenzstein. Im lateinisch-römisch geprägten Sprachraum hingegen galt marca als ein Eigentums- und Herkunftsnachweis. ${ }^{2}$ Gerade dieser Begriff wurde im Mittelalter in Italien von Produzenten wie Händlern für das marcare [marchiare], also das Kennzeichnen einer Ware, aber vor allem auch für das Brandkennzeichnen ${ }^{3}$ von Tieren (ital. marchio a fuoco; engl. brand) ${ }^{4}$

\footnotetext{
${ }^{1}$ Umfassend dazu S. Di Palma, L'Histoire des marques depuis l'Antiquité jusqu'au Moyen Âge, Société des Écrivains, Paris, 2014.

${ }^{2}$ Vgl. L. Köster, Markenstärkemessung unter besonderer Berücksichtigung von Konsumentenheterogenität, Deutscher Universitätsverlag, Wiesbaden, 2006, S. 15.

${ }^{3}$ Es wurden auch Menschen gebrandmarkt, beispielsweise Sklaven in der Antike oder in den Vereinigten Staaten. Verbreitet war es in der Vergangenheit auch, verurteilte Kriminelle bei bestimmten Straftaten zu brandmarken (marchio d'infamia). Heute ist in diesem Zusammenhang das Branding als Form einer freiwilligen Body-Modification und Scarification eine Modeerscheinung.

${ }^{4}$ Die Begriffe marchio und brand sind aus rechtlicher Sicht keine Synonyme verschiedener Sprachherkunft. Der ursprünglich englische Begriff brand könnte in Italien am ehesten mit marca synonymisch übersetzt werden. Brand ist methodisch ein Begriff der Sozial- und Wirtschaftswissenschaften und widerspiegelt sie Gesamtidentität des Unternehmens, d. h. so wie das Image dieses Unternehmens am Markt wahrgenommen wird. Es spielt somit eine ganze Reihe von Faktoren mit, die das Unternehmen an sich als Werte verkörpert und die durch geschickte Kommunikation und
}

\author{
C. Perathoner $(\bowtie)$ \\ Rechtsanwaltssozietät Christoph Perathoner und Partner, Bozen, Italien \\ E-Mail: christoph.perathoner@ perathoner-partner.com
}


verwendet. Daraus entwickelte sich in Italien ab dem 16. Jahrhunderten der heute gebräuchliche Begriff des màrchio.

Im deutschen Sprachraum ist der Begriff Marke für die Bezeichnung eines Handels-, Waren- oder Fabrikzeichens seit dem frühen 18. Jahrhundert nachgewiesen. Dieser Begriff ist nicht dem Italienischen, sondern dem Französischen entlehnt, wo marque (marquer = kennzeichnen) - ähnlich dem Italienischen und Englischen - so viel wie das auf einer Ware eingebrachte Zeichen oder Kennzeichen hieß. ${ }^{5}$

Das Markenrecht hat in der Folgezeit - vor allem im 19. Jahrhundert ${ }^{6}$ - im nationalen und internationalen Handels- und Wirtschaftsrecht einen festen Platz eingenommen.

In den letzten Jahren und Jahrzehnten hat das Markenrecht - gegenüber früher Zeiten - entschieden an Bedeutung gewonnen. Dieser Umstand ist dem Wandel hin zur Informationsgesellschaft zuzurechnen. In der virtuellen Welt, die hier nicht nur als E-Commerce oder in der Ausprägung durch die sozialen Medien zu verstehen ist, erfolgt die moderne Informationsbeschaffung durch die Nutzung von Begriffen, die mittels Eingabe in Internet-Suchmaschinen die gewünschte Information beschaffen. Marken werden somit zum entscheidenden Informationsträger, mittels dem Unternehmen mit ihren Produkten und Dienstleistungen im global gewordenen Markt überhaupt erst gefunden und wahrgenommen werden. Das zwingt geradezu alle Unternehmen, die am Markt erfolgreich sein wollen, dazu, in ihre Marken zu investieren.

Das ist eines der Gründe, wieso bei Mergers and Acquisitions (M\&A) die Bewertungen der Marken in den letzten Jahren immer höhere Preise erzielt haben. Verschiedene Marktforschungsinstitute, die in diesem spezifischen Bereich tätig sind, bewerten heutzutage die reinen Markenwerte führender multinationaler Unternehmen im dreistelligen US-Dollar oder Euro Milliarden-Bereich. ${ }^{7}$ Bei Unternehmen in bestimmten Marksegmenten kann der Wert der Marke mehr als die Hälfte des Unternehmenswertes ausmachen. Registrierte Markenrechte stellen somit in den Handelsbilanzen ${ }^{8}$ von Unternehmen wichtige Werte dar. ${ }^{9}$

strategisches Marketing dem Markt vermittelt werden. Demnach versteht man unter brand image im Italienischen die imagine di marca und unter brand loyalty die fedeltà dei clienti alla marca. Unter branding versteht man die Entwicklung eines Markennamens und die Markenführung. Weiterführend: K. L. Keller/B. Busacca/M. C. Ostillio, La gestione del brand. Strategie e sviluppo, Egea, Milano 2005; A. Fittante, Brand, industrial design e made in Italy: la tutela giuridica. Lezioni di diritto della proprietà industriale, Giuffrè, Milano, 2. Aufl., 2017.

${ }^{5}$ Vgl. Duden, Das Herkunftswörterbuch. Etymologie der deutschen Sprache, Bd. 7, Dudenverlag, Berlin - Mannheim - Zürich, 5. Aufl., 2014, S. 544.

${ }^{6}$ Das erste italienische Markengesetz - das Königreich Italien (Regno d'Italia), wurde am 17. März 1861 gegründet - war die Legge 30.08.1868, n. 4577, concernente i marchi e segni di fabbrica, in: Gazzetta Ufficiale [del Regno d' Italia], 23.09.1868, n. 259. Zu diesem Markengesetz wurde eine Durchführungsverordnung erlassen: Regolamento 07.02.1869, n. 4860, in: Gazzetta Ufficiale [del Regno d' Italia], 16.02.1869, n. 47.

${ }^{7}$ Vgl. https://www.interbrand.com/best-brands/best-global-brands/2019/ranking/ oder https:// www.brandz.com/admin/uploads/files/BZ_Global_2018_DL.pdf (zugegriffen am 20.04.2020).

${ }^{8}$ Markenrechte sind gemäß Art. 2424 Codice civile (ital. Zivilgesetzbuch - c.c.) in der Jahresabschlussbilanz (bilancio) italienischer Unternehmen bei den Aktiva (attivo) unter dem Posten B)I „Immaterielles Anlagevermögen“ (immobilizzazioni [di natura] immateriale) und dann unter Punkt 4 gemeinsam mit Konzessionen und Lizenzen zu finden.

${ }^{9}$ Vgl. G. Fabbris/L. Minestroni, Valore e valori della marca. Come costituire una marca di suc- 
Aber ein weiterer Aspekt prägt seit wenigen Jahrzehnten das neue Markenrecht: das Markenrecht wurde in den letzten drei Jahrzehnten stark europäisiert und internationalisiert, während es historisch von der nationalen Territorialität geprägt ist. So wurden in der Vergangenheit Markenrechte vielfach ausschließlich mit einer auf das Staatsgebiet, in dem der Unternehmenssitz war, beschränkten Rechtswirksamkeit bei den Markenregistrierungsbehörden registriert. Nur größere, multinational agierende Unternehmen, haben auch internationale Marken registriert. Das hat sich grundlegend geändert. Mit der wachsenden Bedeutung des Markenrechts hat sich auch dieser Rechtsbereich verändert, sodass die Registrierung der erst vor rund dreißig Jahren eingeführten Unionsmarken (bis zum 23. März 2016: Gemeinschaftsmarke) und internationalen Marken heute durchaus von vielen Klein- und Mittelunternehmen vorgenommen wird. Dies muss ihnen darüber hinaus auch empfohlen werden.

In diesem Beitrag wird somit auch immer wieder ersichtlich, dass das italienische Markenrecht heute besonders stark von unionsrechtlichen Bestimmungen, aber auch von Instituten, die auf internationale Markenübereinkünfte zurück gehen, durchdrungen ist.

\section{Kennzeichenrecht: Unterscheidungszeichen und Marke}

\subsection{Unterscheidungszeichen}

Eine der wesentlichsten Voraussetzung für einen funktionierenden marktwirtschaftlichen Wettbewerb ist jener, dass alle Akteure am Markt möglichst klar und eindeutig unterschieden werden können. Um diese Markttransparenz garantieren zu können, müssen die Akteure aber so gekennzeichnet sein, dass sie selbst, ihre Funktion, ihre Tätigkeit und die somit erbrachten Waren und Dienstleistungen verwechslungsfrei wahrgenommen werden.

Das Unternehmen muss daher leicht individualisierbar und lokalisierbar sein. Diese Individualisierung kann das Unternehmen als solches, wie auch die Waren und Dienstleistungen des Unternehmens, oder auch den Herkunfts- und Produktionsort betreffen.

Hierfür wurde in der italienischen Rechtsordnung ein System von typischen und atypischen ${ }^{10}$, titulierten und nicht titulierten ${ }^{11}$ Unterscheidungszeichen im Sinne

cesso, Franco Angeli, Milano, 2004; A. Vanzetti, I marchi nel mercato globale, in: Rivista di diritto industriale, 2002, fasc. 1, S. 102.

${ }^{10}$ Vgl. Art. 1 Decreto Legislativo 10.02.2005, n. 30: Codice della proprietà industriale, a norma dell'articolo 15 della legge 12 dicembre 2002, n. 273, in: Gazzetta Ufficiale, 04.03.2005, n. 52, kurz „CPI“.

${ }^{11}$ Vgl. Art. 2 CPI. 
von Kennzeichenrechten ${ }^{12}$ geschaffen, wie beispielsweise die Firma (ditta) ${ }^{13}$, der Gesellschaftsname (ragione sociale bzw. denominazione sociale) ${ }^{14}$, die Geschäftsbezeichnung oder Geschäftsabzeichen (insegna) ${ }^{15}$, der Domainname (nome a dominio) $)^{16}$ und die Marke (marchio). ${ }^{17}$ Sie alle werden vom Gesetz geschützt, indem dem Unternehmer das Ausschließlichkeitsrecht ihrer Nutzung zuerkennt wird. Allerdings handelt es sich um ein begrenztes, warenbezogenes Ausschließlichkeitsrecht, das sich auf die Waren und/oder Dienstleistungen beschränkt, mit denen der Inhaber des Zeichens auftritt.

\subsection{Die Marke}

\subsubsection{Begriff}

Damit der Wettbewerb zwischen zwei oder mehreren Unternehmern korrekt und marktkonform ablaufen kann, müssen die Verbraucher, wie auch jeder andere Handels- und Geschäftspartner in die Lage versetzt werden, die angebotenen Waren und Dienstleistungen zu unterscheiden, ihre Vorzüge und Mängel zu erkennen, um sich anhand dieser Kriterien für die qualitativ Hochwertigeren, oder einfach jene, die sie aus anderen Gründen vorziehen, verwechslungsfrei entscheiden zu können.

Das marktrelevanteste von der italienischen Rechtsordnung geschützte Unterscheidungszeichen ist zweifellos die (Unternehmens-)Marke (marchio di impresa). Ihre Hauptfunktion besteht darin, Waren (prodotti) und Dienstleistungen (servizi) zu kennzeichnen, weshalb sie ein unverzichtbarer Informationsträger, aber auch Kommunikationsinstrument für Unternehmen und Verbraucher sind.

Die Marke wird sowohl von der (a) nationalen (marchio nazionale) als auch von der (b) unionsrechtlichen (marchio dell'Unione europea) und (c) internationalen Rechtsordnung (marchio internazionale) geregelt, wobei eine Marke auch gleich-

\footnotetext{
${ }^{12}$ Weiterführend, siehe V. Di Cataldo, I segni distintivi, 2. Aufl., Giuffrè, Milano, 1993; P. Kindler, Italienisches Handels- und Wirtschaftsrecht, Fachmedien Recht und Wirtschaft, Frankfurt am Main, 2. Aufl., 2013, S. 54 ff.

${ }^{13}$ Siehe Artt. 2563-2567 c.c.; engl. company name.

${ }^{14}$ Für die Gesellschaftsnamen gelten in der italienischen Rechtsordnung eigene Bestimmungen. Die Bezeichnungen der Personengesellschaften werden „ragione sociale“ (Artt. 2292, 2314 c.c.) genannt. Die Namen der Kapitalgesellschaften werden hingegen als „denominazione sociale“ (Artt. 2326, 2463, 1473 c.c.) bezeichnet.

${ }^{15}$ Siehe Art. 2568 c.c.; engl. business name.

${ }^{16}$ Wachsende Bedeutung gewinnen heute die domain names, die die (Markt-)Präsenz im virtuellen Raum eines Unternehmens bezeichnen, siehe dazu: C.A. Giusti, I nomi a dominio: un nuovo segno distintivo?, in: Diritto Mercato Tecnologia, 2016, 3, S. $24 \mathrm{ff}$.

${ }^{17}$ Für die engl. Bezeichnung des Begriffes Marke gibt es in den englischsprachigen Staaten unterschiedliche Schreibweisen: trademark (USA), trade mark (UK, EU, [ex-]Commonwealth) und trade-mark (CAN).
} 
zeitig in den Regelungsbereich aller drei Rechtsordnungen fallen kann, wie noch dargestellt sein wird.

Die nationale Marke ist in Art. 2569-2574 Codice civile (ital. Zivilgesetzbuch c.c.) sowie in den Artt. 7-28 des mit gesetzesvertretendem Dekret vom 10.02.2005, Nr. $30^{18}$ eingeführten Codice della proprietà intelettuale (Gesetzbuch des gewerblichen Eigentums - CPI) geregelt.

Die internationale Marke ist von der Pariser Verbandsübereinkunft zum Schutz des gewerblichen Eigentums von 1883 (Convenzione di Parigi per la protezione della proprietà industriale $)^{19}$ sowie vom Madrider Abkommen über die internationale Registrierung von Marken von 1891 (Accordo di Madrid per la registrazione internazionale dei marchi) ${ }^{20}$ samt Madrider Protokoll (Intesa di Madrid concernente la registrazione internazionale dei marchi $)^{21}$ geregelt.

Die Unionsmarke (früher Gemeinschaftsmarke; marchio comunitario) wurde mit der Verordnung (EG) 40/199422 eingeführt und wird heute grundlegend mit der Verordnung (EU) 2017/100123 normiert.

\subsubsection{Die Funktion der Marke}

Die wesentliche Funktion einer Marke besteht also in ihrer Unterscheidungsfunktion (funzione distintiva). ${ }^{24}$ Diese manifestiert sich in zwei weiteren wichtigen Funktionen, die eine Marken erfüllen sollte, nämlich der Herkunftsfunktion (funzione di indicazione di origine o di provenienza) und der Anziehungsfunktion (funzione attrattiva).

In der modernen Informationsgesellschaft gewinnen neben den drei klassischen, auch anderen Funktionen der Marke zunehmend an Bedeutung. Darunter lassen sich in besonderer Weise folgende Ausprägungen erkennen: die Qualitätsfunktion (funzione di

\footnotetext{
${ }^{18}$ Decreto Legislativo 10.02.2005, n. 30: Codice della proprietà industriale, a norma dell'articolo 15 della legge 12 dicembre 2002, n. 273, in: Gazzetta Ufficiale, 04.03.2005, n. 52.

${ }^{19} \mathrm{Vgl}$. https://www.wipo.int/export/sites/www/treaties/en/documents/pdf/paris.pdf (zugegriffen am 20.04.2020). Italien trat der Pariser Verbandsübereinkunft am 07.07.1884 bei und hat die heute geltende Stockholmer Fassung vom 14.07.1967 mit Legge 28.04.1976, n. 424: Ratifica ed esecuzione di accordi internazionali in materia di proprietà intellettuale, adottati a Stoccolma il 14 luglio 1967, in: Gazzetta Ufficiale, 19.06.1976, n. 160 ratifiziert.

${ }^{20}$ In Italien mit Legge 28.04.1976, n. 424 in der Stockholmer Fassung ratifiziert.

${ }^{21}$ In Italien ratifiziert mit Legge 12.03.1996, n. 169: Ratifica ed esecuzione del protocollo relativo alla intesa di Madrid concernente la registrazione internazionale dei marchi, firmato a Madrid il 27 giugno 1989, in: Gazzetta Ufficiale, 30.03.1996, n. 76.

${ }^{22}$ Verordnung (EG) Nr. 40/94 des Rates vom 20. Dezember 1993 über die Gemeinschaftsmarke, in: Amtsblatt, 14.01.1994, Nr. L 011.

${ }^{23}$ Verordnung (EU) 2017/1001 des Europäischen Parlaments und des Rates vom 14. Juni 2017 über die Unionsmarke (Text von Bedeutung für den EWR), in: Amtsblatt der Europäischen Union, 16.06.2017, L 154/1.

${ }^{24} \mathrm{Vgl}$. A. Vanzetti/V. Di Cataldo, Manuale di diritto industriale, 8. Aufl., Giuffrè, Milano, 2018, S. 148; P. Kindler, Italienisches Handels- und Wirtschaftsrecht, Fachmedien Recht und Wirtschaft, Frankfurt am Main, 2. Aufl., 2013, S. 61 f.
} 
qualità), die Garantiefunktion (funzione di garanzia [oder auch die garanzia qualitativa]), die Vertrauensfunktion (funzione di fiducia), die Identifizierungsfunktion (funzione identificativa), die Kommunikationsfunktion (funzione comunicativa), die Suggestivfunktion (funzione suggestiva) und die Werbefunktion (funzione pubblicitaria). ${ }^{25}$

Es lassen sich auch andere Funktionen der Marke herausarbeiten, aber mehreren Bestimmungen der italienischen Rechtsordnung (Art. 2569 c.c., Artt. 7 und 13, Abs. 2 und 3 CPI) ist zu entnehmen, dass der Gesetzgeber die Unterscheidungsfunktion als vorrangig ansieht, zumal die Marke vor allem ein Unterscheidungszeichen darstellt und als solche dem Verbraucher oder dem Geschäftspartner ermöglichen soll, die von einem bestimmten Unternehmen kommenden Waren und Dienstleistungen ohne Weiteres zu erkennen und von anderen verwechslungsfrei zu unterscheiden.

Die Unterscheidungsfunktion wird demnach dadurch bekräftigt, dass das Markenrecht ein Schutz gegen die tatsächliche Verwechselbarkeit oder die potenzielle Verwechslungsgefahr (tutela contro la confondibilità) darstellen soll. Dieser Schutz kommt nur dann zum Tragen, wenn die Verwendung der Marke oder eines markenähnlichen Zeichens seitens eines Mitbewerbers für identische oder ähnliche Waren oder Dienstleistungen zu einer Verwechslung bei Dritten führen kann. Man spricht in diesem Zusammenhang auch vom Grundsatz der Spezialität oder der Relativität des Markenschutzes (principio di relatività o specialità della tutela del marchio) ${ }^{26}{ }^{26}$ Die Möglichkeit, dass es beim Publikum zu einer Verwechslung über die Herkunft kommt, ist eben umso wahrscheinlicher, je ähnlicher die gekennzeichneten Waren oder Dienstleistungen sind.

Die Marke ist in der Regel auch ein Hinweis auf die Herkunft der Ware aus einer bestimmten Produktionsstätte (Herkunftsfunktion) und gewährleistet somit, wenngleich indirekt, die dauerhafte Beibehaltung identischer Wareneigenschaften. Nach der von der damaligen Europäischen Wirtschaftsgemeinschaft geprägten Markenrechtsreform des Jahres $1992^{27}$ hat diese Funktion allerdings eine deutliche Einschränkung erfahren. So wurde das Verbot aufgehoben, wonach die Marke nicht getrennt vom Unternehmen oder von einem Unternehmenszweig übertragen werden darf. Vor allem wurde es als rechtmäßig anerkannt, dass ein und dieselbe Marke aufgrund einer vom Markeninhaber eingeräumten nicht exklusiven Markenlizenz von mehreren verschiedenen Unternehmern gleichzeitig verwendet werden darf. Demzufolge ist es heute möglich, dass die gleiche, durch ein und dieselbe Marke gekennzeichnete Ware von unterschiedlichen Produzenten in Verkehr gebracht wird. Der Gesetzgeber hat im Bewusstsein dieser Ge-

\footnotetext{
${ }^{25}$ Weiterführend vgl. G. Haybäck, Marken- und Immaterialgüterrecht, LexisNexis, Wien, 2014, S. 10 f.; M. Ricolfi. Trattato dei Marchi. Diritto europeo e nazionale, Giappichelli, Torino, 2015, S. 40 ff.; G. Cuonzo/B. Marsicola, L'identità dell'impresa: i segni distintivi, in: Proprietà industriale, intellettuale e IT, Wolters Kluwer, Milano, 2017, S. 100; G. Sena, Il diritto dei marchi, Giuffrè, Milano, 2007, S. 45 ff.; A.G. Micara, Tutela del marchio e competitività nell'Unione Europea. Giappichelli, Torino, 2018, S. 79 ff.; F. Cionti, La funzione propria del marchio, Giuffrè, Milano, 2004.

${ }^{26} \mathrm{Vgl}$. A. Vanzetti/V. Di Cataldo, Manuale di diritto industriale, Giuffrè, Milano, 8. Aufl., 2018, S. 157.

${ }^{27}$ Siehe: Decreto Legislativo 04.12.1992, n. 480: Attuazione della direttiva n. 89/104/CEE del Consiglio del 21 dicembre 1988, recante ravvicinamento delle legislazioni degli Stati membri in materia di marchi di impresa, in: Gazzetta Ufficiale, 16.12.1992, n. 295.
} 
fahr für die Verbraucher in Art. 23, Abs. 4 CPI iVm Art. 2573 c.c. vorgesehen, dass bei der Übertragung bzw. Lizenzierung der Marke gewährleistet sein muss, dass dadurch keine Täuschung des Verbraucherpublikums in Bezug auf die wesentlichen Merkmale der Waren oder Dienstleistungen bewirkt wird. Die Täuschung ist nach Maßgabe von Art. 26, Bst. b) iVm Art. 14, Abs. 2 CPI zudem ein Grund für den Verfall der Marke, sofern die täuschende Benutzung geeignet ist, den Verbraucher über die Eigenschaften der gekennzeichneten Waren oder Dienstleistungen irrezuführen.

Berühmte bzw. bekannte Marken (marchi celebri) ${ }^{28}$ besitzen aufgrund ihres hohen Bekanntheitsgrades und ihrer Verknüpfung mit berühmten Persönlichkeiten ${ }^{29}$ oder mit herausragenden Ereignissen, eine Suggestivkraft. ${ }^{30}$ Dadurch kommt diesen Marken bei den Verbrauchern eine Anziehungskraft zu, die losgelöst von der Qualität und dem Preis der Ware bzw. der Dienstleistung ist und die ihren Ursprung in irrationalen und rein suggestiven Impulsen hat. Man spricht diesbezüglich von der bereits genannten Anziehungsfunktion der Marke. Damit einher geht das Interesse des Inhabers der berühmten Marke, die Benutzung dieser durch andere Unternehmer zu unterbinden, selbst wenn dies für Waren oder Dienstleistungen erfolgt, die sich von den vom Markeninhaber in den Verkehr gebrachten Waren oder Dienstleistungen völlig unterscheiden. Die heute geltenden Bestimmungen haben ausdrücklich eine Unterscheidung zwischen gewöhnlichen und berühmten Marken vorgenommen und den Schutz der berühmten Marken weiter gefasst als es durch die notwendige Vermeidung von Verwechslungen zwischen ähnlichen Waren bzw. Dienstleistungen geboten ist. Im Hinblick auf die berühmten Marken wird die gegebene Verwechslungsgefahr nicht mehr im Hinblick auf die vom Grundsatz der Spezialität gesetzten Grenzen beurteilt.

\subsection{Markenfähige Zeichen}

\subsubsection{Zusammensetzung der Marke}

Die Marke als Unterscheidungszeichen muss von der zu beschreibenden Ware bzw. Dienstleistung unterscheidbar sein und somit von diesem - zumindest gedanklich trennbar sein und somit keine rein beschreibende Wirkung haben. ${ }^{31}$

\footnotetext{
${ }^{28}$ Es sind auch Begriffe wie marchi rinomati oder marchi famosi gebräuchlich.

${ }^{29}$ Siehe dazu Art. 8 und auch 25, Abs. 1, Bst. c) CPI.

${ }^{30}$ Der Markeninhaber kann die Suggestivkraft der Marke mittels eines Merchandisingvertrags nutzen, was in der geschäftlichen Praxis auch sehr oft geschieht. Mit dem Merchandisingvertrag räumt der Inhaber einer berühmten und daher für alle Waren- und Dienstleistungsklassen geschützten Marke Dritten das Recht zur Benutzung dieser Marke für Waren bzw. Dienstleistungen ein, die zu einer völlig anderen Warengattung bzw. Dienstleistungsklasse gehören, für die die Marke ursprünglich verwendet wurde und Berühmtheit erlangt hat (z. B. Verwendung der Marke „Champagne“ für einen Badeschaum). Das Merchandising ist ein Teillizenzvertrag, da er sich in der Regel auf bestimmte Waren- bzw. Dienstleistungsklassen beschränkt.

${ }^{31}$ Die Marke als Unterscheidungszeichen sollte vor allem ein Zeichen sein, also eine wahrnehm-
} 
Bis zum Inkrafttreten der Richtlinie (EU) 2015/2436 ${ }^{32}$ musste eine Marke zum Zwecke der Registrierung grafisch darstellbar sein. Mit der neuen Richtlinie wird den Bedürfnissen nach modernen Markenformen Rechnung getragen ${ }^{33}$ und sich gleichzeitig an den technischen Möglichkeiten zur Darstellung einer Marke im mittlerweile elektronischen geführten Markenregister orientiert. Das Zeichen kann nunmehr in einer angemessenen Form unter Verwendung allgemein zugänglicher Technologie wiedergegeben werden, wobei die Wiedergabe eindeutig, präzise, abgeschlossen, leicht zugänglich, verständlich, dauerhaft und objektiv sein muss. ${ }^{34}$

Demzufolge können Marken im Sinne des Art. 7 CPI - in Umsetzung von Art. 3 Richtlinie (EU) 2015/2436 - Zeichen aller Art sein, die geeignet sind,

- Waren oder Dienstleistungen eines Unternehmens von denjenigen anderer Unternehmen zu unterscheiden und

- im Register in einer Weise dargestellt zu werden, dass die zuständigen Behörden und das Publikum den Gegenstand des ihrem Inhaber gewährten Schutzes klar und eindeutig bestimmen können.

Das Zeichen kann somit aus geläufigen Namen (marchio denominativo) ${ }^{35}$, beschreibenden Begriffen (marchio descrittivo) ${ }^{36}$ oder Fantasienamen (marchio di

bare Größe, die mit der Ware verknüpft und in der Lage ist, sie von anderen Waren zu unterscheiden. Gleichzeitig muss sie aber von der Ware und von deren Eigenschaften losgelöst sein, d. h. sie muss von der Ware trennbar sein, ohne deren Natur zu verfälschen; andernfalls wäre sie kein Unterscheidungszeichen mehr, sondern eine qualitative Eigenschaft der Ware. Dieser Grundsatz verneint die (potenziell ewige) Schutzwürdigkeit von technischen Innovationen (die durch die Patentierung als Erfindungen oder als Muster in den Genuss eines zeitlich begrenzten Schutzes kommen können), da diese Bestandteile der entsprechenden Ware und von dieser nicht trennbar sind, ohne sie zu verfälschen, vgl. A. Vanzetti/V. Di Cataldo, Manuale di diritto industriale, Giuffrè, Milano, 8. Aufl., 2018, S. $161 \mathrm{ff}$.

${ }^{32}$ Richtlinie (EU) 2015/2436 des Europäischen Parlaments und des Rates vom 16. Dezember 2015 zur Angleichung der Rechtsvorschriften der Mitgliedstaaten über die Marken, in: Amtsblatt der Europäischen Union, 23.12.2015, L 336/1. In Italien umgesetzt mit Decreto Legislativo, 20.02.2019, n. 15: Attuazione della direttiva (UE) 2015/2436 del Parlamento europeo e del Consiglio, del 16 dicembre 2015, sul ravvicinamento delle legislazioni degli Stati membri in materia di marchi d'impresa nonché per l'adeguamento della normativa nazionale alle disposizioni del regolamento (UE) 2015/2424 del Parlamento europeo e del Consiglio, del 16 dicembre 2015, recante modifica al regolamento sul marchio comunitario, in: Gazzetta Ufficiale, 08.03.2019, n. 57.

${ }^{33} \mathrm{Vgl}$. A. G. Micara, Tutela del marchio e competitività nell'Unione Europea. Giappichelli, Torino, 2018, S. 74 ff.; M. Delluniversitá, Via il simbolo grafico, registrabili i segni anche non tradizionali, in: Guida al diritto, 2019, fasc. 25, S. 57 ff.; A. Sirotti Gaudenzi, Marchio Ue, sparisce il criterio del segno grafico, in: Guida al diritto, 2018, fasc. 3, S. 73 ff.; W. Olins, Brand New. The Shape of Brands to Come, Thames \& Hudson, London, 2014.

${ }^{34}$ Vgl. Erwägungsgrund Nr. 13 der Richtlinie (EU) 2015/2436.

${ }^{35}$ Gebräuchlich ist auch marchio verbale.

${ }^{36}$ Beschreibende Marken, die eine Ware oder ein Produkt beschreiben, sind an sich nicht registrierungsfähig (siehe Art. $13 \mathrm{CPI}$ ) und wenn sie registriert wurden, sind sie einem hohen Risiko ausgesetzt, gerichtlich für nichtig erklärt zu werden. Sie können aber dann erfolgreich registriert werden, wenn sie durch eine optisch dominierende, kreative, grafische Stilisierung abgebildet werden. In diesem Fall ist aber das grafische Moment dem Inhaltlich-Begrifflichen übergeordnet. Dasselbe gilt bei Buchstaben, z. B. das grafisch stilisierte „M“ auf rotem Feld bei Mc Donald's oder Zahlen, z. B. die auseinander geschnitten wirkenden Zahl „500“ bei Fiat Cinquecento. 
fantasia) in den unterschiedlichsten Wortkombinationen, Personennamen (marchio patronimico) $)^{37}$, aber auch aus Abbildungen (marchio figurativo) ${ }^{38}$, Buchstaben, Zahlen $^{39}$, oder Kombinationen (marchio complesso) daraus bestehen. Darüber hinaus können Marken auch Klänge (marchio sonoro) ${ }^{40}$, Formen (marchio di for$m a)^{41}$, Muster (marchio a motivi ripetuti) ${ }^{42}$, Farben (marchio di colore) ${ }^{43}$, besondere Aneinanderreihungen oder Zusammenfügungen (marchio d'insieme), bestimmte Positionierungen von Charakteristika (marchio di posizione) und Bewegungen (marchio di movimento) zum Gegenstand haben. Die Registrierbarkeit von Gerüchen (marchio olfattivo) ${ }^{44}$ ist und bleibt hingegen - gelinde gesagt - umstritten. ${ }^{45}$

\footnotetext{
${ }^{37}$ Luis Trenker, UM 1043614. Vielfach bestehen die Marken auch nur aus dem Familiennamen oder den Vornamen. Das ist bei bestimmten Marken in der Modewelt sehr geläufig, wie z.B. Valentino [Clemente Ludovico Garavani], [Dante] Trussardi, [Adele und Edolardo] Fendi, [Mario] Prada, [Guccio] Gucci. Vgl. A. Sirotti Gaudenzi, Preuso di marchi di fatto: la prova deve essere rigorosa anche nel caso di patronimico, in: Quotidiano Giuridico, 2016.

${ }^{38}$ „adidas“ UM 005271598.

${ }^{39} 8025$ Genuin Alpine Gin, IT 302016000124190.

${ }^{40}$ „Brüllender Löwe“, UM 005170113.

${ }^{41}$ Hinsichtlich von Formmarken stellt Art. 9 CPI klar, dass jene Formen nicht eintragungsfähig sind, die durch die Warenform oder andere von der Natur bestimmten Eigenschaften der Waren vorgegebenen sind (warenbedingte Formen), die Formen oder Eigenschaften, die zur Erzielung eines technischen Ergebnisses notwendig sind (technisch notwendige Formen) und/oder jene Formen oder Eigenschaften, die der Ware einen wesentlichen Wert verleihen (wertbedingte Formen). Demzufolge können die Formen der Waren dann eine schutzfähige Marke darstellen, wenn sie aus technischer oder wertbedingter Sicht absolut unerheblich sind und wenn es sich also um willkürliche, unbegründete oder kapriziöse Formen handelt, deren alleinige Funktion darin besteht, die Ware zu erkennen (z. B. Coca-Cola Flasche, UM 010532653).Weiterführend zur Registrierfähigkeit von Formmarken im unionsrechtlichen Kontext vgl. A.G. Micara, Tutela del marchio e com-
} petitività nell'Unione Europea. Giappichelli, Torino, 2018, S. 70 ff.

${ }^{42}$ Burberry, UM 000377580.

${ }^{43}$ RAL 3003 (Victorinox), UM 002087005.

${ }^{44}$ Die einzige erfolgreich registrierte Gemeinschaftsgeruchmarke The smell of fresh cut grass, UM 000428870, ist am 11.12.2006 ausgelaufen und wurde nicht erneuert.

In der Entscheidung vom 12.12.2002, Sieckmann/Deutsches Patent- und Markenamt stellte der EUGH fest, dass ein „Zeichen, das als solches nicht visuell wahrnehmbar ist, eine Marke sein kann, sofern insbesondere mit Hilfe von Figuren, Linien oder Schriftzeichen grafisch dargestellt werden kann und die Darstellung klar, eindeutig, in sich abgeschlossen, leicht zugänglich, verständlich, dauerhaft und objektiv ist.", vgl. Urteil vom 12.12.2002, C-273/00, Sieckmann/Deutsches Patent- und Markenamt, in: ECLI:EU:C:2002:748.

Abgelehnt wurde der Duft einer reifen Erdbeere, zumal es ,nicht nur einen einzigen Erdbeerduft gebe und demzufolge die Beschreibung weder eindeutig und präzise noch frei von subjektiven Wahrnehmbarkeiten " sei, vgl. EuG, Urteil vom 27.10.2005, T-305/04, Eden SARL/HABM, in: ECLI:EU:T:2005:380. Auch ,nicht ausreichend ist die Darstellung eines Geruchs in Form eines nur für Fachleute der Parfümindustrie verständlichen Farbcodes“, weshalb der Schutz für den Duft Grasgrün, Zitrusfrüchten (Bergamotte, Zitrone), Blumen (Orangenblüten, Hyazinthe), Rosen, Moschus abgelehnt worden ist, vgl. Geruchsmarke UM 000521914: EUIPO, Entscheidung vom 19.01.2004, R 186/2000-4, in: https://euipo.europa.eu/copla/trademark/data/000521914/download/CLW/APL/2004/EN/20040119_R0186_2000-4.pdf?app=caselaw \&casenum=R0186/2000-4\&trTypeDoc=Human\&sourceLang=fr (zugegriffen am 20.04.2020).

${ }^{45}$ Unter dem Gesichtspunkt der Richtlinie (EU) 2015/2436 scheint eine Registrierfähigkeit von 
Durch den Wegfall des Erfordernisses der grafischen Darstellbarkeit können, vorausgesetzt, dass die Zeichen schutzfähig sind, insbesondere Klangmarken (marchio sonoro), Multimediamarken (marchio multimediale), oder Hologramme (marchio olografico) in den vorgesehenen elektronischen Formaten sowie sonstige Markenformen eingetragen werden.

\subsubsection{Art der Marken}

Die Marken lassen sich nach verschiedenen Kriterien einteilen und bezeichnen.

Aus Sicht der Art der Unternehmenstätigkeit des Markeninhabers wird zwischen Fabrikmarken oder Herstellermarken (marchio di fabbrica) ${ }^{46}$, Handelsmarken (marchio di commercio $)^{47}$ sowie Waren- (marchio di prodotto) und Dienstleistungsmarken (marchio di servizio $)^{48}$ unterschieden.

Die Unterscheidung zwischen Fabrikmarke und Handelsmarke ist insofern relevant, zumal es dem Händler gemäß Art. 20, Abs. 3 CPI gestattet ist, seine eigene Marke auf den von ihm zum Verkauf angebotenen Waren anzubringen. Gleichzeitig ist es ihm jedoch untersagt, die Marke des eigentlichen Herstellers, beziehungsweise des Händlers, von dem er die Ware gegebenenfalls erhalten hat, zu entfernen.

Eine weitere Unterscheidung wird aus Sicht der Waren, auf denen die Marke angebracht wird, vorgenommen, wobei zwischen Spezialmarke (marchio speciale) und Generalmarke (marchio generale) unterschieden wird. Während der Markeninhaber die Spezialmarke nur zur Kennzeichnung einer spezifischen Ware (Warentyp) verwendet (z. B. Fiat Panda), wird mit der Generalmarke eine Gesamtheit von,

Gerüchen nicht gegeben zu sein, zumal die Marke weiterhin im Register in irgendeiner Weise dargestellt sein muss; vgl. G. Sena/S. Giudici, Il civilista: La nuova disciplina di marchi e brevetti, Giuffrè, Milano, 2019, S. 9 f.

${ }^{46}$ Mit der Fabrikmarke werden Waren gekennzeichnet, die vom Markeninhaber selbst hergestellt werden. Die Marke wird vom Hersteller auf der Ware angebracht. Güter, die anschließend weiterbearbeitet werden, oder die aus dem Zusammenbau von getrennt hergestellten Teilen entstehen (ein Auto beispielsweise), können auch mehrere Fabrikmarken tragen.

${ }^{47}$ Die Handelsmarke wird vom Wiederverkäufer auf von Dritten hergestellten Waren angebracht (z. B. Eigenmarke von Supermärkten), wobei jedoch der Wiederverkäufer die Marke des Herstellers nicht entfernen darf (Art. 2572 c.c.).

${ }^{48}$ Mit der Dienstleistungsmarke werden im Gegensatz zur Warenmarke keine Waren, sondern Dienstleistungen, genauer gesagt die Tätigkeit von Unternehmen der Sektoren Transport und Kommunikation, Werbung, Bau, Versicherungs- und Kreditwesen, Schauspiel, Rundfunk und Fernsehen, Bearbeitung von Materialien, gekennzeichnet. Die Dienstleistungsmarke wurde mit Art. 3, Legge 24.12.1959, n. 1178: Ratifica ed esecuzione dei seguenti Accordi internazionali: a) Accordo di Madrid del 14 aprile 1891 concernente la registrazione internazionale dei marchi di fabbrica o di commercio, riveduto a Bruxelles il 14 dicembre 1900, a Washington il 2 giugno 1911, all'Aja il 6 novembre 1925, a Londra il 2 giugno 1934 ed a Nizza il 15 giugno 1957; b) Accordo di Nizza del 15 giugno 1957 concernente la classificazione internazionale dei prodotti e dei servizi ai quali si applicano i marchi di fabbrica o di commercio, in: Gazzetta Ufficiale, 16.01.1960, n. 12 in die italienische Rechtsordnung eingeführt. 
eventuell auch heterogenen, Waren - die der Markeninhaber herstellt oder verkauft - gekennzeichnet (z. B. Fiat).

Schließlich können die Marken auch aus Sicht der Gestalt des Zeichens unterschieden werden. Demnach unterscheidet man die einfache Marke (marchio semplice), welche aus einem einzigen Element besteht, von sogenannten komplexen Marken (marchio complesso). Letztere bestehen aus der Zusammenfügung mehrerer Elemente, von denen eine jede eine autonome Unterscheidungskraft besitzt.

Schlussendlich kann auch aus Sicht des Markeninhabers zwischen der Individualmarke und der Kollektivmarke unterschieden werden. Während Individualmarken (marchio individuale) von jedem Unternehmer - oder auch von mehreren physischen wie juristischen Personen als Unternehmer gemeinsam ${ }^{49}$ - registriert und auch verwendet werden können, steht die Registrierung einer Kollektivmarke (marchio collettivo $)^{50}$ nur spezifischen vom Gesetz bestimmten Rechtssubjekten zu.

Das Rechtsinstitut der Kollektivmarke hat in Italien im Zuge der Anpassung an die Verordnung (EU) 2015/2424 im Jahre 2019 eine einschneidende Novellierung ${ }^{51}$ erfahren, sodass nun zwischen (a) Kollektivmarken (marchi collettivi) $)^{52}$ und (b) Garantie- oder Zertifizierungsmarken (marchi di garanzia oder marchi di certificazione $^{53}$ grundlegend zu unterscheiden ist.

Für die Kollektivmarken ist der Umstand charakterisierend, dass die Inhaber der Kollektivmarken die Nutzung derselben einzelnen Herstellern, Händlern oder Dienstleistern übertragen können, sodass es zu einer Mehrfachnutzung derselben Marke durch mehrere verschiedene Unternehmen kommt, wobei der Kollektivmarkeninhaber in der Regel diese gar nicht selbst nutzt. Die Finalität einer Kollektivmarke besteht darin, die spezifische Herkunft, die Art oder die Beschaffenheit wie die Qualität bestimmter Waren oder Dienstleistungen zu garantieren. Die Unternehmen, die diese Marke nutzen, müssen also die Standards erfüllen, die der Kollektivmarkeninhaber vorgibt. Aus formalrechtlicher Sicht ist deshalb der Umstand zentral, dass für jede Kollektivmarke eine eigene Markensatzung, oder ein entsprechendes Reglement (regolamento concernente l'uso del marchio collettivo oder disciplinare) urkundlich errichtet werden muss, dem alle Unternehmen, die diese Kollektivmarke verwenden, verpflichtet werden. In einer solchen Markensatzung werden beispielsweise die Voraussetzungen festgeschrieben, die erfüllt werden müssen, um

\footnotetext{
${ }^{49}$ Vgl. Art. 6 CPI; entsprechend für die Unionsmarke Art. 19, Abs. 3 Verordnung (EU) 2017/1001.

${ }^{50}$ Weiterführend zu Kollektivmarken vgl. C. Galli, Profilo giuridico del marchio collettivo privato, Edizioni Scientifiche Italiane, Napoli, 2019; M. Ricolfi. Trattato dei Marchi. Diritto europeo e nazionale, Giappichelli, Torino, 2015, S. 1753 ff.; G. Cuonzo/B. Marsicola, L'identità dell'impresa: i segni distintivi, in: Proprietà industriale, intellettuale e IT, Wolters Kluwer, Milano, 2017, S. 224.

${ }^{51}$ Decreto Legislativo 20.02.2019, n. 15: Attuazione della direttiva (UE) 2015/2436 del Parlamento europeo e del Consiglio, del 16 dicembre 2015, sul ravvicinamento delle legislazioni degli Stati membri in materia di marchi d'impresa nonché' per l'adeguamento della normativa nazionale alle disposizioni del regolamento (UE) 2015/2424 del Parlamento europeo e del Consiglio, del 16 dicembre 2015, recante modifica al regolamento sul marchio comunitario, in: Gazzetta Ufficiale, 08.03.2019, n. 57.

${ }^{52} \mathrm{Vgl}$. Art. 11 CPI.

${ }^{53}$ Vgl. Art. 11-bis CPI.
} 
die entsprechenden Kollektivmarken nutzen zu können. Zudem müssen auch Kontrollmechanismen und Sanktionen vorgesehen sein, für den Fall, dass es zu Übertretungen oder Satzungsverletzungen kommt, damit die festgeschriebenen Standards gehalten werden können. Seit der Reform im Jahre 2019 legt Art. 11 CPI $^{54}$ fest, dass die Registrierung von Kollektivmarken folgenden Subjekten zusteht: juristischen Personen öffentlichen Rechts, d. h. dem Staat, wie auch allen anderen öffentlichen Körperschaften, sowie Fach- und Berufsverbänden von Herstellern, Erzeugern, Dienstleistern oder Händlern. Damit ist es Aktiengesellschaften, Gesellschaften mit beschränkter Haftung oder Kommanditgesellschaften auf Aktien untersagt, Kollektivmarken zu registrieren.

Die Garantie- oder Zertifizierungsmarken im Sinne des Art. 11-bis CPI ${ }^{55}$ sind eine neue Art von Marken, deren Zweck es ist, bestimmte Eigenschaften von Waren und Dienstleistungen zu zertifizieren. Im Gegensatz zu Kollektivmarken können alle natürlichen oder juristischen Personen - somit auch Behörden, Institutionen, Berufsverbände, Interessensvertretungen usw. - die Eintragung von Zertifizierungsmarken beantragen, um den Ursprung, die Art oder die Qualität bestimmter Waren oder Dienstleistungen zu garantieren. Der Gesetzgeber verlangt allerdings, dass der Zertifizierungsmarkeninhaber keine Tätigkeit ausüben darf, die die Bereitstellung von Waren oder Dienstleistungen des zertifizierten Typs beinhaltet. Zertifizierungsmarken können in Abweichung zu Art. 13, Abs. 1, Bst. b) CPI aus geografischen Bezeichnungen bestehen, oder diese enthalten. In diesem letzten Fall ist der Inhaber allerdings nicht dazu berechtigt, Dritten die Benutzung des geografischen Namens im geschäftlichen Verkehr zu verbieten, sofern diese Benutzung den Grundsätzen der gewerblichen Lauterkeit entspricht. Bei Antrag auf Eintragung einer Zertifizierungsmarke muss, gleich wie bei der Kollektivmarke, eine Markensatzung (regolamento d'uso) hinterlegt werden.

Es darf in diesem Zusammenhang kurz darauf hingewiesen werden, dass Italien das europäische Land mit der höchsten Anzahl von Lebensmittelprodukten mit Herkunftsbezeichnung und geografischer Angabe ist, die von der Europäischen Union anerkannt sind ${ }^{56}$ Die Grundlage für diese geografischen Ursprungsbezeichnungen findet sich im Sekundärrecht der Europäischen Union. Die Verordnung (EG) Nr. 479/2008 betrifft geografische Angaben für Weine und wurde durch die Verord-

\footnotetext{
${ }^{54}$ Vgl. Art. 3 Decreto Legislativo 20.02.2019, n. 15: Attuazione della direttiva (UE) 2015/2436 del Parlamento europeo e del Consiglio, del 16 dicembre 2015, sul ravvicinamento delle legislazioni degli Stati membri in materia di marchi d'impresa nonché' per l'adeguamento della normativa nazionale alle disposizioni del regolamento (UE) 2015/2424 del Parlamento europeo e del Consiglio, del 16 dicembre 2015, recante modifica al regolamento sul marchio comunitario, in: Gazzetta Ufficiale, 08.03.2019, n. 57.

${ }^{55}$ Eingeführt durch Art. 4 Decreto Legislativo 20.02.2019, n. 15.

${ }^{56} \mathrm{Vgl}$. die Angaben der Website des italienischen Agrar-, Lebensmittel- und Forstministeriums https://www.politicheagricole.it/flex/cm/pages/ServeBLOB.php/L/IT/IDPagina/396 (zugegriffen am 20.04.2020).
} 
nung (EG) Nr. 491/200957 ersetzt. Die Verordnung (EG) Nr. 110/2008 ${ }^{58}$ betrifft geografische Angaben für Spirituosen. Die Verordnung (EU) Nr. 1151/2012 $2^{59}$ regelt die geschützten Ursprungsbezeichnungen (g.U.; Denominazioni di Origine Protetta $D O P$ ) und die geschützten geografischen Angaben (g.g.A.; Indicazioni Geografische Protette - IGP) für Lebensmittel und Getränke. Gemäß Art. 29 CPI können Ursprungsbezeichnungen und geografische Angaben, die ein Land, eine Region oder einen Ort bezeichnen, dann unter besonderen Schutz gestellt werden, wenn sie zur Bezeichnung eines Erzeugnisses verwendet werden, das aus diesem Land, dieser Region, oder diesem Ort stammt und dessen Qualität, Ansehen oder Eigenschaften ausschließlich, oder im Wesentlichen auf sein geografisches Herkunftsumfeld, einschließlich natürlicher, menschlicher und traditioneller Faktoren, zurückzuführen sind. ${ }^{60}$

Darüber hinaus, wiewohl damit zusammenhängend, gibt es die garantierten traditionellen Spezialitäten (g.t.S.; Specialità Tradizionali Garantite - STG). Sie schützen bestimmte Produkte, die nach traditionellen Rezepten oder Herstellungsmethoden hergestellt werden. ${ }^{61}$

Eine eigenständige Erwähnung verdienen schließlich die sogenannten historischen Marken von nationalem Interesse (marchi storici di interesse nazionale). ${ }^{62}$ Es handelt sich hierbei um ein völlig neues Institut, das von französischen Vorbildern stammen dürfte. ${ }^{63}$ Mit Gesetzesdekret vom 30.04.2019, Nr. $34^{64}$ wurde die Möglich-

\footnotetext{
${ }^{57}$ Verordnung (EG) Nr. 491/2009 des Rates vom 25. Mai 2009 zur Änderung der Verordnung (EG) Nr. 1234/2007 über eine gemeinsame Organisation der Agrarmärkte und mit Sondervorschriften für bestimmte landwirtschaftliche Erzeugnisse (Verordnung über die einheitliche GMO), in: Amtsblatt der Europäischen Union, 17.06.2009, L 154/1.

${ }^{58}$ Verordnung (EG) Nr. 110/2008 des Europäischen Parlaments und des Rates vom 15. Januar 2008 zur Begriffsbestimmung, Bezeichnung, Aufmachung und Etikettierung von Spirituosen sowie zum Schutz geografischer Angaben für Spirituosen und zur Aufhebung der Verordnung (EWG) Nr. 1576/89, in: Amtsblatt der Europäischen Union, 13.02.2008, L 39/16.

${ }^{59}$ Verordnung (EU) Nr. 1151/2012 des Europäischen Parlaments und des Rates vom 21. November 2012 über Qualitätsregelungen für Agrarerzeugnisse und Lebensmittel, in: Amtsblatt der Europäischen Union, 14.12.2012, L 343/1.

${ }^{60} \mathrm{Vgl}$. A. D'Andrea, Contraffazione di indicazioni geografiche o denominazioni di origine dei prodotti agroalimentari, in: A. Cadoppi/S. Canestrari/A. Manna/M. Papa, Trattato di diritto penale, Parte speciale, vol. V, I delitti contro la fede pubblica e l'economia pubblica, Utet, Torino, 2010; C. Galli, Globalizzazione dell'economia e tutela delle denominazioni di origine dei prodotti agro-alimentari, in: Rivista di diritto industriale, 2004, fasc. 1, S. $60 \mathrm{ff}$.

${ }^{61}$ Regelungsgrundlage: Verordnung (EU) Nr. 1151/2012 in Verbindung mit der Delegierten Verordnung (EU) Nr. 664/2014 der Kommission vom 18. Dezember 2013 zur Ergänzung der Verordnung (EU) Nr. 1151/2012 des Europäischen Parlaments und des Rates im Hinblick auf die Festlegung der EU-Zeichen für geschützte Ursprungsbezeichnungen, geschützte geografische Angaben und garantiert traditionelle Spezialitäten sowie im Hinblick auf bestimmte herkunftsbezogene Vorschriften, Verfahrensvorschriften und zusätzliche Übergangsvorschriften, in: Amtsblatt der Europäischen Union, 19.06.2014, L 179/17.

${ }^{62} \mathrm{Vgl}$. Art. 11-ter CPI.

${ }^{63} \mathrm{Vgl}$. LOI n ${ }^{\circ}$ 2014-384 du 29 mars 2014 visant à reconquérir l'économie réelle, in : Journal officiel de la République française $\mathrm{n}^{\circ} 0077$ du 1 avril 2014, S. 6227.

${ }^{64}$ Decreto Legge 30.04.2019, n. 34: Misure urgenti di crescita economica e per la risoluzione di
} 
keit zur Eintragung in ein Sonderregister von ,historischen Marken von nationalem Interesse" vorgesehen (Art. 11-ter iVm 185-ter CPI). Den in diesem Register eingetragenen Markeninhabern ist es gestattet, zusätzlich zur eigenen Marke ein Logo mit der Bezeichnung ,marchio storico di interesse nazionale“ $\mathrm{zu}$ führen. ${ }^{65}$ Eine Marke wird gemäß Art. 11-ter CPI dann als historisch definiert, wenn sie seit mindestens 50 Jahren auf dem Markt ist und dies unabhängig davon, ob sie registriert wurde oder nicht. Darüber hinaus muss sie die Vermarktung von Waren oder Dienstleistungen aufweisen, die in nationalen Unternehmen von herausragender Qualität hergestellt wurden, die historisch mit Italien verbunden sind.

\section{Schutzvoraussetzungen}

Um markenfähig zu sein, muss das Zeichen bestimmte Voraussetzungen erfüllen, die als Schutzvoraussetzungen ${ }^{66}$ bezeichnet werden. Bei Fehlen dieser Voraussetzungen ist die Marke nichtig. Diese Schutzvoraussetzungen sind die Unterscheidungskraft (capacità distintiva), die Neuheit (novità), die Rechtmäßigkeit (liceità) sowie die Wahrheit (verità). Bei Fehlen dieser Voraussetzungen spricht man in der EU-Terminologie, wie beispielsweise der Richtlinie (EU) 2015/2436, von Eintragungshindernissen oder Nichtigkeitsgründen.

\subsection{Unterscheidungskraft}

Die Marke besitzt Unterscheidungskraft - vielfach als Originalität (originalità) bezeichnet -, wenn sie dazu geeignet ist, die Waren bzw. die Dienstleistungen, für die die Eintragung beantragt wird, als von einem bestimmten Unternehmen stammend zu kennzeichnen und diese Waren bzw. Dienstleistungen somit von denjenigen anderer Unternehmen zu unterscheiden. ${ }^{67}$

\footnotetext{
specifiche situazioni di crisi, in: Gazzetta Ufficiale, 30.04.2019, n. 100 umgesetzt mit Legge 28.06.2019, n. 58: Conversione in legge, con modificazioni, del decreto-legge 30 aprile 2019, n. 34 , recante misure urgenti di crescita economica e per la risoluzione di specifiche situazioni di crisi, in: Gazzetta Ufficiale, 29.06.2019, n. 151.

${ }^{65}$ Die Eintragung in das Register der ,historischen Marken von nationalem Interesse“ hat insbesondere Marketinggründe. Die Eintragung kann sowohl der Inhaber einer seit mindestens 50 Jahren eingetragenen Marke (italienweit betrifft das in etwa 850 Marken) als auch der Inhaber einer nicht-eingetragenen Marke erlangen, der gleichzeitig den Nachweis einer seit mindestens 50 Jahren andauernden tatsächlichen Benutzung erbringen kann, vgl. G. Sena/S. Giudici, Il civilista: La nuova disciplina di marchi e brevetti, Giuffrè, Milano, 2019, S. 7 f.

${ }^{66} \mathrm{Vgl}$. P. Kindler, Italienisches Handels- und Wirtschaftsrecht, Fachmedien Recht und Wirtschaft, Frankfurt am Main, 2. Aufl., 2013, S. 62 ff.

${ }^{67} \mathrm{Vgl}$. auch Prüfungsrichtlinien für Unionsmarken, Amt der Europäischen Union für geistiges Eigentum (EUIPO), Absolute Eintragungshindernisse, S. 4, in: https://euipo.europa.eu/tunnel-web/
} 
Diese Voraussetzung besteht im Wesentlichen in den Eigenschaften, die das Zeichen besitzen muss, um geeignet zu sein, beim Publikum eine Warenspezies oder Dienstleistungsspezies - nämlich die Spezies, die sich aus der konstanten Herkunft oder generell aus den mit der kommunizierten Botschaft betonten Eigenschaften ergibt - in Bezug auf eine Gattung von Waren oder Dienstleistungen zu identifizieren.

Im Sinne von Art. 13, Abs. 1, Bst. a) CPI fehlt es einer Marke an Unterscheidungskraft, sofern diese ausschließlich aus Zeichen bestehen, die in der Alltagssprache oder im konstanten geschäftlichen Verkehr zum Bestandteil des allgemeinen Sprachgebrauchs geworden sind. Ist dies eingetreten, so spricht man von der Vulgarisierung einer Marke (volgarizzazione del marchio), was zu einem Verfall (decadenza) des Markenrechts führt. ${ }^{68}$

secure/webdav/guest/document_library/contentPdfs/trade_marks/draft-guidelines-2017-wp-lr2/16_part_b_examination_section_4_AG_chap_3_article_7(1)(b)_clean_lr2_de. pdf (zugegriffen am 20.04.2020). Vgl. C. Galli, Il marchio come segno e la capacità distintiva nella prospettiva del diritto comunitario, in: Il diritto industriale, fasc. 5, 2008, S. $425 \mathrm{ff}$.

${ }^{68}$ Klassische Beispiele für registrierte Marken, die in Italien vulgarisiert wurden und somit ihre Unterscheidungsfähigkeit verloren haben, sind: Scotch (allgemein für Klebestreifen), scottex und Kleenex (allgemein für Saug- oder Wischtuch), nutella (allgemein für Streichschokolade), moka (allgemein für Kaffeemaschine), cellofan (allgemein für eine durchsichtige Einpackfolie), post-it (allgemein für selbstklebende Merkzettel), walkman (allgemein für tragbaren Kassettenrekorder), aspirina (allgemein für Medikamente gegen Kopfschmerzen). In Bezug auf die Marke „Cellophane[cellofane]" vgl. Corte di Cassazione, 11.12.1978, n. 5833.

Als Maßnahme gegen die Vulgarisierung wird die Anwendung gemäß Art. 12 VO (EU) 2017/1001 angesehen. Diese Bestimmung sieht die Wiedergabe der Unionsmarke in einem Wörterbuch vor. Die Bestimmung besagt wörtlich: „Erweckt die Wiedergabe einer Unionsmarke in einem Wörterbuch, Lexikon oder ähnlichem Nachschlagewerk den Eindruck, als sei sie eine Gattungsbezeichnung der Waren oder Dienstleistungen, für die sie eingetragen ist, so stellt der Verleger des Werkes auf Antrag des Inhabers der Unionsmarke sicher, dass der Wiedergabe der Marke spätestens bei einer Neuauflage des Werkes der Hinweis beigefügt wird, dass es sich um eine eingetragene Marke handelt. "Auf dieser Rechtsgrundlage ist es dem italienischen Unternehmen Ferrero gelungen zu erwirken, dass der Begriff Nutella unter Streichschokolade im Wörterbuch wiedergegeben, aber mit einem „®“ versehen wurde und somit als Nutella® aus dem Wörterbuch gelesen wird. Dasselbe hat das US-amerikanische Unternehmen mit dem Scotch ${ }^{\circledR}$ und Post-it ${ }^{\circledR}$ getan.

Weiterführend zur Vulgarisierung vgl. M. Ricolfi. Trattato dei Marchi. Diritto europeo e nazionale, Giappichelli, Torino, 2015, S. 305 ff.; G. Cuonzo/B. Marsicola, L'identità dell'impresa: i segni distintivi, in: Proprietà industriale, intellettuale e IT, Wolters Kluwer, Milano, 2017, S. 140; A. Vanzetti, Codice della Proprietà industriale, Giuffrè, Milano 2013, S. 245 ff.; C. Galli, I toponimi, tra tutele, volgarizzazione e ditti consolidati, in: A. Bartolini/D. Brunelli/G. Caforio, I beni immateriali tra regole privatistiche e pubblicistiche, Jovene, Napoli, 2014. 
Daneben sind gemäß Art. 13, Abs. 1, Bst. b) CPI auch die allgemeinen Bezeichnungen ${ }^{69}$ der Waren oder der Dienstleistung, ${ }^{70}$ die beschreibenden Angaben der Waren (bzw. der Dienstleistung) sowie Angaben, die auf ihre Beschaffenheit ${ }^{71}$ abzielen, nicht eintragungsfähig. Art. 13, Abs. 1 CPI stellt dabei die beschreibenden Angaben den geografischen Herkunftsangaben gleich. Die geografische Angabe stellt nämlich, abgesehen von den Fällen, in denen sie als reiner Fantasiename verwendet wird, die Beschreibung der Warenqualität dar. Dies gilt besonders bei Produkten im Sektor der Landwirtschaft.

Streng genommen ist also die Voraussetzung der Unterscheidungskraft dann erfüllt, wenn entweder Zeichen mit einer Bedeutung verwendet werden, die mit der zu kennzeichnenden Ware nichts gemein haben, oder aber Zeichen, denen als solche kein semantischer Wert zukommt, wie dies bei Fantasienamen der Fall ist. ${ }^{72}$

Man spricht von einer phonetisch expressiven Marke (marchio espressivo), wenn ein Zeichen einen Bestandteil einer Marke bildet, das zwar nicht mit dem Namen oder mit der Beschreibung der Ware übereinstimmt, jedoch dazu in der Lage ist, irgendwie auf die Ware oder auf ihre Eigenschaften zu ,verweisen“. Voraussetzung

\footnotetext{
${ }^{69}$ Vgl. Corte di Cassazione, 25.09.1998, Nr. 9617: „Il requisito essenziale del marchio è la capacità distintiva, la quale indice sulla valutazione della sua confondibilitá coi marchi posteriori ai fini del giudizio di contraffazione. La pratica commerciale, tuttavia, conosce l'adozione di marchi costituiti da segni che combinano elementi dotati di capacità distintiva con espressioni generiche o descrittive o che comunque richiamano, si pure originalmente modificate, dette espressioni. Tali marchi, per la cui ammissibilità uno spunto letterale può trarsi dalla normativa vigente, la quale esclude la validità dei segni costituiti „esclusivamente“ da denominazioni generiche o descrittive lasciando intendere che sono tutelabili i marchi costituiti da espressioni che non lo sono totalmente, vengono notoriamente indicati dalla dottrina e dalla giurisprudenza come marchi „deboli“, essendo dotati di minore originalità, onde sono tutelabili soltanto se riprodotti integralmente imitati in modo molto prossimo, laddove ad essi si contrappongono $i$ marchi rappresentati da segni del tutto arbitrari o di fantasia, e perciò privi di qualsiasi contenuto significativo o anche solo evocativo, che si definiscono, forti “ e che sono tutelati nel loro nucleo ideologico, cosicché debbono ritenersi interferenti (tanto nel giudizio di validità quanto nel giudizio di contraffazione) tutte le variazioni e modificazioni che lascino persistere l'identità concettuale di essi. “

${ }^{70}$ Unter allgemeinen Bezeichnungen werden die üblichen Namen der Waren verstanden, die zur Kennzeichnung von Waren einer bestimmten Art verwendet werden. Beispielsweise kann die Bezeichnung „Milch“ keine Marke für Milch darstellen.

${ }^{71}$ Unter beschreibenden Angaben sind Hinweise auf die wesentlichen Eigenschaften und Leistungen der Ware bzw. der Dienstleistung zu verstehen (z. B. der Ausdruck „Glanz“ zur Kennzeichnung von Polituren).

${ }^{72}$ Bezüglich der Unionsmarke ist ferner darauf hinzuweisen, dass die Unterscheidungskraft des Zeichens in allen Sprachen und allen Ländern gegeben sein muss. Demzufolge verhindern die Beschreibungskraft oder die Täuschungskraft, auch soweit sie nur einen kleinen Teil der Union betreffen, die erfolgreiche Eintragung des Zeichens.
} 
für die Schutzfähigkeit dieser Art von Marken ist, dass die Marke zusätzlich zu dem beschreibenden Element Unterscheidungselemente enthält, die aus Vor- oder Nachsilben, Wortverdrehungen oder besonderen Kombinationen bestehen. ${ }^{73}$ Die phonetisch expressive Marke stellt unter dem Gesichtspunkt des Schutzes eine schwache Marke (marchio debole) dar.

Demgegenüber werden als starke Marke (marchio forte) jene bezeichnet, die nichts über die Art der durch sie gekennzeichneten Waren aussagt. Dadurch ist ihre Schutzwirkung besonders weitrechend, was vor allem bei Fantasiemarken der Fall ist. Die Schutzwirkung erstreckt sich auf eine Art, dass auch erhebliche Abänderungen eine Nachahmung nicht verhindern können, sofern die wesentliche Identität bestehen bleibt.

Die Unterscheidung zwischen schwachen und starken Marken ist in der Praxis jedoch nicht immer einfach ${ }^{74}$ und es kann auch vorkommen, dass ein Zeichen mit ursprünglich geringer Unterscheidungskraft infolge eines Gebrauchs und einer intensiven erfolgreichen Werbung ,stark“ wird. In diesem Fall spricht man davon,

\footnotetext{
${ }^{73}$ Beispiele in Italien: die Marke Melinda®, die von einem Konsortium aus dem Trentino (Provinz Trient) für die Produktion und Vermarktung von Äpfeln (ital. mele) registriert wurde; die Marken Softdrinks Lemonsoda ${ }^{\circledR}($ Zitrone $=$ ital. limone und soda $)$, Oransoda ${ }^{\circledR}($ Orange $=$ ital. arancia und soda) und Pelmosoda ${ }^{\circledR}$ (Grapefruit = ital. pompelmo und soda), die italienischen Traditionsunternehmen Campari (Tochterfirma: Freedea) bis 2017 gehörten, als sie dem dänischen Unternehmen Royal Unibrew verkauft wurden. Gescheitert ist hingegen die Registrierung von Camiciaio (Hemd = ital. camicia) für Hemden- und Krawattenprodukte.

${ }^{74} \mathrm{Vgl}$. Corte di Cassazione, 09.02.1995, Nr. 1473: „La quantificazione di un marchio come "forte“, ovvero „debole“ - espressioni, queste, intese, nel loro senso tecnico, giuridico, come valutazioni conclusive su accertamenti di fatto operanti alla luce di precise categorie giuridiche esplica fondamentali conseguenze sul piano della sua tutela giurisdizionale (ad es. in tema di apprezzamento sulla confondibilitá fra segni distintivi), più o meno incisiva a seconda, appunto, che dipenda dalla prima o dalla seconda delle predette qualificazioni.

La tutela del marchio „forte", per essere frutto di fantasia senza aderenze concettuali con $i$ prodotti contraddistinti, si caratterizza per una maggiore incisività, rispetto a quella dei marchi „,deboli“", poiché rende illegittime le variazioni, anche se rilevanti ed originali, che lascino sussistere l'identità sostanziale del nucleo ideologico in cui si riassume l'attitudine individuante. "
} 
dass das Zeichen in der Wahrnehmung des Publikums eine secondary meaning, ${ }^{75}$ also eine nicht mehr allgemeine, sondern spezifische Bedeutung erlangt hat. ${ }^{76}$

Die Unterscheidungskraft eines Zeichens ist im Zeitverlauf nicht unveränderlich. So kann es vorkommen, dass ein ursprünglich unterscheidungskräftiges Zeichen später zum gemeingültigen Begriff zur Bezeichnung einer Waren- oder Dienstleistungsgattung wird. Wobei wir dann wieder beim bereits angesprochenen Thema der Vulgarisierung der Marke sind.

\footnotetext{
${ }^{75}$ Vgl. Corte di Cassazione, 19.04.2016, Nr. 7738: „Il fenomeno del c.d. secondary meaning, secondo il senso letterale dell'espressione $(<<$ significato secondario $>>$, inteso sia come successivo, si come aggiunto) e le ricostruzioni degli interpreti, si verifica tutte le volte in cui un segno, originariamente sprovvisto di capacità distintiva per genericità, mera descrittivista o mancanza di originalità, si trovi ad acquistare, in seguito, tali capacità, in conseguenza del consolidarsi del suo uso sul mercato. Tale fenomeno è stato elaborato ai fini della c.d. $<<$ riabilitazione $>>o<<$ convalidazione $>>$ del segno originariamente privo di capacità distintiva perché mancante di originalità, in quanto generico o descrittivo, e che, tuttavia, finisce con il riceverla dall'uso; pertanto, pur a volte utilizzato ai fini di cogliere ogni evoluzione della capacità distintiva (anche come rafforzamento della capacità di distintiva del marchio in origine debole), ricorre propriamente quando il marchio descrittivo divenga successivamente distintivo attraverso la diffusione, la propaganda e la pubblicità. “

Corte di Cassazione, 16.11.2015, Nr. 23393: „,La tutela del c.d. secondary meaning, si riferisce ai casi in cui un segno, originariamente sprovvisto di capacità distintive per genericità, mera discrittivitá o mancanza di originalità, acquisti in seguito tali capacità, in conseguenza del consolidarsi del suo uso sul mercato, così che l'ordinamento si trova a recepire il fatto della acquisizione successiva di una „distintivitá “ attraverso un meccanismo di $<<$ convalidazione $>>$ del segno. Il secondary meaning è estensibile anche al caso di trasformazione di un marchio originariamente debole in un marchio forte. "

Corte die Cassazione, 26.01.1999, Nr. 697: „Il secondary meaning è un fenomeno che si verifica quando un segno, originariamente sprovvisto di capacità distintive in quanto meramente descrittivo oppure privo di originalità, acquista in seguito tali capacità grazi all'affermato uso di mercato. Quindi, l'ordinamento attribuisce valore al fatto dell'acquisizione successiva di una distintivitá attraverso un meccanismo di convalidazione del segno. Tale protezione deve essere applicata anche ai segni distintivi anteriori all'entrata in vigore della riforma, in virtù dell'articolo 89 , n. 2, della legge 480/1992. “

Corte di Cassazione, 19.04.2000, Nr. 5091: „Nel sistema della legge marchi, la distinzione tra marchi forti e marchi deboli non si specifica ulteriormente quanto ai marchi forti a seconda che tale natura sia originaria oppure acquisita con l'uso di mercato, anzi, si deve precisare in via di principio la logica del secondary meaning oggi esplicitata dalla legge, ma riconosciuta da tempo dalla giurisprudenza suggerisce che proprio perché in origine il segno risultava caratterizzato da un minore capacità individualizzante una volta prevenuto alla convalidazione dovuta all'uso abbisogna della protezione più rigorosa che si riconosce al marchio forte, senza della quale le lievi modificazioni che il marchio debole deve tollerare nel segno antagonista, frusterebbero il prodotto risultato all'uso. “

Weiterführend zur secondary meaning vgl. M. Ricolfi. Trattato dei Marchi. Diritto europeo e nazionale, Giappichelli, Torino, 2015, S. 288 ff.; A. Vanzetti, Codice della Proprietà industriale, Giuffrè, Milano 2013, S. 238 ff.; A. Sirotti Gaudenzi, Manuale pratico dei marchi e dei brevetti, Maggioli, Santarcangelo di Romagna, 2020, S. 110 ff.; N. Dauskardt, Die Verkehrsdurchsetzung im deutschen und europäischen Markenrecht, Mohr Siebeck, Tübingen, 2017, S. 89 ff.

${ }^{76}$ Die fehlende Unterscheidungskraft des Porsche 718 Boxster zum Porsche 911 wurde durch Verkehrsdurchsetzung überwunden, vgl. BGH, Beschluss vom 14.12.2005, I ZB 33/04 - Porsche Boxster (Bundespatentgericht), in: https://www.markenmagazin.de/bgh-porsche-boxster/ (zugegriffen am 20.04.2020).
} 


\subsection{Neuheit}

Die zweite Voraussetzung für die Schutzfähigkeit einer Marke ist die Neuheit. Um der Unterscheidungsfunktion voll gerecht zu werden, muss sich die Marke technisch gesehen von den Marken unterscheiden, an denen ein Dritter vor Anmeldung der fraglichen Marke ein Recht erworben hat. Aus praktischer Sicht darf die Marke also im Verkehr nicht bereits bekannt sein.

Die Neuheit wird von Art. 12 CPI als Voraussetzung für die Schutzfähigkeit einer Marke festgelegt. Diese Norm bestimmt, welche Zeichen als Marke nicht eintragungsfähig sind und somit nicht als neu gelten können. Dazu zählen zum einen jene Zeichen, die identisch oder ähnlich mit Zeichen sind, die bereits als Marke oder Kenn- und Unterscheidungszeichen für identische oder ähnliche Waren oder Dienstleistungen bekannt, aber nicht als solche eingetragen sind (nicht-eingetragene Marken). ${ }^{77}$ Zum anderen fehlt es auch jenen Zeichen an der geforderten Neuheit, die mit registrierten Marken inkompatibel sind. ${ }^{78}$

\subsubsection{Konflikte mit Benutzungsmarken}

Gemäß Art. 12, Abs. 1, Bst. a) CPI fehlt es der Marke an Neuheit, wenn das Zeichen zum Zeitpunkt der Anmeldung einem Zeichen identisch oder ähnlich ist, das bereits als Marke oder Unterscheidungszeichen für identische oder ähnliche Waren und Dienstleistungen bekannt ist ${ }^{79}$ und aufgrund der Identität oder Ähnlichkeit der Zeichen, beziehungsweise der Identität oder Ähnlichkeit der Waren oder Dienstleistungen, eine Verwechslungsgefahr für das Publikum entstehen kann, die auch in der Gefahr der gedanklichen Verbindung zwischen den beiden Zeichen bestehen kann.

Diese Bestimmung schützt den Markeninhaber, der zwar eine Marke zur Kennzeichnung der eigenen Waren und Dienstleistungen genutzt hat, diese Marke aber nicht eingetragen hat. Damit eine nicht eingetragene Marke die Neuheit einer später angemeldeten Marke beeinträchtigen kann, reicht eine wie immer geartete Vorbenutzung (preuso) einer verwechselbaren Marke nicht aus. Vielmehr ist es zudem erforderlich, dass es sich um eine Marke mit breiter und ausreichend intensiver Bekanntheit (notorietà) handelt. ${ }^{80}$ Die Tatsache, dass es sich bei der Benutzung und

\footnotetext{
${ }^{77}$ Art. 12, Abs. 1, Bst. a), b) und f) CPI.

${ }^{78}$ Art. 12, Abs. 1, Bst. c), d) und e) CPI.

${ }^{79}$ Gemäß Art. 12, Abs. 1, Bst. a) CPI gilt dies auch für notorisch bekannte Marken im Sinne von Art. 6-bis der Pariser Verbandsübereinkunft zum Schutz des gewerblichen Eigentums vom 20.03.1883. Aufgrund dieser Bestimmung hat Italien als Verbandsland die Eintragung einer Marke zu versagen oder für ungültig zu erklären, wenn sie mit einer anderen Marke verwechselt werden kann, die bereits als Unterscheidungszeichen eines anderen Verbandslandes bekannt ist.

${ }^{80}$ Der Gesetzgeber sieht ausdrücklich vor, dass die Vorbenutzung, sofern sie durch denjenigen erfolgt ist, der die Eintragung beantragt, keinen Grund für die Schutzverweigerung aufgrund fehlender Neuheit darstellt. In diesem Fall besteht für das Publikum keine Verwechslungsmöglichkeit, zumal die zunächst lediglich benutzte und erst später eingetragene Marke nach wie vor die von ein
} 
Bekanntheit um zwei unterschiedliche Begriffe handelt, bestätigt der zweite Teil des Art. 12, Abs. 1, Bst. a) CPI. Diese Bestimmung besagt, dass die Vorbenutzung einer nicht eingetragenen Marke die Neuheit der nachfolgend registrierten Marke nicht ausschließt, wenn die Vorbenutzung nicht die Bekanntheit der Marke, beziehungsweise nur eine örtlich begrenzte Bekanntheit bewirkt. ${ }^{81}$ Allerdings wird dem Vorbenutzer einer faktischen Marke mit örtlich begrenzter Bekanntheit das Recht zugestanden, die Marke weiterhin für denselben Geltungsbereich und denselben begrenzten örtlichen Raum zu verwenden und das, selbst wenn ein Dritter zu einem späteren Zeitpunkt eine identische oder ähnliche Marke registriert (Art. 2571 c.c. und Art. 12, Abs. 1, Bst. a) CPI).

\subsubsection{Konflikte mit Firmen, Namen und Firmenbezeichnungen, Geschäftsbezeichnungen und Domainnamen}

Die Schutzvoraussetzung der Neuheit fehlt auch dann, wenn gemäß Art. 12, Abs. 1, Bst. b) CPI Zeichnen einem im geschäftlichen Verkehr benutzten Zeichen identisch oder ähnlich sind, das bereits als Firma, Name oder Firmenbezeichnung, ${ }^{82} \mathrm{Ge}$ schäftsabzeichen, Domainname oder als ein anderes benutztes Unterscheidungszeichen bekannt ist, wenn aufgrund der Identität oder Ähnlichkeit der Zeichen und der Identität oder Ähnlichkeit der Unternehmenstätigkeit eine Verwechslungsgefahr für das Publikum entstehen kann, oder die Gefahr der gedanklichen Verbindung bzw. Assoziierung zwischen den beiden Zeichen besteht.

\subsubsection{Konflikte mit identischen Marken für identische Waren und Dienstleistungen}

Die Neuheit ist im Sinne von Art. 12, Abs. 1, Bst. c) CPI auch dann nicht gegeben, wenn das Zeichen identisch ist mit einer Marke für identische Waren oder Dienstleistungen, die bereits von anderen im Staatsgebiet eingetragenen wurde, oder die infolge einer früher erfolgten Anmeldung im Staatsgebiet wirksam ist. Im Unterschied zu den bisher betrachteten Fällen spielt hier kein materieller (Vorbenutzung; preuso), sondern ein formeller Aspekt (Registrierung; registrazione) eine Rolle. Demnach ist für das Fehlen der Neuheit das Bestehen einer Eintragung, beziehungsweise Anmeldung - und anschließenden gültigen Eintragung - einer identischen

und demselben Unternehmer stammenden Waren beziehungsweise Dienstleistungen kennzeichnet. Vgl. A. Sirotti Gaudenzi, Preuso di marchi di fatto: la prova deve essere rigorosa anche nel caso di patronimico, in: Quotidiano Giuridico, 2016.

${ }^{81} \mathrm{Vgl}$. Corte di Appello di Napoli, 30.11.2015: „, Sono nulli i marchi anticipati, da segni distintivi aventi notorietà non puramente locale ed in particolare estesi all'ambito regionale. "

${ }^{82}$ Vgl. Corte di Appello di Roma, 09.09.1999: „Il marchio avente come cuore della propria caratterizzazione un'espressione già utilizzata quale denominazione sociale di altra impresa è privo „,del requisito della novità“."“ 
Marke ausreichend, und zwar unabhängig von ihrer Vorbenutzung beziehungsweise der Feststellung einer Verwechslungsgefahr.

Eine Identität zwischen einem Zeichen und einer Marke liegt dann vor, wenn das Zeichen ohne Änderung oder Hinzufügung alle Elemente wiedergibt, die die Marke bilden und somit identisch ist, oder wenn das Zeichen in seiner Gesamtheit betrachtet so geringfügige Unterschiede gegenüber der Marke aufweist, dass sie einem Durchschnittsverbraucher entgehen können. ${ }^{83}$

Sowohl für die identischen als auch für die ähnlichen Marken gilt die Regel, wonach eine Marke weder durch eine frühere seit mehr als zwei Jahren abgelaufene Eintragung noch durch eine wegen Nichtbenutzung verfallene Eintragung der Neuheit beraubt wird, sofern der Verfall wegen Nichtbenutzung vor Erhebung der Klage auf Nichtigkeit der späteren Eintragung eingetreten ist. ${ }^{84}$ Auf diese Weise soll, ganz im Einklang mit der Funktion der Neuheitsvoraussetzung, verhindert werden, dass alte, nicht mehr wirksame Eintragungen die Ungültigkeit von späteren Eintragungen Dritter bewirken.

\subsubsection{Konflikte mit identischen oder ähnlichen Marken für identische oder ähnliche Waren und Dienstleistungen}

Einer Marke fehlt es am Kriterium der Neuheit, sofern das Zeichen identisch oder ähnlich einer anderen Marke für identische oder ähnliche Waren oder Dienstleistungen ist, die bereits von anderen im Staatsgebiet eingetragenen wurde, infolge einer früher erfolgten Anmeldung im Staatsgebiet wirksam ist, oder ab einem früheren Datum aufgrund einer Priorität oder einer gültigen Inanspruchnahme des Zeitrangs wirksam ist. Auch ist das der Fall, wenn aufgrund der Identität oder Ähnlichkeit der Zeichen und der Identität oder Ähnlichkeit der Waren oder Dienstleistungen eine Verwechslungsgefahr für das Publikum entstehen kann, die auch in der Gefahr der gedanklichen Verbindung zwischen den beiden Zeichen bestehen kann. ${ }^{85}$

Die Voraussetzungen für die Registrierungsfähigkeit einer Marke im Sinne von Art. 12, Abs. 1, Bst. d) CPI entsprechen somit jenen gemäß Art. 12, Abs. 1, Bst. a) CPI, mit dem einzigen Unterschied, dass die frühere Marke eingetragen ist, weshalb der Nachweis der Bekanntheit entfällt. Im Gegensatz zu Art. 12, Abs. 1, Bst. c) CPI ist jedoch für das Fehlen der Neuheit eine Verwechslungsgefahr erforderlich.

\footnotetext{
${ }^{83}$ Vgl. EuGH, Urteil, 20.03.2003, C-291/00, LTJ Diffusion SA/Sadas Vertbaudet SA, ECLI:EU:C:2003:169.

${ }^{84} \mathrm{Vgl}$. Art. 12, Abs. 2 CPI.

${ }^{85} \mathrm{Vgl}$. Art. 12, Abs. 1, Bst. d) CPI.
} 


\subsubsection{Konflikte mit notorisch bekannten (renommierten oder berühmten) eingetragenen und nicht-eingetragenen Marken}

Schließlich fehlt es einem Zeichen an Neuheit, wenn es mit einer früheren Marke für identische, ähnliche oder nicht ähnliche Waren oder Dienstleistungen identisch oder ähnlich ist, wenn die ältere Marke einen besonderen Ruf genießt und wenn die Nutzung der späteren Marke ohne berechtigten Grund unzulässigerweise einen Vorteil aus dem Unterscheidungscharakter oder aus dem besonderen Ruf der älteren Marke nach sich ziehen, oder den Unterscheidungscharakter bzw. den besonderen Ruf beeinträchtigen würde. ${ }^{86}$ Selbiges gilt auch für notorisch bekannten nichteingetragenen Marken. ${ }^{87}$

Während Marken grundsätzlich nur für jene Waren und Dienstleistungen geschützt sind, für die sie eingetragen beziehungsweise tatsächlich benutzt werden, kann der Inhaber einer notorisch bekannten Marke Dritten den Gebrauch seiner Markenbezeichnung für jede Art von Waren und Dienstleistungen verbieten, selbst wenn diese in der Markeneintragung nicht angeführt sind und mit diesen somit weder identisch noch ähnlich sind. Voraussetzung ist allerdings, dass der älteren Marke ein besonderer Ruf, d. h. eine hohe Wertschätzung zukommt, da sie einen hohen Bekanntheitsgrad sowie positive Qualitätsvorstellungen hat.

\subsubsection{Die Gültigkeitserklärung der Marke}

Das Fehlen der Voraussetzung der Neuheit der Marke kann ausgeglichen werden, was auch als Gültigkeitserklärung ${ }^{88}$ (convalidazione) bezeichnet wird. Die ursprüngliche Nichtigkeit einer Marke aufgrund fehlender Neuheit entfällt hier. Insbesondere verwirkt dabei das Recht des Inhabers der älteren eingetragenen oder nicht eingetragenen Marke, die Nichtigkeit der jüngeren Marke geltend zu machen, beziehungsweise sich der Benutzung der jüngeren Marke, für die Waren, oder Dienstleistungen, für die die genannte Marke benutzt wurde, zu widersetzen.

Die Heilung tritt ein, wenn der Inhaber der älteren eingetragenen oder nicht eingetragenen Marke während fünf aufeinander folgenden Jahren die ihm bekannte Benutzung einer jüngeren, gleichen oder ähnlichen eingetragenen Marke duldet. ${ }^{89}$

Diese Bestimmung entspricht der in der Rechtsordnung besonders stark empfundenen Notwendigkeit, einen über einen langen Zeitraum andauernden Zustand rechtlich zu konsolidieren und einen Zustand der Unsicherheit zu beseitigen. Der Beweis, wonach der Inhaber der älteren eingetragenen oder nicht eingetragenen Marke von dieser Benutzung wusste und diese geduldet hat, liegt allerdings beim Inhaber der jüngeren Marke. Hierzu hat das Kassationsgericht festgestellt, dass die

\footnotetext{
${ }^{86} \mathrm{Vgl}$. Art. 12, Abs. 1, Bst. e) CPI.

${ }^{87} \mathrm{Vgl}$. Art. 12, Abs. 1, Bst. f) CPI.

${ }^{88}$ In Bezug auf die Unionsmarke spricht man von Verwirkung durch Duldung (preclusione per tolleranza), vgl. Art. 61 Verordnung (EU) 2017/1001.

${ }^{89}$ Siehe Art. 28 CPI.
} 
Duldung nur durch ein entsprechendes gerichtliches Vorgehen des Inhabers der früheren Rechte (Nichtigkeits- oder Nachahmungsklage) unterbunden werden kann, während etwa außergerichtliche Abmahnungen nicht ausreichend sind. ${ }^{90}$

Das Gesetz schließt die Gültigkeitserklärung jedoch ausdrücklich aus, wenn der Nachweis erbracht wird, dass die jüngere Marke böswillig angemeldet wurde. Kein Hindernis für die Gültigkeitserklärung liegt indessen vor, wenn bösgläubiges Handeln nach der Anmeldung stattgefunden hat.

\subsection{Rechtmäßigkeit und Rechte Dritter}

Die dritte Voraussetzung für die Schutzfähigkeit einer Marke wird allgemein als Voraussetzung der Rechtmäßigkeit (liceità) definiert. Unter diesen Begriff fällt eine Vielzahl von heterogenen Fällen, die von Art. 14 CPI geregelt sind. Heute spricht man der Vollständigkeit halber auch von den Rechten Dritter (diritti di terzi), zumal die Unrechtmäßigkeit nicht nur in einer dem Zeichen innewohnenden UnrechtmäBigkeit beruht, sondern auf der Tatsache, dass das Zeichen unter Verletzung von Rechten Dritter eingetragen wurde.

Nicht erfüllt wird die Voraussetzung der Rechtmäßigkeit unter anderem

- von Zeichen, die gegen das Gesetz, die öffentliche Ordnung (ordine pubblico) oder die guten Sitten (buon costume) ${ }^{91}$ sind. Man denke beispielsweise an Zeichen, die Obszönitäten oder einen Aufruf zur Gewalt enthalten. ${ }^{92}$

- von Zeichen, deren Verwendung das Urheberrecht, das gewerbliche Eigentum, oder ein anderes ausschließliches Recht einer anderen Person verletzen würde;

- von Zeichen, die Wappen (stemmi) oder andere durch internationale Abkommen geschützte Zeichen enthalten. ${ }^{93}$ Einschlägig ist diesbezüglich beispielhaft das Zeichen Rotes Kreuz oder die Olympischen Ringe.

- von Zeichen, die Symbole (simboli), Embleme (emblemi) und Wappen (stemmi) von öffentlichem Interesse enthalten, es sei denn, die zuständige Behörde hat ihre Eintragung erlaubt. ${ }^{94}$

\footnotetext{
${ }^{90}$ Vgl. Corte di Cassazione, 01.07.2008, n. 17927.

${ }^{91}$ Vgl. Art. 14, Bst. a) CPI.

${ }^{92}$ Diese Voraussetzung muss nicht nur zum Zeitpunkt der Anmeldung, sondern während der gesamten Lebensdauer der Marke erfüllt sein. Im Sinne von Art. 14, Abs. 2 iVm Art. 26, Bst. c) CPI verfällt die Marke nämlich, wenn sie einen Verstoß gegen das Gesetz, gegen die öffentliche Ordnung oder gegen die guten Sitten darstellt und somit eine später eingetretene Unrechtmäßigkeit begründet wird.

${ }^{93}$ Vgl. Art. 10, Abs. 1, erster Teil CPI.

${ }^{94} \mathrm{Vgl}$. Art. 10, Abs. 1, zweiter Teil CPI.
} 


\subsection{Keine Irreführung}

Die Voraussetzung, dass das Zeichen keine Irreführung bewirken darf, ist in Art. 14, Bst. b) CPI festgeschrieben. Demnach sind jene Zeichen nicht markenfähig, die geeignet sind das Publikum irrezuführen, und insbesondere über die geografische Herkunft, über die Art oder Beschaffenheit der Waren bzw. der Dienstleistungen sowie die Art der Marke zu täuschen (requisito della non recettività del marchio) ${ }^{95}$

In Bezug auf die geografische Herkunft der Waren gilt festzustellen, dass die Schutzfähigkeit jenen Marken verwehrt wird, wenn die enthaltenen geografischen Angaben nicht der tatsächlichen Herkunft der Ware entsprechen, oder sich nicht als Fantasiebezeichnungen präsentieren, sondern glauben machen, der tatsächlichen Herkunft zu entsprechen.

Allerdings findet die gegenständliche Bestimmung selten Anwendung, zumal in der Regel nicht die Marke als solche, sondern deren Benutzung irreführend ist. ${ }^{96}$

\section{Erwerb des Markenrechts}

\subsection{Eintragungsberechtigte}

Im Sinne von Art. 19 CPI kann derjenige die Eintragung einer Marke erlangen, der bei der Herstellung und dem Handel von Waren sowie bei der Erbringung von Dienstleistungen die Marke benutzt, oder zu benutzen beabsichtigt, wobei die Benutzung sowohl im eigenen oder kontrollierten Unternehmen als auch durch einen Dritten erfolgen kann, der die Marke mit seiner Zustimmung benutzt. Somit kann die Markeneintragung auch von demjenigen erlangt werden, der nicht die Absicht hat, sie für eigene Waren oder Dienstleistungen zu benutzen, sondern lediglich Dritten das Recht zur Benutzung der Marke und zur Kennzeichnung ihrer Waren oder Dienstleistungen einräumen möchte. Schließlich ist es auch Nicht-Unternehmern gestattet, die Eintragung einer Marke rechtswirksam zu erlangen, vorausgesetzt, dass der Wille besteht, die Marke tatsächlich zu benutzen oder benutzen zu lassen.

Auch allen Gebietskörperschaften (Staat, Regionen, Provinzen, Gemeinden) wird die Möglichkeit eingeräumt, Marken einzutragen, deren Gegenstand grafische Unterscheidungselemente sind, die dem kulturellen, historischen, architektonischen oder Umwelterbe ihres Einzugsgebiets entstammen, um sie für kommerzielle Zwecke, zur Finanzierung institutioneller Aktivitäten oder zur Sanierung ihrer Haushalte zu benutzen.

In Bezug auf Drittstaatenangehörige ist die Pariser Verbandsübereinkunft zum Schutz des gewerblichen Eigentums ${ }^{97}$ vom 20. März 1883 einschlägig, wonach die

\footnotetext{
${ }^{95}$ Weiterführend dazu vgl. S. Giudici, Il marchio decettivo, Giuffrè, Milano 2012, S. 7 ff.

${ }^{96}$ Vgl. Art. 21, Abs. 2 CPI.

${ }^{97}$ Italienisch: Convenzione di Parigi per la protezione della proprietà industriale. Italien trat der
} 
Angehörigen eines jeden Verbandslandes den Staatsangehörigen in den anderen Verbandsländern in Bezug auf den Schutz des gewerblichen Eigentums gleichgestellt sind (Prinzip der Inländergleichbehandlung).

\subsection{Grenzen bei der Markenwahl}

Die generelle Bestimmung, wonach jeder eine Marke eintragen kann, wird für bestimmte Kategorien von Zeichen eingeschränkt, deren Eintragung bestimmten Subjekten oder solchen Subjekten, die hierzu ermächtigt wurden, vorbehalten ist. Solche Beschränkungen liegen unter anderem für die Verwendung des Abbilds oder Namens einer anderen Person und für die Nutzung bekannter Zeichen vor.

In Bezug auf die Verwendung des Abbilds einer Person als Marke bestimmt Art. 8, Abs. 1 CPI, dass diese Benutzung vom Einverständnis des Abgebildeten beziehungsweise, nach dessen Tod, vom Einverständnis der engsten Verwandten nach einer Reihenfolge, ${ }^{98}$ die bis zum vierten Verwandtschaftsgrad reicht, abhängig gemacht wird.

Die Eintragung des Abbilds einer Person als Marke seitens nicht legitimierter oder nicht ermächtigter Rechtssubjekte, zieht die Nichtigkeit der Marke nach sich. Allerdings kann die Nichtigkeit im Sinne von Art. 28, Abs. 2 CPI geheilt werden, wobei das Recht zur Erhebung der Nichtigkeitsklage seitens der abgebildeten Person verwirkt, wenn diese während fünf aufeinander folgenden Jahren die ihm bekannte Nutzung der Marke duldet und die Eintragung nicht bösgläubig erfolgt ist.

Die gesetzliche Regelung zur Verwendung des Namens einer Person als Marke ist hingegen weniger einschränkend. So besteht - es sei denn, es handelt sich um einen berühmten Namen - generell keine Beschränkung hinsichtlich der Registrierung des Namens einer Person als Marke..$^{99}$ Die einzige Einschränkung ist jene, dass durch die Nutzung nicht der Ruf, die Glaubwürdigkeit oder die Würde des Betroffenen beschädigt werden darf. ${ }^{100}$

Die Ratio des Grundsatzes der freien Verwendbarkeit des Namens einer Person und dessen Anwendungsbereich begründet sich im notwendigen Schutz desjenigen, der gutgläubig davon ausging einen Fantasienamen zu verwenden, während es sich in Wirklichkeit um den Namen einer anderen Person handelt. Eingeschränkt wird der Grundsatz der freien Verwendbarkeit des Namens einer Personen als Marke durch das dem italienischen Patent- und Markenamt gesetzlich zugebilligte Recht,

\footnotetext{
Pariser Verbandsübereinkunft am 07.07.1884 bei und hat die heute geltende Stockholmer Fassung vom 14.07.1967 mit Legge 28.4.1976, n. 424 ratifiziert.

${ }^{98}$ Das sind zunächst (a) der Ehegatte und die Kinder, bei deren Fehlen oder nach deren Tod (b) die Eltern und anderen Vorfahren sowie in weiterer Folge (c) die Verwandten bis zum vierten Grad.

${ }^{99}$ Siehe Art. 8, Abs. 2 CPI.

${ }^{100}$ Der Verstoß gegen die Beschränkungen nach Art. 8, Abs. 2 CPI hat gemäß Art. 25 CPI die Nichtigkeit der Marke zur Folge.
} 
die Eintragung vom Einverständnis des Betroffenen beziehungsweise nach dessen Tod vom Einverständnis der nächsten Verwandten abhängig zu machen.

Eine Ausnahme vom Grundsatz der freien Verwendbarkeit von Personennamen gilt für den Fall, dass der Name einer bekannten Person oder generell ein bekanntes Zeichen als Marke eingetragen werden soll. Die bekannten Zeichen können nur vom Berechtigten, mit seiner Zustimmung, oder mit Zustimmung der nächsten Verwandten, eingetragen oder benutzt werden. ${ }^{101}$ Es handelt sich hier um eine jener Bestimmungen, bei denen der Gesetzgeber am stärksten von der Unterscheidungsfunktion der Marke abgerückt ist, um einen Wert zu berücksichtigen, den die bekannten Zeichen aufweisen - nämlich ihre Suggestivkraft.

Gemäß Art. 14, Abs. 1, Bst. c) CPI können Zeichen, deren Benutzung eine Verletzung des Urheberrechts eines Dritten, des gewerblichen Eigentumsrechts oder eines anderen Ausschließlichkeitsrechts eines Dritten darstellen, nicht als Marken eingetragen werden. Die Eintragung solcher Zeichen durch Dritte bewirkt deren Nichtigkeit, während die Eintragung seitens des Inhabers des entsprechenden Urheberrechts, gewerblichen Eigentumsrechts oder eines anderen Ausschließlichkeitsrechts jedenfalls möglich ist.

\subsection{Die Eintragung seitens Nichtberechtigter}

In den bisher behandelten Fällen ${ }^{102}$ geht es um Zeichen, die nur von bestimmten Rechtssubjekten als Marke eingetragen werden können, die demzufolge auch als Eintragungsberechtigte bezeichnet werden.

Art. 118 CPI sieht eine systematische Regelung für den Fall der Eintragung durch einen Nichtberechtigten vor. Demnach kann der Rechtsinhaber die Klage auf Herausgabe (azione di rivendica) gegenüber dem Nichtberechtigter erheben, der rechtswidrig das Zeichen angemeldet oder gar dessen Eintragung erlangt hat.

Für den Fall, dass die Eintragung bereits erfolgt ist, kann der Eintragungsberechtigte (a) die Übertragung und zwar auch die rückwirkende Übertragung der Eintragung auf seinen Namen oder (b) die Nichtigkeit der Eintragung begehren.

Sofern die Eintragung noch nicht erfolgt und somit das Anmeldeverfahren noch im Gang ist, kann der Berechtigte (a) die vom Nichtberechtigten vorgenommene Anmeldung auf seinen Namen übernehmen, (b) die Zurückweisung der Anmeldung erwirken oder (c) eine neue Anmeldung vornehmen, die ab dem Tag der Anmeldung durch den Nichtberechtigten wirksam ist.

\footnotetext{
${ }^{101}$ Vgl. Art. 8, Abs. 3 CPI.

${ }^{102}$ Eintragung des Abbilds oder des Namens einer anderen Person gemäß Art. 8, Abs. 1 und 2 CPI; Eintragung eines bekannten Zeichen gemäß Art. 8, Abs. 3 CPI; Eintragung eines Zeichens, das Gegenstand von Rechten Dritter ist gemäß Art. 14, Abs. 1, Bst. c) CPI.
} 


\subsection{Das Eintragungsverfahren}

Das Ausschließlichkeitsrecht an der Marke wird durch die Eintragung verliehen. Diese besteht aus der Erteilung einer Bescheinigung durch das Italienische Patentund Markenamt (Ufficio Italiano Brevetti e Marchi; UIBM) ${ }^{103}$, das beim italienischen Wirtschaftsministerium (Ministero dello sviluppo economico) in Rom angesiedelt ist, am Ende eines mehrphasigen Verwaltungsverfahrens.

\subsubsection{Anmeldung}

Das Eintragungsverfahren wird durch Einreichung der Markenanmeldung (domanda di registrazione per marchio d'impresa) beim Italienischen Patent- und Markenamt eingeleitet. Die Einreichung der Anmeldung kann in Papierform bei den Handelskammern oder auch auf elektronischem Wege direkt an das Italienische Patent- und Markenamt erfolgen. ${ }^{104}$ Jede Anmeldung darf sich auf nur eine Marke beziehen. Andernfalls wird der Anmelder vom Amt aufgefordert, die Anmeldung entsprechend einzuschränken. Es besteht aber die Möglichkeit, die Anmeldung, die mehrere Waren oder Dienstleistungen zum Gegenstand hat, in mehrere Teilanmeldungen aufzuteilen. ${ }^{105}$ Diese Teilung kann entweder vor der Eintragung, während eines etwaigen Widerspruchsverfahrens, beziehungsweise Beschwerdeverfahrens, gegen die Entscheidung über die Eintragung der Marke beantragt werden.

\subsubsection{Prüfungsphase}

Nach Eingang der Anmeldung prüft das Amt zunächst, ob die Anmeldung die Formerfordernisse erfüllt. Ist dies der Fall, prüft das Amt das Vorliegen absoluter Eintragungshindernisse, die zum großen Teil den absoluten Nichtigkeitsgründen entsprechen. ${ }^{106}$

\footnotetext{
${ }^{103}$ Sitz in 00187 Roma, Via Molise 19 - https://uibm.mise.gov.it (zugegriffen am 20.04.2020).

${ }^{104}$ Der Inhalt der Anmeldung ist gesetzlich vorgeschrieben und muss unter anderem folgende Angaben enthalten: Angaben zur Identität des Anmelders und ggf. zur Identität des Bevollmächtigten; die etwaige Geltendmachung der Priorität; die Wiedergabe der Marke (bei Bildmarken deren Darstellung); ein Verzeichnis der Waren bzw. Dienstleistungen, die durch die Marke gekennzeichnet werden sollen.

${ }^{105}$ Siehe dazu Art. 158 CPI.

${ }^{106} \mathrm{Im}$ Einzelnen soll mit dieser Prüfung festgestellt werden, ob das Zeichen, für das der Schutz begehrt wird, unter die in Art. 7 CPI genannten Zeichen fällt, also unter diejenigen Zeichen, die geeignet sind, (a) Waren oder Dienstleistungen eines Unternehmens von denjenigen anderer Unternehmen zu unterscheiden und (b) im Register in einer Weise dargestellt zu werden, dass die zuständigen Behörden und das Publikum den Gegenstand des ihrem Inhaber gewährten Schutzes klar und eindeutig bestimmen können. Ferner soll festgestellt werden, dass es sich nicht um ein Zeichen handelt, das gegen das Gesetz, die öffentliche Ordnung oder die guten Sitten verstößt beziehungsweise es sich um ein irreführendes Zeichen handelt. Weiters darf es sich nicht um ein rein
} 
Wird die Anmeldung nach Abschluss der Prüfung als eintragungsfähig angesehen, wird sie vom Amt im Amtsblatt der Unternehmensmarken (Bollettino ufficiale dei Marchi di impresa) ${ }^{107}$ veröffentlicht.

\subsubsection{Eingreifen der Drittbetroffenen}

Es steht jedem Interessierten das Recht zu, ohne deshalb die Eigenschaft als Partei im Eintragungsverfahren zu erwerben, schriftliche Einwände unter Angabe der Gründe, aus denen die Marke von Amts wegen von der Anmeldung ausgeschlossen werden sollte, an das Italienische Patent- und Markenamt zu richten. ${ }^{108}$ Die Einwände werden, sofern sie vom Amt als stichhaltig und relevant betrachtet werden, dem Anmelder mitgeteilt, der innerhalb von dreißig Tagen ab der Mitteilung dazu Stellung nehmen kann.

\subsubsection{Widerspruch gegen die Eintragung}

Innerhalb von neunzig Tagen ab dem Tage der Veröffentlichung im Amtsblatt der Unternehmensmarken, kann Widerspruch gegen die Eintragung als Marke eingelegt werden. ${ }^{109}$ Widerspruchsberechtigt sind sowohl der Inhaber einer früher eingetragenen Marke beziehungsweise der Inhaber einer Marke mit Wirksamkeit in Italien als auch derjenige, der zu einem früheren Zeitpunkt eine Marke angemeldet hat oder eine Priorität oder einen Zeitrang ${ }^{110}$ in Anspruch nimmt. ${ }^{111}$ Weiters widerspruchsberechtigt sind die Inhaber einer Lizenz zur ausschließlichen Benutzung einer Marke sowie Personen, Körperschaften oder Verbände, die den Schutz der bekannten Namen gemäß Art. 8 CPI geltend machen können.

Mit der Einbringung eines Widerspruchs können die in Art. 12, Abs. 1, Bst. c) und d) CPI genannten Eintragungshindernisse für alle, für einen Teil der Waren, oder für Dienstleistungen, für die Schutz begehrt wird, sowie das Fehlen des Einverständnisses des Eintragungsberechtigten im Sinne von Art. 8 CPI geltend gemacht werden. Somit reduzieren sich die Widerspruchsgründe in Italien auf (a) das Vorhandensein älterer eingetragener identischer oder ähnlicher Marken für identische oder ähnliche Waren oder Dienstleistungen sowie auf (b) das Fehlen des

beschreibendes Zeichen sowie um eine Form im Sinne von Art. 9 CPI, ein Wappen oder um ein anderes in den internationalen Übereinkommen genanntes Zeichen, Symbol oder Emblem von öffentlichem Interesse handeln. Schließlich wird geprüft, ob es sich um den Namen oder die Abbildung einer Person handelt, die nicht der Anmelder ist, oder ob es sich um ein bekanntes Zeichen handelt.

${ }^{107}$ https://www.uibm.gov.it/bancadati/bollettini/index/ (zugegriffen am 20.04.2020).

${ }^{108}$ Vgl. Art. 175 CPI.

${ }^{109}$ Vgl. Art. 176 CPI.

${ }^{110}$ Vgl. Art. 39 f. Verordnung (EU) 2017/1001.

${ }^{111}$ Vgl. Art. 177 CPI. 
Einverständnisses seitens der Eintragungsberechtigten im Falle von Personenabbildungen, Namen und bekannten Zeichen.

Das Widerspruchsverfahren stellt ein Verwaltungsverfahren vor dem Italienischen Patent- und Markenamt dar, welches der Erteilung der Eintragung vorausgeht. Nach der Prüfung der Zulässigkeit des Widerspruchs, wird der Widerspruch dem Markenanmelder von Amts wegen mitgeteilt. Gleichzeitig werden die Parteien über die Möglichkeit informiert, dass sie innerhalb der verlängerbaren Frist von zwei Monaten (cooling-off Frist) nach der Mitteilung eine Schlichtungsvereinbarung treffen können. Für den Fall, dass die Widerspruchsparteien keine Schlichtungsvereinbarung treffen, beginnt die Phase der Widerspruchsprüfung, in der die Parteien ihre Ansprüche dokumentieren und begründen können. Die Entscheidung des Amtes muss spätestens 24 Monate nach Einlegung des Widerspruchs erfolgen.

\subsubsection{Entscheidungsphase}

Nach Abschluss der Prüfung trifft das Amt seine Entscheidung, indem es die Anmeldung annimmt oder zurückweist. Im ersten Fall nimmt das Amt die Eintragung der Marke vor und stellt die diesbezügliche Eintragungsbescheinigung aus. Verweigert das Amt hingegen die Eintragung, kann der Anmelder innerhalb von sechzig Tagen ab Mitteilung den Beschwerdeausschuss (Commissione dei ricorsi) anrufen. ${ }^{112}$ Gibt dieser der Beschwerde statt, ordnet er dem Amt die Eintragung der Marke an.

Gegen das Urteil des Beschwerdeausschusses kann das Rechtsmittel der Kassationsbeschwerde (ricorso per cassazione) eingelegt werden.

\subsubsection{Wirkungen der Eintragung}

Der Anmelder erlangt durch die Eintragung das Ausschließlichkeitsrecht an der Marke. Die Eintragung, wie auch das damit verbundene Ausschließlichkeitsrecht, haben eine Wirksamkeit von zehn Jahren ab dem Datum der Anmeldung. Vorbehaltlich der besonderen Regelung für notorisch bekannte Marken, betrifft das Ausschließlichkeitsrecht lediglich die in der Eintragung genannten oder ihnen ähnlichen Waren und Dienstleistungen.

In Bezug auf die räumliche Wirkung des Markenschutzes erstreckt sich dieser auf das gesamte Staatsgebiet, unabhängig davon, in welchem räumlichen Bereich die Marke tatsächlich benutzt wird.

Die Eintragung der Marke kann ohne Einschränkung um jeweils weitere zehn Jahre verlängert werden, wobei die Verlängerung nur für die identische Marke und

\footnotetext{
${ }^{112}$ Das Verfahren vor dem Beschwerdeausschuss wurde durch Decreto Legislativo 20.02.2019, n. 15 reformiert, vgl. G. Sena/S. Giudici, Il civilista: La nuova disciplina di marchi e brevetti, Giuffrè, Milano, 2019, S. 23 ff.
} 
dieselben Waren oder Dienstleistungen - beziehungsweise auch nur einen Teil davon - erfolgen kann.

\section{Der Rechtsschutz}

\subsection{Das Recht zur ausschließlichen Benutzung der Marke}

Die Marke ist ein Unterscheidungszeichen, mit dem der Unternehmer seine Waren und Dienstleistungen am Markt kennzeichnet. Die Rechtsordnung hat dieses Interesse für schutzwürdig anerkannt und verleiht dem Inhaber das für die Gewährleistung der Unterscheidungsfunktion wesentliche Ausschließlichkeitsrecht, wobei Dritten die Eintragung und Benutzung identischer und verwechselbarer Zeichen sowie von Zeichen, die in die Relevanzsphäre des Markeninhabers eingreifen untersagt wird.

Das dem Markeninhaber mit der Eintragung verliehene Recht zur ausschließlichen Benutzung der Marke, ${ }^{113}$ beinhaltet die dem Inhaber zuerkannte Möglichkeit, Dritten, soweit er diesen keine Zustimmung erteilt hat, bestimmte Verhaltensweisen zu untersagen. Diese Verhaltensweisen bestehen in den verschiedenen Arten der Markenbenutzung, die aufgrund der Identität oder Ähnlichkeit der Zeichen sowie aufgrund der Identität oder Ähnlichkeit der gekennzeichneten Waren und Dienstleistungen zu einer Verwechslungsgefahr für das Publikum führen können, wobei diese auch in der Gefahr der gedanklichen Verbindung zwischen den beiden Zeichen bestehen kann.

Das ausschließliche Recht zur Benutzung der Marke stellt ein absolutes Recht ${ }^{114}$ dar, weshalb eine Verletzung in jeder unzulässigen Wiedergabe der Marke zu sehen ist, unabhängig einer subjektiven - gutgläubigen oder bösgläubigen - Konnotation, also unabhängig davon, ob ein fahrlässiges oder vorsätzliches Handeln vorliegt. Nichtsdestotrotz ist der subjektive Aspekt, insbesondere bei der gegenüber dem Urheber der Verletzung anwendbaren Sanktionen, von Relevanz.

\subsubsection{Die Verwechslungsgefahr}

Die Verwechslungsgefahr (rischio di confusione), die zumindest im Normalfall die Schranke des Markenschutzes darstellt, muss die Herkunft der Waren bzw. Dienstleistungen betreffen, und nicht eine bloße Verwechslungsmöglichkeit von Zeichen beziehungsweise Waren und Dienstleistungen.

\footnotetext{
${ }^{113}$ Siehe Art. 20, Abs. 1 CPI.

${ }^{114}$ Vgl. Corte di Cassazione, 28.07.2015, n. 15840; Corte di Cassazione, 19.06.2008, n. 16647; Corte di Cassazione, 25.09.1998, n. 9617; Corte di Cassazione, 04.12.1999, n. 13592 sowie A. Vanzetti/V. Di Cataldo, Manuale di diritto industriale, Giuffrè, Milano, 2018, S. 239 f.
} 
Die Benutzung eines identischen oder ähnlichen Zeichens für identische oder ähnliche Waren oder Dienstleistungen durch einen Dritten ist demnach unzulässig, wenn sie geeignet ist, das Publikum zur Annahme zu verleiten, dass die Waren oder Dienstleistungen von dem Unternehmen des Markeninhabers oder zumindest von einem mit dem Markeninhaber aufgrund von Konzern- oder Vertragsbeziehungen verbundenen Unternehmen stammen. Demnach kann die Verwechslungsgefahr auch in einer Gefahr der gedanklichen Verbindung zwischen zwei Zeichen bestehen. ${ }^{115}$

Grundsätzlich ist die Marke somit entsprechend ihrer Unterscheidungsfunktion nur im Rahmen der Verwechslungsgefahr geschützt. Damit diese Verwechslungsmöglichkeit besteht, müssen gleichzeitig zwei Elemente gegeben sein, nämlich eine Identität oder Ähnlichkeit von Zeichen einerseits und eine Identität oder Affinität der gekennzeichneten Waren und Dienstleistungen andererseits.

Eine Ausnahme davon liegt für den Fall der Benutzung eines identischen Zeichens für identische Waren oder Dienstleitungen vor. In diesem Fall steht dem Markeninhaber im Sinne von Art. 20, Abs. 1, Bst. a) CPI das Recht zu, es Dritten - unabhängig vom Bestehen einer Verwechslungsgefahr - zu untersagen, im Rahmen des geschäftlichen Verkehrs ein mit der Marke identisches Zeichen für Waren oder Dienstleistungen zu benutzen, die identisch sind mit den Waren oder Dienstleistungen, für welche die Marke eingetragen wurde. ${ }^{116}$

\subsubsection{Die Identität und Ähnlichkeit zwischen Zeichen}

Für den Fall, dass zwei Marken nicht identisch, sondern lediglich ähnlich sind, muss festgestellt werden, ob zwischen ihnen eine Verwechselungsgefahr besteht, wobei dabei mehrere Aspekte zu berücksichtigen sind.

Zunächst ist die Art des Verbrauchers zu berücksichtigen, für den die gekennzeichneten Waren und Dienstleistungen bestimmt sind. Demnach kann etwa im Fall hochpreisiger Waren, die für fachlich hoch qualifizierte Kunden bestimmt sind, die Verwechslungsgefahr auch dann ausgeschlossen werden, wenn zwischen den beiden Zeichen eine beachtliche Nähe besteht, zumal in diesen Fällen die Aufmerksamkeit des Käufers besonders hoch ist. Demgegenüber wird bei gängigen und

\footnotetext{
${ }^{115}$ Dies ist dann der Fall, wenn Zeichen zwar nicht ähnlich und damit auch nicht verwechselbar sind, jedoch als eng miteinander verbunden erscheinen, wie beispielsweise bei den sogenannten Serienmarken (z. B. Cartier, Le Must de Cartier).

${ }^{116}$ Dies ist für den Markeninhaber eindeutig ein Vorteil, zumal er vom Nachweis des Bestehens einer Verwechslungsgefahr oder der Gefahr einer gedanklichen Verbindung entbunden wird. Diese Regelung fand aufgrund des Übereinkommens über handelsbezogene Aspekte der Rechte des geistigen Eigentums von 1994 (Agreement on Trade-Related Aspects of Intellectual Property Rights, TRIPS - Accordo relativo agli aspetti dei diritti di proprietà intellettuale attinenti al commercio) Eingang in die nationale Rechtsordnung; vgl. Decreto Legislativo 19.03.1996, n. 198: Adeguamento della legislazione interna in materia di proprietà industriale alle prescrizioni obbligatorie dell'accordo relativo agli aspetti dei diritti di proprietà intellettuale concernenti il commercio Uruguay Round, in: Gazzetta Ufficiale, 15.04.1996, n. 88.
} 
preisgünstigen Konsumgütern, die für undifferenzierte und daher grundsätzlich unaufmerksamere Kundenschicht bestimmt sind, das Bestehen einer Verwechslungsgefahr auch dann bejaht werden, wenn zwischen den beiden Zeichen ein verhältnismäßig größerer Unterschied besteht.

Zudem ist zu berücksichtigen, dass der Verbraucher beim Kauf normalerweise keine direkte Gegenüberstellung der beiden vermeintlich ähnlichen Zeichen vornehmen kann, sondern lediglich einen gedanklichen Vergleich zwischen dem Zeichen des vermeintlichen Nachahmers und dem anderen (in Erinnerung verbliebenen) Zeichen anstellen kann. Für diese Fälle ist jenen Unterschieden keine Relevanz beizumessen, die zwar wahrnehmbar sind, wenn beide Marken gleichzeitig präsent sind, die aber nicht so deutlich sind, dass sie sich im Gedächtnis einprägen.

Schließlich sind die vermeintlich verwechselbaren Marken in Bezug auf ihre grafischen, fonetischen und konzeptuellen Aspekte miteinander zu verglichen. Dabei geht es zunächst insbesondere um die Ähnlichkeiten und Unterschiede zwischen den mit dem Auge wahrnehmbaren Merkmalen (z. B. Design, Schriftzeichen, Verzierungen und Farben). Bei Wortmarken sind neben den grafischen auch die fonetischen Elemente zu beachten, zumal es vorkommen kann, dass sich die beiden Marken zwar grafisch unterscheiden, fonetisch jedoch ähneln sind. Bei Marken mit semantischem Wert muss schließlich auch festgestellt werden, ob zwischen den beiden Zeichen eine gedankliche Verbindung besteht.

Im Hinblick auf die Prüfung der Verwechslungsgefahr besteht in der Rechtsprechung ${ }^{117}$ Einigkeit darüber, dass die Gegenüberstellung der beiden Marken nicht analytisch, also durch eine detaillierte Prüfung jedes einzelnen Elements zu erfolgen hat, sondern einheitlich und gesamtheitlich, also durch eine ganzheitliche Beurteilung, welche nur die wesentlichen Elemente berücksichtigt. ${ }^{118}$

Insbesondere bei komplexen Marken, also Marken, die aus verschiedenen Elementen zusammengesetzt sind, ist es erforderlich, das wesentliche und charakteristische Element zu individualisieren, zumal nur seine Nachahmung eine Markenrechtsverletzung begründen kann. Damit rechtfertigt sich auch der unterschiedliche Schutzbereich der schwachen Marke einerseits beziehungsweise starken Marke

\footnotetext{
${ }^{117}$ Vgl. unter vielen EuGH, Urteil, 11.11.1997, C-251/95, Sabèl BV/Puma AG, Rudolf Dassler Sport, ECLI:EU:C:1997:528; „Zur Beurteilung der Verwechslungsgefahr sei auf den Gesamteindruck der betreffenden Zeichen abzustellen. Es sei nicht zulässig, ein Element aus einer Gesamtbezeichnung herauszugreifen und die Prüfung der Verwechslungsgefahr nur auf dieses Element zu beschränken. Dennoch könne einem einzelnen Bestandteil eines Zeichens eine besondere, die das Gesamtzeichen prägende Kennzeichnungskraft zugemessen und deshalb bei einer Übereinstimmung des Drittzeichens mit dem so geprägten Gesamtzeichen eine Verwechslungsgefahr im kennzeichenrechtlichen Sinne angenommen werden. Es gehe aber auch in einem solchen Fall immer nur um die Betrachtung der beiden Zeichen in ihrer Gesamtheit und nicht etwa nur der einzelnen (prägenden) Elemente. “

${ }^{118}$ In der Literatur findet sich auf jene Theorie, wonach zunächst die Notwendigkeit besteht, dass das Gericht analytisch die einzelnen konstitutiven Elemente der beiden Marken prüft und erst nachdem Punkt für Punkt die festgestellten Ähnlichkeiten und Unterschiede aufgezeigt wurden, den einzelnen Elementen - abhängig von ihrer größeren oder geringeren Unterscheidungskraft unterschiedliches „Gewicht“ beigemessen werden kann; vgl. A. Vanzetti/V. Di Cataldo, Manuale di diritto industriale, Giuffrè, Milano, 2018, S. 243 f.
} 
andererseits. Während Abänderungen bei einer schwachen Marke keine Nachahmung darstellen, da keinem Element der Marke eine besondere Unterscheidungskraft zuerkannt wird, genügen bei einer starken Marke, also einer Marke mit besonderer Unterscheidungskraft, bereits geringfügige Ähnlichkeiten, um den Tatbestand der Nachahmung zu erfüllen. ${ }^{119}$

Um den Schutzbereich einer Marke gegen Verwechselbarkeit auszuweiten, werden in der Praxis häufig mehrere Anmeldungen vorgenommen, wobei eine Anmeldung die zu benutzende Marke, die anderen Anmeldungen, die sogenannten Defensivmarken (marchio protettivo oder marchio difensivo), zum Gegenstand haben. Die Defensivmarken ähneln dabei der Hauptmarke, wodurch ein erweiterter Schutzbereich geschaffen wird, mit dem Ziel es zu verhindern, dass sich andere Marken der Hauptmarke in einem ansonsten zulässigen Ausmaß annähern. ${ }^{120}$ Art. 24, Abs. 4 CPI begünstigt diese Praxis, indem bestimmt wird, dass kein Verfall wegen Nichtbenutzung eintritt, wenn der Inhaber der nicht benutzten Marke gleichzeitig Inhaber einer oder mehrerer ähnlicher, nach wie vor gültigen Marken ist, von denen er mindestens eine tatsächlich benutzt, um die gleichen Waren oder Dienstleistungen zu kennzeichnen. Die Defensivmarke verfällt demzufolge nicht durch Nichtbenutzung.

\subsubsection{Die Identität und Ähnlichkeit zwischen Waren und Dienstleistungen}

Für das Bestehen der Verwechslungsgefahr ist neben der Verwechselbarkeit der Zeichen auch die Identität oder Ähnlichkeit der gekennzeichneten Waren beziehungsweise Dienstleistungen erforderlich. Das bedeutet, dass selbst bei identischen Zeichen keine Verwechslungsgefahr gegeben ist, sofern die gekennzeichneten Waren oder Dienstleistungen sehr unterschiedliche Waren- oder Dienstleistungsgruppen betreffen. In diesem Zusammenhang spricht man vom bereits genannten Grundsatz der Relativität oder Spezialität des Markenschutzes. Art. 15, Abs. 3 CPI iVm Art. 2569 c.c. und Art. 20 CPI bestimmt diesbezüglich, dass die Eintragung ihre Wirkung lediglich für die in der Eintragung angegebenen Waren oder Dienstleistungen oder für die ähnlichen Produkte oder Dienstleistungen entfaltet. Zudem bestimmt Art. 156, Abs. 1 CPI, dass die Markenanmeldung ein Verzeichnis der durch die Marke zu kennzeichnenden Waren bzw. Dienstleistungen enthalten muss, wobei diesbezüglich auf die Internationale Klassifikation von Waren und Dienstleistungen für die Eintragung von Marken gemäß dem Abkommen von Nizza vom 15. Juni 1957 abgestellt wird. ${ }^{121}$

\footnotetext{
${ }^{119}$ Vgl. A. Vanzetti/V. Di Cataldo, Manuale di diritto industriale, Giuffrè, Milano, 2018, S. 246 ff.

${ }^{120} \mathrm{Vgl}$. G. Cuonzo/B. Marsicola, L'identità dell'impresa: i segni distintivi, in: Proprietà industriale, intellettuale e IT, Wolters Kluwer, Milano, 2017, S. 121 f.; A. Vanzetti/V. Di Cataldo, Manuale di diritto industriale, Giuffrè, Milano, 2018, S. 251 f.

${ }^{121}$ Die Internationale Klassifikation von Waren und Dienstleistungen für die Eintragung von Marken (Classificazione internazionale dei prodotti e dei servizi - Classificazione di Nizza) teilt die Produkt- und Dienstleistungsgattungen in 45 Klassen ein.
} 
Bei der Beurteilung der Ähnlichkeit, also der Frage, ob eine Ware oder Dienstleistung einer anderen ähnlich ist, wird anhand der traditionellen These in Betracht gezogen, ob die Waren oder Dienstleistungen (a) gleicher Natur sind, (b) für den gleichen Kundenkreis bestimmt sind oder (c) die gleichen Bedürfnisse befriedigen. Nach der neuesten Theorie wird in Anbetracht der Herkunftsfunktion der Marke dann von einer Ähnlichkeit der Waren und Dienstleistungen ausgegangen, wenn der Verbraucher berechtigterweise annehmen kann, dass Waren und Dienstleistungen vom gleichen Unternehmen stammen. ${ }^{122}$ Entsprechend dieser These wird der Schutz nicht lediglich auf die Möglichkeit der Verwechslung beschränkt, sondern auch auf solche Fälle ausgedehnt, in denen die gekennzeichneten Waren und Dienstleistungen zwar aus Sicht der Waren- oder Dienstleistungsgruppen zwar unterscheidbar sind, die konkrete Situation allerdings dazu führt, das Publikum annehmen zu lassen, dass die Waren und Dienstleistungen aus ein und demselben Unternehmen stammten.

Analog zu den Defensivmarken kommt es in der markenrechtlichen Praxis häufig vor, dass der Markeninhaber eine Marke nicht nur für die Waren oder Dienstleistungen anmeldet, für die er die Marke tatsächlich zu benutzen beabsichtigt, sondern die Marke auch für andere Waren und Dienstleistungen angemeldet wird. In diesem Zusammenhang spricht man von Defensivlisten oder Schutzlisten (liste di protezione o di difesa), zumal sich der Schutzbereich der Marke ausweitet. Allerdings gesteht der Gesetzgeber den Schutzlisten im Gegensatz zu den Defensivmarken nicht dieselbe Regelung zu und die herrschende Rechtsprechung erklärt seit längerem, gestützt auf Art. 27 CPI, den Teilverfall des Markenschutzes in Bezug auf jene Waren und Dienstleistungen, für die die Marke zwar eingetragen, allerdings nicht benutzt wird. ${ }^{123}$

Das Prinzip der Relativität des Markenschutzes gilt nicht für jene Marken, die einen besonderen Ruf genießen (notorisch bekannte, renommierte oder berühmte Marken). Demnach kann der Inhaber einer bekannten Marke im Sinne von Art. 12, Abs. 1, Bst. e) CPI Dritten die Benutzung einer identischen oder ähnlichen Marke auch für nicht ähnliche Produkte oder Dienstleistungen untersagen, wenn es (a) die Benutzung des Zeichens ohne berechtigten Grund ermöglicht, unzulässiger Weise einen Nutzen aus dem Unterscheidungscharakter oder aus dem besonderen Ruf der

\footnotetext{
${ }^{122}$ Vgl. A. Vanzetti/V. Di Cataldo, Manuale di diritto industriale, Giuffrè, Milano, 2018, S. 253 ff. ${ }^{123}$ Vgl. M. ScuffilM. Franzosi, Diritto industriale italiano, Cedam, Padova, 2013, S. 310 f.; A. Vanzetti/V. Di Cataldo, Manuale di diritto industriale, Giuffrè, Milano, 2018, S. 256 f.; A. Vanzetti, Codice della Proprietà industriale, Giuffrè, Milano 2013, S. 522 ff.; siehe auch Corte di Cassazione, 27.09.2006, n. 21013.
} 
Marke zu ziehen, oder wenn sie (b) den Unterscheidungscharakter und den besonderen Ruf ${ }^{124}$ beeinträchtigt.

\subsubsection{Der Inhalt des Ausschließlichkeitsrechts}

In Art. 20, Abs. 2 CPI wird der Inhalt des Ausschließlichkeitsrechts beschrieben, indem eine Aufzählung davon erfolgt, was der Markeninhaber Dritten untersagen kann. Dabei wird der Begriff der Markenbenutzung und demzufolge der Nachahmung weit gefasst. Der Markeninhaber kann Dritten demzufolge (a) die Anbringung des Markenzeichens auf seinen Waren und Dienstleistungen, wie auch (b) das Angebot, das Inverkehrbringen sowie das Verwahren von mit dem Markenzeichen gekennzeichneten Waren untersagen. Untersagt ist weiters (c) die Ein- oder Ausfuhr dieser Waren und Dienstleistungen als auch (d) die Benutzung des Zeichens zu Werbezwecken.

Während der Gesetzgeber somit jegliche Benutzung der Marke anderer zum Zwecke der Kennzeichnung der eigenen Waren und Dienstleistungen (Unterscheidungsfunktion) untersagt, sind im Sinne von Art. 21, Abs. 1 CPI sogenannte atypische Benutzungen der fremden Marke, die eine andere Funktion als die vorgenannten Funktionen haben, grundsätzlich zulässig. Der häufigste und bekannteste Fall einer atypischen Benutzung ist die Benutzung einer fremden Marke zu beschreibenden Zwecken. ${ }^{125}$

\footnotetext{
${ }^{124}$ Was unter einer Marke von besonderem Ruf zu verstehen ist, wird vom Gesetz nicht ausdrücklich definiert. Allerdings steht der Marke dieser erweiterte Schutz immer dann zu, wenn ihre Nachahmung zu dem „Nutzen“ bzw. zu der „Beeinträchtigung“ führen kann, von dem das Gesetz spricht. Die Beweislast bezüglich des Nutzens bzw. der Beeinträchtigung und damit des besonderen Rufs trägt der Markeninhaber, der auf Nichtigkeit der späteren verwechselbaren Marke klagen kann.

${ }^{125}$ Gemäß Art. 21, Abs. 1 CPI kann der Markeninhaber Dritten im geschäftlichen Verkehr nicht

(a) die Nutzung des eigenen Namens oder der Adresse, sofern es sich um eine natürliche Person handelt, untersagen

(b) die Nutzung von Angaben oder Zeichen ohne Unterscheidungskraft oder solche, die die Art, die Beschaffenheit, die Quantität, die Zweckbestimmung, den Wert, die geografische Herkunft, das Alter oder andere Eigenschaften der Waren oder Dienstleistungen betreffen, untersagen, oder

(c) die Nutzung der Marke eines anderen untersagen, wenn dies notwendig ist, um die Zweckbestimmung einer eigenen Ware oder einer eigenen Dienstleistung anzugeben, oder sich darauf zu beziehen.
}

Im Sinne des Art. 21, Abs. 1 CPI wäre somit die Nutzung des eigenen Namens als Marke beim gleichzeitigen Bestehen einer eingetragenen Marke nur für natürliche Personen gestattet. Demgegenüber vertritt der Europäische Gerichtshof die Auffassung, dass diese Ausnahme auch für juristische Personen gilt, vgl. u.a. EuGH, Urteil, 16.11.2004, Rechtssache C-245/02, Anheuser-Busch Inc./Budějovický Budvar, národní podnik, in: ECLI:EU:C:2004:717: „Ein Dritter kann sich grundsätzlich auf die Ausnahme des Artikels 6 Absatz 1 Buchstabe a der Richtlinie 89/104 berufen, um ein mit einer Marke identisches oder ihr ähnliches Zeichen zur Angabe seines Handelsnamens zu benutzen, auch wenn es sich um eine Benutzung handelt, die unter Artikel 5 Absatz 1 der Richtlinie 


\subsection{Die Nachahmungsklage}

Der Markeninhaber, dessen Ausschließlichkeitsrecht von einem Dritten verletzt wurde - sowie auch der Lizenznehmer, der ein Exklusivrecht an der Marke hat ${ }^{126}$-, ist aktivlegitimiert, zum Schutz dieses Rechts die Nachahmungsklage (azione di contraffazione $)^{127} \mathrm{zu}$ erheben. Das Verfahren kann auch bereits bei Vorliegen der Anmeldung eingeleitet werden, wobei die erfolgreiche Eintragung der Marke eine notwendige Voraussetzung darstellt, damit der Nachahmungsklage stattgegeben werden kann. Dementsprechend muss die Eintragung jedenfalls vor dem Urteil erfolgen.

Die sachmäßige Zuständigkeit für die Nachahmungsklage liegt bei den Fachkammern für Unternehmensfragen (Tribunale delle imprese), welche nach Maßgabe von Art. 1 gesetzesvertretendes Dekret 27.06.2003, Nr. $168^{128}$ bei den Landesgerichten (Tribunale; Gericht erster Instanz) und Oberlandesgerichten (Corte d'Appello; Gericht zweiter Instanz) mit Sitz in den Hauptstädten der Regionen eingerichtet worden sind. ${ }^{129}$ Die örtliche Zuständigkeit ergibt sich aus Art. 120 CPI,

fällt und die der Markeninhaber aufgrund der ihm nach dieser Bestimmung zustehenden ausschließlichen Rechte grundsätzlich verbieten könnte."

${ }^{126}$ Vgl. A. Sirotti Gaudenzi, Marchi. Legittimato ad agire solo chi possiede licenza esclusiva, in: Guida al diritto, 2019, fasc. 25, S. 54 ff.

${ }^{127}$ Weiterführend zur Nachahmungsklage vgl. M. Ricolfi. Trattato dei Marchi. Diritto europeo e nazionale, Giappichelli, Torino, 2015, S. 1047 ff.; D. Capelli/F. Ruggieri/F. Bocedi, La tutela dei diritti IP, in: Proprietà industriale, intellettuale e IT, Wolters Kluwer, Milano, 2017, S. 688 ff.; A. Vanzetti/V. Di Cataldo, Manuale di diritto industriale, Giuffrè, Milano, 2018, S. 260 ff.; A. Sirotti Gaudenzi, Manuale pratico dei marchi e dei brevetti, Maggioli, Santarcangelo di Romagna, 2020, S. 138 ff.; G. Ratti, La contraffazione del marchio, in: N. Bottero/M. Travostino (a cura di), Il diritto dei marchi d'impresa. Profili sostanziali, processuali e contabili, Wolters Kluwer, Padova, 2009; A. Saraceno, La contraffazione del marchio. Presupposti sostanziali, in: N. Bottero/M. Travostino (a cura di), Il diritto dei marchi d'impresa. Profili sostanziali, processuali e contabili, Wolters Kluwer, Padova, 2009; P. Kindler, Italienisches Handels- und Wirtschaftsrecht, Fachmedien Recht und Wirtschaft, Frankfurt am Main, 2. Aufl., 2013, S. 77 f.

${ }^{128}$ Decreto Legislativo 27.06.2003, n. 168: Istituzione di Sezioni specializzate in materia di proprietà industriale ed intellettuale presso tribunali e corti d'appello, a norma dell'articolo 16 della legge 12 dicembre 2002, n. 273: in: Gazzetta Ufficiale, 11.07.2003, n. 159.

${ }^{129}$ Eine Ausnahme davon bildet die Autonome Region Trentino-Südtirol. Im Sinne von Art. 1, Abs. 1-bis gesetzesvertretendes Dekret 27.06.2003, n. 168 ist eine Fachkammer für Unternehmensfragen auch beim Landesgericht Bozen sowie bei der Außenabteilung Bozen des Oberlandesgerichtes Trient eingerichtet. Das Charakteristische ist dabei, dass beim Unternehmensgericht in erster und zweiter Instanz innerhalb Südtirols ein Markenstreit auch in deutscher Prozesssprache abgewickelt werden kann und das auf der Grundlage des Dekrets des Präsidenten der Republik vom 15. Juli 1988, Nr. 574: Durchführungsbestimmungen zum Sonderstatut für die Region Trentino-Südtirol über den Gebrauch der deutschen und der ladinischen Sprache in den Beziehungen zur öffentlichen Verwaltung und in den Gerichtsverfahren, in: Gazzetta Ufficiale, 08.05.1989, n. 105.

In der Region Lombardei und in der Region Sizilien gibt es jeweils zwei Sitze des Unternehmensgerichts, welches für Markenstreitigkeiten sachlich zuständig ist. In der Region Aosta gibt es kein entsprechendes Unternehmensgericht. Markenstreitigkeiten aus der Region Aosta werden vor dem Unternehmensgericht in Turin verhandelt. 
wobei der allgemeine Gerichtsstand (foro generale) grundsätzlich am Wohnsitz bzw. Sitz ${ }^{130}$ des Beklagten liegt. Ist hingegen der Wohnsitz des Beklagten unbekannt, beziehungsweise dieser nicht in Italien ansässig, gilt als allgemeiner Gerichtsstand der Sitz des Klägers. Sind weder Kläger noch Beklagter in Italien ansässig, liegt die Zuständigkeit beim Landesgericht in Rom.

Alternativ hierzu kann die Zuständigkeit nach Art. 120, Abs. 6 CPI nach Wahl des Klägers bei jenem Gericht des Ortes liegen, an dem die vermeintliche Nachahmung, d. h. das Inverkehrbringen oder die Bewerbung der mit der nachgeahmten Marke gekennzeichneten Ware oder Dienstleistung, erfolgt ist (forum commissi delicti).

Im Hinblick auf den gewerblichen Eigentumsschutz wurden Sondervorschriften eingeführt, die den Beweis der Nachahmung betreffen und mit denen ein aus den USA stammendes Institut, die sogenannte „discovery“, in die italienische Rechtsordnung Eingang gefunden hat. Zwar hat grundsätzlich der Markeninhaber den Beweis der Nachahmung zu erbringen, allerdings wurde die Rechtsposition des Markeninhabers mit Art. 121 CPI gestärkt. Demnach kann jene Partei, die ernsthafte Anhaltspunkte zur Begründetheit ihrer Ansprüche liefert und Dokumente oder Informationen identifiziert, die sich bei der Gegenseite befinden, erwirken, dass das Gericht deren Vorlage anordnet, oder sich die Informationen durch Einvernahme der Gegenseite beschafft. Des Weiteren kann das Gericht die Gegenseite dazu auffordern, Angaben zur Identifizierung jener Rechtssubjekte zu machen, die an der Herstellung und dem Vertrieb der vermeintlich nachgeahmten Waren oder Dienstleistungen mitwirken. ${ }^{131}$

Grundsätzlich kann der Inhaber eines gewerblichen Ausschließlichkeitsrechts den Beweis der Nachahmung dadurch erbringen, indem er sich ein Exemplar des vermeintlich nachgeahmten Objekts oder das dieses Objekt beschreibende Werbeund Illustrationsmaterial besorgt. Allerdings ist diese Methode der Beweisbeschaffung nicht immer praktikabel, da es sich um noch nicht auf dem Markt befindliche Waren handeln könnte. In diesem Fall kann der Inhaber des Ausschließlichkeitsrechts vorab und zum Zwecke der Verwendung im späteren Hauptsacheverfahren einen Beschreibungs- oder Beschlagnahmebeschluss beantragen. Beide Rechtsmittel haben Beweisfunktion, auch wenn sich die Beschlagnahme nicht nur auf die Beschaffung von Beweisen für die Verletzung beschränkt, sondern auch darauf abzielt, den weiteren Umlauf der nachgeahmten Objekte zu verhindern. ${ }^{132}$

\footnotetext{
${ }^{130}$ Neben dem Wohnsitz bzw. dem Sitz kann der Gerichtsstand auch beim Domizil oder Aufenthaltsort des Beklagten erwählt werden.

${ }^{131}$ Die Ermittlungsbefugnisse des Richters reichen soweit, dass gemäß Art. 121, Abs. 2-bis CPI im Falle der gewerbsmäßigen Verletzung durch Piraterie-Handlungen auf Parteiantrag die Vorlage der sich bei der Gegenseite befindlichen Bank-, Finanz- und Geschäftsunterlagen angeordnet werden kann. Weiters ist der Richter befugt, auf Parteiantrag vom vermeintlichen Nachahmer, wie auch von bestimmten Dritten Angaben zur Herkunft und zu den Vertriebsnetzen von Waren oder Dienstleistungen zu verlangen. Weitgehende Befugnisse werden dem Richter auch in der Phase der Beweisaufnahme zugestanden, indem er - zusätzlich zu den von den Parteien genannten Beweiskapiteln - weitere Fragen stellen kann.

${ }^{132} \mathrm{Vgl}$. Tribunale di Modena, 30.03.1993: „Il sequestro dei prodotti contraddistinti dal marchio contraffatto dev'essere esteso presso i terzi che ne facciano commercio. “
} 


\subsection{Nichtigkeitsklage und Klage auf Verfallserklärung}

Die Nichtigkeitsklage (azione di nullità) und Klage auf Verfallserklärung (azione di decadenza $)^{133}$ ist von Art. 122 ff. CPI normiert. Aktiv klageberechtigt ist grundsätzlich jeder, der ein Interesse daran hat und somit insbesondere der Wettbewerber, der im Vorhandensein einer Marke ein Hindernis für die Ausübung seiner Tätigkeit sieht. Die Klage kann auch von Amtswegen durch den Staatsanwalt erhoben werden, wobei abweichend von Art. 70, Abs. 1, Nr. 1 codice di procedura civile (c.p.c.) der ursprünglich zwingend vorgesehene Beitritt des Staatsanwaltes abgeschafft worden ist.

Passivlegitimation im Verfahren auf Feststellung der Nichtigkeit oder des Verfalls ist grundsätzlich der Markeninhaber. Notwendige Streitgenossen sind all jene Personen, die im Markenregister als Rechtsinhaber und damit als Berechtigte eingetragen sind. ${ }^{134}$

Die sachmäßige Zuständigkeit für Klagen auf Feststellung der Nichtigkeit oder Verfall einer Marke liegt bei den Fachkammern für Unternehmensfragen. ${ }^{135}$ Alternativ zum ordentlichen Gerichtsverfahren kann gemäß Art. 184-bis ff. CPI die Nichtigkeit oder der Verfall einer Marke auch im Wege eines Verwaltungsverfahrens vor dem italienischen Markenamt festgestellt werden. ${ }^{136}$ Die Einleitung dieses

\footnotetext{
${ }^{133}$ Weiterführend zur Nichtigkeitsklage und Klage auf Verfallserklärung vgl. D. Capelli/F. Ruggieri/F. Bocedi, La tutela dei diritti IP, in: Proprietà industriale, intellektuelle e IT, Wolters Kluwer, Milano, 2017, S. 672 ff.; M. Ricolfi. Trattato dei Marchi. Diritto europeo e nazionale, Giappichelli, Torino, 2015, S. 1016 ff.; A. Vanzetti/V. Di Cataldo, Manuale di diritto industriale, Giuffrè, Milano, 2018, S. 277 ff.; S. Carasso, La cassazione nega la rilevabilità d'ufficio della nullità assoluta del marchio, in: Giurisdizione italiana, 2018, fasc. 11, S. 2418; P. Kindler, Italienisches Handels- und Wirtschaftsrecht, Fachmedien Recht und Wirtschaft, Frankfurt am Main, 2. Aufl., 2013, S. 76 ff.

${ }^{134}$ Siehe Art. 122, Abs. 4 CPI.

${ }^{135}$ Gemäß Art. 24, Abs. 1, Nr. 4 Brüssel Ia Verordnung (Verordnung (EU) Nr. 1215/2012 des Europäischen Parlaments und des Rates vom 12. Dezember 2012 über die gerichtliche Zuständigkeit und die Anerkennung und Vollstreckung von Entscheidungen in Zivil- und Handelssachen, in: Amtsblatt der Europäischen Union, 20.12.2012, L 351/1) liegt die ausschließliche Zuständigkeit „,ür Verfahren, welche die Eintragung oder die Gültigkeit von Patenten, Marken, Mustern und Modellen sowie ähnlicher Rechte, die einer Hinterlegung oder Registrierung bedürfen, zum Gegenstand haben " unabhängig vom Wohnsitz/Sitz des Beklagten beim Gericht des Mitgliedstaats, „, in dessen Hoheitsgebiet die Hinterlegung oder Registrierung beantragt oder vorgenommen worden ist oder aufgrund eines Unionsrechtsakts oder eines zwischenstaatlichen Übereinkommens als vorgenommen gilt".

Im Gegensatz dazu kann die Nachahmungsklage (neben Gericht am Wohnsitz/Sitz des Beklagten) auch am Gerichtsstand des Ortes erhoben werden, an dem die als schädigend behauptete Handlung stattfindet.

${ }^{136}$ Umgesetzt mit Decreto Legislativo, 20.02.2019, n. 15: Attuazione della direttiva (UE) 2015/2436 del Parlamento europeo e del Consiglio, del 16 dicembre 2015, sul ravvicinamento delle legislazioni degli Stati membri in materia di marchi d'impresa nonché per l'adeguamento della normativa nazionale alle disposizioni del regolamento (UE) 2015/2424 del Parlamento europeo e del Consiglio, del 16 dicembre 2015, recante modifica al regolamento sul marchio comunitario, in: Gazzetta Ufficiale, 08.03.2019, n. 57. Vgl. G. Sena/S. Giudici, Il civilista: La nuova disciplina di marchi e brevetti, Giuffrè, Milano, 2019, S. 37 ff.
} 
Verfahrens erfolgt durch einen schriftlichen begründeten Antrag an das italienische Markenamt. Das Verfahren ist allerdings nicht verfolgbar, sofern gleichzeitig ein Verfahren vor dem ordentlichen Gericht anhängig ist.

Die Beweislast im Verfahren zur Feststellung der Nichtigkeit oder Verfall einer Marke liegt grundsätzlich bei demjenigen, der den gewerblichen Eigentumstitel anficht. ${ }^{137}$ In Bezug auf die Klage zur Feststellung des Verfalls wegen Nichtbenutzung wurde in Anbetracht dessen, dass es Dritten praktisch unmöglich ist, den umfassenden Beweis dafür zu erbringen, dass die von ihm angefochtene Marke zu keiner Zeit und an keinem Ort benutzt wurde, Art. 121, Abs. 1 CPI abgeändert. ${ }^{138}$ Nunmehr liegt die Beweislast im Verfahren zur Feststellung des Verfalls wegen Nichtbenutzung beim Markeninhaber, der die Benutzung im Sinne des Art. 24 CPI nachzuweisen hat.

Im Sinne von Art. 123 CPI hat das Urteil, mit denen die Nichtigkeit oder der Verfall einer Marke erklärt wird, mit Erlangung der Rechtskraft erga-omnes-Wirkung. ${ }^{139}$ Abweichend von der allgemeinen Bestimmung von Art. 2909 c.c., wonach die Rechtskraft nur zwischen den Parteien (inter-partes-Wirkung), den Erben und Rechtsnachfolgern eintritt, haben diese Urteile eine Tragweite, die über die normale Tragweite der Rechtskraft hinausgeht und somit das Erlöschen des Rechts des Markeninhabers bewirkt. Zudem kommt den Urteilen Rückwirkung zu. Während diese in Bezug auf die Feststellung der Nichtigkeit bis zum Datum der Anmeldung zurück reicht, reicht die Rückwirkung bei der Verfallserklärung hingegen nur bis zu jenem Datum zurück, an dem der den Verfall bewirkende Umstand eingetreten ist.

Die Nichtigerklärung der Marke bewirkt für den Inhaber grundsätzlich nur die Unmöglichkeit, die ausschließliche Benutzung der Marke zu beanspruchen. Führt die mit gerichtlichem Urteil festgestellte Nichtigkeit zur Unrechtmäßigkeit der Markennutzung, ist die Nutzung der Marke nach Art. 21, Abs. 3 CPI jedem untersagt. ${ }^{140}$

\footnotetext{
${ }^{137}$ Vgl. Art. 121, Abs. 1 CPI.

${ }^{138}$ Art. 13 Decreto Legislativo 20.02.2019, n. 15: Attuazione della direttiva (UE) 2015/2436 del Parlamento europeo e del Consiglio, del 16 dicembre 2015, sul ravvicinamento delle legislazioni degli Stati membri in materia di marchi d'impresa nonché per l'adeguamento della normativa nazionale alle disposizioni del regolamento (UE) 2015/2424 del Parlamento europeo e del Consiglio, del 16 dicembre 2015, recante modifica al regolamento sul marchio comunitario, in: Gazzetta Ufficiale, 08.03.2019, n. 57. Vgl. G. Sena/S. Giudici, Il civilista: La nuova disciplina di marchi e brevetti, Giuffrè, Milano, 2019, S. 21 f.

${ }^{139}$ Selbiges gilt für die Feststellung der Nichtigkeit oder des Verfalls im Wege des Verwaltungsverfahrens vor dem italienischen Markenamt im Sinne von Art. 184-bis ff. CPI.

${ }^{140}$ Eine Unrechtmäßigkeit und somit ein Verbot zur Benutzung der für nichtig erklärten Marke liegt bei einem Verstoß gegen das Gesetz, gegen die öffentliche Ordnung und gegen die guten Sitten (Art. 14, Abs. 1, Bst. a) iVm Art. 21, Abs. 2 CPI), im Falle von Irreführung (Art. 14, Abs. 1, Bst. b) iVm Art. 21, Abs. 2 CPI) sowie im Falle der Verletzung von Rechten Dritter (Art. 10 und Art. 14, Abs. 1, Bst. c) iVm Art. 21, Abs. 2 CPI) vor.
} 


\subsection{Die Sicherungsmaßnahmen: Beschreibung, Beschlagnahme und richterliche Untersagung}

Die mögliche Länge eines Nachahmungsverfahrens und die dem Markeninhaber aus der vermeintlichen Markenrechtsverletzung zwischenzeitlich entstehenden Schäden, haben den Gesetzgeber dazu veranlasst, besondere Sicherungsmaßnahmen einzuführen, die auch während des noch behängenden Eintragungsverfahrens gewährt werden können. ${ }^{141}$

Diese Maßnahmen sind:

- die Beschreibung (descrizione) mit der Funktion, vorab den Nachweis der Nachahmung zu erbringen;

- die Beschlagnahme (sequestro) mit der Funktion, den Umlauf der Waren und Dienstleistungen zu verhindern, die, solange sie sich auf dem Markt befinden, eine Markenrechtsverletzung darstellen;

- die richterliche Untersagung (inibitoria) mit der Funktion, dem Nachahmer die weitere oder erneute Herstellung, Vermarktung und/oder Benutzung der rechtsverletzenden Güter zu untersagen.

\subsubsection{Die Beschreibung und die Beschlagnahme}

Die Beschreibung und die Beschlagnahme ${ }^{142}$ stellen gegenüber dem Verfahren zu fachkundigen Ermittlungen (consulenza tecnica preventiva) ${ }^{143}$ unabhängige Sicherungsmaßnahmen dar.

Der Inhaber eines gewerblichen Eigentumsrechts kann die Beschreibung oder die Beschlagnahme - wie auch die Beschlagnahme mit vorhergehender Beschreibung - einiger oder aller Objekte verlangen, die eine Verletzung dieses Rechts darstellen sowie der für ihre Herstellung eingesetzten Mittel und der Elemente zum Beweis der geltend gemachten Verletzung und ihres Ausmaßes. ${ }^{144}$

In Bezug auf die Verfahren der Beschreibung und der Beschlagnahme finden in prozeduraler Hinsicht die Vorschriften der Zivilprozessordnung über die Verfahren zum einstweiligen Rechtsschutz Anwendung, soweit diese mit dem Gesetzbuch des

\footnotetext{
${ }^{141}$ Vgl. Art. 132, Abs. 1 CPI.

${ }^{142}$ Vgl. Art. 129 CPI; weiterführend zur Beschreibung und Beschlagnahme vgl. A. Vanzetti, Codice della Proprietà industriale, Giuffrè, Milano 2013, S. 1343 ff.; A. Sirotti Gaudenzi, Manuale pratico dei marchi e dei brevetti, Maggioli, Santarcangelo di Romagna, 2020, S. 143 ff.; D. Capelli/F. Ruggieri/F. Bocedi, La tutela dei diritti IP, in: Proprietà industriale, intellettuale e IT, Wolters Kluwer, Milano, 2017, S. 746 ff.; C. Bacchini, La descrizione secondo il nuovo Art. 129 c.p.i., in: Rivista di diritto industriale, 2010, fasc. 6, S. 505 ff.; S. Corona, Le misure della descrizione e del sequestro, in: C. Galli/A.M. Gambino, Codice commentato della proprietà industriale e intellettuale, Utet, Torino, 2012, S. $1161 \mathrm{ff}$.

${ }^{143}$ Vgl. Art. 128 CPI.

${ }^{144} \mathrm{Vgl}$. Art. 129 CPI.
} 
gewerblichen Eigentums kompatibel sind oder dieses nicht davon abweichende Regelungen vorsieht.

Auf die Beschreibung, wie auch auf die Beschlagnahme, wurde die Möglichkeit ausgedehnt, Sicherungsmaßnahmen auch ohne die vorherige Anhörung der Gegenseite zu erlassen (inaudita altera parte). Entsprechende Maßnahmen finden in Fällen besonderer Dringlichkeit Anwendung und insbesondere, wenn etwaige Verzögerungen dem Rechteinhaber einen irreparablen Schaden zufügen könnten, oder wenn die Ladung der Gegenseite die Durchführung der Beschreibungs- oder Beschlagnahmemaßnahme beeinträchtigen könnte.

\subsubsection{Die (provisorische) richterliche Untersagung}

Ein weiteres vorbeugendes Rechtsmittel bildet die richterliche Untersagung. ${ }^{145}$ Demnach kann der Inhaber eines gewerblichen Eigentumsrechts die vorläufige Untersagung und den Rückruf aus dem Handel in Anwendung der Bestimmungen der Zivilprozessordnung über die Verfahren zum einstweiligen Rechtsschutz verlangen. ${ }^{146}$ Die entsprechende Anordnung kann sowohl vor dem Hauptsacheverfahren (ante causam) als auch während des laufenden Verfahrens ergehen. Schließlich kann der Richter einen Betrag festsetzen, der für jeden anschließenden Verstoßes oder Nichtbeachtung sowie verspätete Umsetzung der Verfügung zu bezahlen ist.

\subsubsection{Verhältnis zwischen Sicherungs- und Hauptsacheverfahren}

Die Maßnahmen der Beschreibung beziehungsweise der Beschlagnahme werden wirkungslos, wenn das Hauptsacheverfahren nicht innerhalb der vom Gericht gesetzten Frist eingeleitet wird. ${ }^{147}$ Sofern hingegen keine gerichtliche Fristsetzung erfolgt, werden die Maßnahmen innerhalb von 20 Arbeitstagen beziehungsweise 31 Kalendertagen ab Erlass des in der Verhandlung ergangenen Beschlusses oder ab Mitteilung des außerhalb der Verhandlung ergangenen Beschlusses wirkungslos.

Diese Form der Wirkungslosigkeit tritt allerdings nicht ein, wenn die Sicherungsmaßnahmen geeignet sind, die Wirkungen des Urteils im Hauptsacheverfahren

\footnotetext{
${ }^{145}$ Vgl. Art. 131 CPI; weiterführend zur provisorischen richterlichen Untersagung vgl. A. Vanzetti, Codice della Proprietà industriale, Giuffrè, Milano 2013, S. 1400 ff.; A. Sirotti Gaudenzi, Manuale pratico dei marchi e dei brevetti, Maggioli, Santarcangelo di Romagna, 2020, S. 145 ff.; D. Capelli/F. Ruggieri/F. Bocedi, La tutela dei diritti IP, in: Proprietà industriale, intellettuale e IT, Wolters Kluwer, Milano, 2017, S. 763 ff.

${ }^{146}$ Vgl. Tribunale di Napoli, 5 luglio 2001: „Non può riconoscersi il periculum in mora qualora si trascorso un apprezzabile periodo di tempo tra il verificarsi del presumo evento dannoso e la proposizione della domanda cautelare."

Tribunale di Napoli, 28.12.2001: „Il periculum di mora risulta presene nella permanenza dell'illecito, tale da determinare uno sviamento di clientela, con conseguente irreparabili pregiudizio per i soggetti che denunciano la violazione dei propri diritti di privativa."

${ }^{147} \mathrm{Vgl}$. Art. 132 CPI.
} 
vorwegzunehmen. ${ }^{148}$ In diesen Fällen wird die ergangene richterliche Maßnahme nicht unwirksam, wenn nicht innerhalb der vorgenannten Fristen das Hauptsacheverfahren eingeleitet wird. ${ }^{149} \mathrm{Zu}$ den vorwegnehmenden Sicherungsmaßnahmen gehören die richterliche Untersagung und die Anordnung des Rückrufs aus dem Handel.

\subsection{Zivilrechtliche Sanktionen und Abhilfemaßnahmen}

Mit dem Urteil, das die Nachahmung feststellt, kann der Richter gegenüber der unterlegenen Partei eine Reihe zivilrechtlicher Sanktionen verhängen. ${ }^{150}$ Voraussetzung für alle Sanktionen - mit Ausnahme des Schadenersatzes - bildet die streng objektive, also unabhängig vom Beweis des Verschuldens oder des Schadens getroffene Feststellung, dass das Recht des Markeninhabers verletzt wurde.

\subsubsection{Die (definitive) richterliche Untersagung}

Die richterliche Untersagung (inibitoria) ${ }^{151}$ ist die an den Nachahmer gerichtete richterliche Anordnung, das als Verletzung der eingetragenen Marke und damit als rechtswidrige Handlung beurteilte Handeln einzustellen beziehungsweise nicht zu wiederholen. Voraussetzung für die Verhängung dieser Sanktion stellt daher die Gefahr der Fortsetzung oder Wiederholung des rechtswidrigen Handelns dar. Nicht verlangt wird indessen der Beweis für ein vorsätzliches oder fahrlässiges Verhalten des Nachahmers.

Adressat dieser Anordnung kann neben dem Urheber der Rechtsverletzung auch jedes andere Rechtssubjekt sein, dessen Dienste genutzt werden, um ein gewerbliches Eigentumsrecht zu verletzen. Das sind beispielsweise Unternehmen, die im Vertrieb oder im Verkauf tätig sind.

Der Verstoß gegen die richterliche Untersagung wird nach Art. 388 codice penale (Strafgesetzbuch - c.p.) geahndet, der die vorsätzliche Nichtbefolgung einer richterlichen Anordnung mit einer Gefängnisstrafe von bis zu drei Jahren oder alternativ mit einer Geldstrafe von Euro 103,00 bis 1032,00 bestraft.

Mit der richterlichen Untersagung kann der Richter - was vielfach auch der Fall ist - ein Strafgeld für jede anschließende Wiederholung der rechtswidrigen Hand-

\footnotetext{
${ }^{148}$ Dies ist laut Gesetzgeber bei einstweiligen Verfügungen gemäß Art. 700 c.p.c. immer der Fall. Es kann aber natürlich auch bei anderen entsprechenden Maßnahmen des einstweiligen Rechtsschutzes der Fall sein.

${ }^{149}$ Vgl. Art. 132, Abs. 4 CPI.

${ }^{150}$ Siehe Art. 124 CPI.

${ }^{151}$ Vgl. Art. 124 CPI; weiterführend zur definitiven richterlichen Untersagung vgl. A. Vanzetti, Codice della Proprietà industriale, Giuffrè, Milano 2013, S. 1268 ff.; D. Capelli/F. Ruggieri/F. Bocedi, La tutela dei diritti IP, in: Proprietà industriale, intellettuale e IT, Wolters Kluwer, Milano, 2017, S. $792 \mathrm{ff}$.
} 
lung oder für die Verzögerung bei der Umsetzung der richterlichen Verfügung verhängen. ${ }^{152}$

\subsubsection{Der Schadenersatz}

Mit dem Urteil, das die Nachahmung feststellt, kann der Beklagte zur Leistung von Schadenersatz (risarcimento del danno) ${ }^{153}$ zugunsten des Klägers verurteilt werden, wenn gemäß Art. 2043 c.c. (risarcimento per fatto illecito) ein vorsätzliches oder fahrlässiges Handeln des Nachahmers und ein tatsächlicher rechtswidriger Schaden vorliegt.

In Bezug auf den Nachweis des subjektiven Elements herrschen unterschiedliche Auffassungen darüber vor, ob durch das System der öffentlichen Kundmachung der eingetragenen Marken eine (relative) Schuldvermutung beim Nachahmer begründet wird, ${ }^{154}$ oder ob der Kläger das vorsätzliche oder fahrlässige Handeln des vermeintlichen Nachahmers nachzuweisen hat. ${ }^{155}$

Im Hinblick auf die Schadensbemessung auf die allgemeinen Grundsätze nach Zivilgesetzbuch ist Art. 1223, 1226 und 1227 c.c. anzuwenden, ${ }^{156}$ wobei der Schadenersatz alle negativen wirtschaftlichen Folgen, einschließlich des entgangenen

\footnotetext{
${ }^{152}$ Vgl. Art. 131, Abs. 2 CPI.

${ }^{153}$ Weiterführend zum Schadenersatz vgl. A. Vanzetti, Codice della Proprietà industriale, Giuffrè, Milano 2013, S. 1300 ff.; M. Ricolfi. Trattato dei Marchi. Diritto europeo e nazionale, Giappichelli, Torino, 2015, S. 1454 ff.; A. Vanzetti/V. Di Cataldo, Manuale di diritto industriale, Giuffrè, Milano, 2018, S. 556 ff.; D. Capelli/F. Ruggieri/F. Bocedi, La tutela dei diritti IP, in: Proprietà industriale, intellettuale e IT, Wolters Kluwer, Milano, 2017, S. 814 ff.; M. Franzosi, Il risarcimento del danno da lesione di diritto di proprietà intellettuale, in: Rivista di diritto industriale, 2006, fasc. 2, S. 205 ff.; C. Galli, Diritti IP e risarcimento dei danni: un rapporto che sta cambiando, in: Rivista di diritto industriale, 2012, fasc. 2, S. 105 ff.; M. Ricolfi, Risarcimento del danno da contraffazione. Il danno da violazione di proprietà intellettuale nella giurisprudenza della Corte di Giustizia, in: Giurisprudenza italiana, 2017, fasc. 3, S. 680 ff.; C. Scarpa, Proprietá intellettuale e misurazione del danno: alcuni problemi applicativi, in: Rivista di diritto industriale, 2012, fasc. 2, S. 175 ff.; A. Plaia, Proprietá intellettuale e risarcimento del danno, Giappichelli, Torino, 2005; G. Ratti, Il risarcimento del danno, in: $N$. Bottero/M. Travostino (a cura di), Il diritto dei marchi d'impresa. Profili sostanziali, processuali e contabili, Wolters Kluwer, Padova, 2009; M. Cartella, Il risarcimento del danno nella contraffazione di marchio, in: Rivista di diritto industriale, 2001, fasc. 2, S. 141.

${ }^{154}$ Eine relative Schuldvermutung führt dazu, dass der vermeintliche Nachahmer den Nachweis im Verfahren erbringen müsste, dass er keine Kenntnis vom entgegenstehenden eingetragenen Markenrecht hatte. Selbiges würde im Sinne von Art. 2600, Abs. 3 c.c. auch im Falle der Verletzung einer nicht eingetragenen Marke gelten, wenn die Handlungen des vermeintlichen Nachahmers als unlauterer Wettbewerb qualifiziert werden könnten; vgl. A. Vanzetti/V. Di Cataldo, Manuale di diritto industriale, Giuffrè, Milano, 2018, S. 558 ff.

${ }^{155}$ Insbesondere bei Markenrechtsverletzungen, die erst infolge von sehr komplexen Sachverständigengutachten festgestellt werden können, wird von einer Schuldvermutung der vermeintlichen Nachahmers ausgegangen; vgl. A. Vanzetti/V. Di Cataldo, Manuale di diritto industriale, Giuffrè, Milano, 2018, S. 558 ff.; M. Ricolfi. Trattato dei Marchi. Diritto europeo e nazionale, Giappichelli, Torino, 2015, S. $1454 \mathrm{ff}$.
}

${ }^{156}$ Siehe Art. 125 CPI. 
Gewinns und der Rufschädigung des Geschädigten, die erzielte Vorteile des Schädigers sowie, bei Vorliegen der Voraussetzungen, auch die immateriellen Schäden umfassen muss.

Das Gericht kann die Höhe des Schadenersatzes in einer Gesamtsumme bestimmen, die aufgrund der Aktenlage und nach den daraus resultierenden Vermutungen festgesetzt wird. ${ }^{157}$ Diesbezüglich stellt der Gesetzgeber klar, dass in Bezug auf die Bestimmung des entgangenen Gewinns jedenfalls nicht ein geringerer Betrag festgesetzt werden kann, den der Nachahmer hätte zahlen müssen, sofern er beim Markeninhaber eine Lizenz beantragt hätte.

Der Geschädigte kann aber auch, alternativ zum Ersatz des entgangenen Gewinns, die Herausgabe der vom Urheber der Rechtsverletzung erzielten Gewinne verlangen. ${ }^{158}$

\subsubsection{Weitere zivilrechtliche Sanktionen und Abhilfemaßnahmen}

Weitere zivilrechtliche Sanktionen und Abhilfemaßnahmen sind:

- die richterliche Anordnung zum definitiven Rückruf der nachgeahmten Waren aus dem Handel (ritiro definitio dal commercio); $;{ }^{159}$

- die richterliche Anordnung zu Vernichtung (distruzione) ${ }^{160}$ der Zeichen, mit denen die Nachahmung begangen wurde und, soweit zur Beseitigung der nachgeahmten Marke erforderlich, der Waren oder des Materials, das im Zusammenhang mit der Erbringung der Dienstleistung steht;

- das Gericht kann aber auch, wenn sich die Waren nach einer entsprechenden Abänderung gesetzeskonform nutzen lassen, anstelle ihres definitiven Rückrufs oder ihrer Vernichtung den vorübergehenden Rückruf aus dem Handel (ritiro temporaneo dal commercio) ${ }^{161}$ anordnen, mit der Möglichkeit, sie nach Vornahme der Anpassungen, erneut in den Handel einzuführen; ${ }^{162}$

- mit dem Urteil, das die Verletzung eines gewerblichen Eigentumsrechts feststellt, kann angeordnet werden, dass das Eigentum an den in Verletzung des Markenrechts importierten oder verkauften Waren und die spezifischen Mittel, die eindeutig ihrer Herstellung dienen, dem Rechtsinhaber zugewiesen werden, wo-

\footnotetext{
${ }^{157} \mathrm{Vgl}$. Art. 125, Abs. 2 CPI.

${ }^{158} \mathrm{Vgl}$. Art. 125, Abs. 3 CPI.

${ }^{159}$ Weiterfürhrend zum definitiven Rückruf vgl. A. Vanzetti, Codice della Proprietà industriale, Giuffrè, Milano 2013, S. 1285 ff.; D. Capelli/F. Ruggieri/F. Bocedi, La tutela dei diritti IP, in: Proprietà industriale, intellettuale e IT, Wolters Kluwer, Milano, 2017, S. 800 ff.

${ }^{160}$ Weiterfürhrend zur Vernichtung vgl. A. Vanzetti, Codice della Proprietà industriale, Giuffrè, Milano 2013, S. 1287 ff.; D. Capelli/F. Ruggieri/F. Bocedi, La tutela dei diritti IP, in: Proprietà industriale, intellettuale e IT, Wolters Kluwer, Milano, 2017, S. 802 ff.

${ }^{161}$ Weiterfürhrend zum vorübergehenden Rückruf vgl. A. Vanzetti, Codice della Proprietà industriale, Giuffrè, Milano 2013, S. 1289 ff.; D. Capelli/F. Ruggieri/F. Bocedi, La tutela dei diritti IP, in: Proprietà industriale, intellettuale e IT, Wolters Kluwer, Milano, 2017, S. 800 ff.

${ }^{162}$ Siehe Art. 124, Abs. 3 CPI.
} 
bei der Anspruch auf Schadenersatz hiervon unberührt bleibt (assegnazione in proprietà) ${ }^{163}$

- die richterliche Anordnung zur öffentlichen Bekanntmachung des Urteils (pubblicazione della sentenza) ${ }^{164}$ auf Kosten des Nachahmers in Zeitungen oder Zeitschriften; ${ }^{165}$

- das Gericht kann ein Strafgeld (penalità di mora) ${ }^{166}$ für jede zukünftig festgestellte Rechtsverletzung oder Nichtbeachtung und jede Verzögerung bei der Umsetzung der im Urteil genannten Maßnahmen verfügen; ${ }^{167}$

- schließlich ist der Richter berechtigt, auf Antrag des Inhabers des gewerblichen Eigentumsrechts, die Beschlagnahme (sequestro) ${ }^{168}$ der Waren und der Produktionsmittel auf Kosten des Urhebers der Verletzung bis zum Erlöschen des Titels anzuordnen.

\subsection{Strafrechtliche Sanktionen}

Im Sinne von Art. 473 c.p. wird jeder, der Marken oder Unterscheidungszeichen nachmacht oder verfälscht, mit einer Gefängnisstrafe von sechs Monaten bis zu drei Jahren und mit einer Geldstrafe zwischen 2500 und 25.000 Euro bestraft. Selbiges gilt für denjenigen, der nachgeahmte oder verfälschte Marken oder Unterscheidungszeichen verwendet. Hinsichtlich des subjektiven Elements wird verlangt, dass der vermeintliche Täter von der Existenz des gewerblichen Eigentumstitels Kenntnis haben konnte. Dies bedeutet, dass zur Erfüllung des Straftatbestands die Möglichkeit der Kenntnis der Marke oder des Unterscheidungszeichens ausreicht und ein Beweis der tatsächlichen Kenntnis nicht verlangt wird.

\footnotetext{
${ }^{163}$ Weiterführend zur Zuweisung ins Eigentum vgl. A. Vanzetti, Codice della Proprietà industriale, Giuffrè, Milano 2013, S. 1290 ff.; D. Capelli/F. Ruggieri/F. Bocedi, La tutela dei diritti IP, in: Proprietà industriale, intellettuale e IT, Wolters Kluwer, Milano, 2017, S. 806 ff.

${ }^{164}$ Weiterführend zur öffentlichen Bekanntmachung des Urteils vgl. A. Vanzetti, Codice della Proprietà industriale, Giuffrè, Milano 2013, S. 1309 ff.; D. Capelli/F. Ruggieri/F. Bocedi, La tutela dei diritti IP, in: Proprietà industriale, intellettuale e IT, Wolters Kluwer, Milano, 2017, S. 811 ff.; Vgl. Corte di Cassazione, 12.03.2014, Nr. 5722: „La pubblicazione, prescinde dall' accertamento di qualunque stato soggettivo di chi ha violato il diritto del marchio, dato che alla stessa non va attribuita funzione risarcitoria, mirando unicamente alla ricostruzione dell'immagine del titolare del marchio. “

${ }^{165}$ Vgl. Art. 126 CPI.

${ }^{166}$ Weiterführend zum Strafgeld vgl. A. Vanzetti, Codice della Proprietà industriale, Giuffrè, Milano 2013, S. 1266; D. Capelli/F. Ruggieri/F. Bocedi, La tutela dei diritti IP, in: Proprietà industriale, intellettuale e IT, Wolters Kluwer, Milano, 2017, S. 798 ff.

${ }^{167} \mathrm{Vgl}$. Art. 124, Abs. 2 CPI.

${ }^{168}$ Weiterführend zur Beschlagnahme vgl. A. Vanzetti, Codice della Proprietà industriale, Giuffrè, Milano 2013, S. 1293; D. Capelli/F. Ruggieri/F. Bocedi, La tutela dei diritti IP, in: Proprietà industriale, intellettuale e IT, Wolters Kluwer, Milano, 2017, S. 808.
} 
Eine Gefängnisstrafe von einem bis zu vier Jahren und eine Geldstrafe zwischen 3500 und 35.000 Euro wird hingegen im Sinne von Art. 474 c.p. ${ }^{169}$ gegen denjenigen verhängt, der zum Zwecke der Gewinnerzielung gewerbliche Erzeugnisse mit nachgeahmten oder verfälschten Marken und Unterscheidungszeichen in das italienische Staatsgebiet einführt.

Art. 474-ter und 474-quater c.p. sehen einen straferschwerenden und einen strafmildernden Umstand vor. Der erschwerende Umstand ${ }^{170}$ kommt zum Tragen im Falle der Nachahmung und Verfälschung von Waren und der Einführung von Waren mit gefälschten Zeichen, wenn die Straftat durch Einsatz fortdauernder und organisierter Mittel und Handlungen begangen wurde. Der mildernde Umstand ${ }^{171}$ greift hingegen im Falle der Kooperation bei der Prävention und Bekämpfung der Straftat.

Vorbehaltlich der Anwendbarkeit der Straftatbestände laut den Art. 473 und 474 c.p., wird im Sinne von Art. 517-ter c.p. derjenige, der sich bei der Herstellung, Einfuhr und dem Verkauf von Waren widerrechtlich gewerbliche Eigentumstitel aneignet und von der Existenz des gewerblichen Eigentumstitels Kenntnis haben konnte, mit einer Gefängnisstrafe von bis zu zwei Jahren und einer Geldstrafe bis zu 20.000 Euro bestraft.

\footnotetext{
${ }^{169}$ Weiterführend zu den strafrechtlichen Sanktionen vgl. G. Manca, Il diritto penale dei marchi e del made in Italy, Wolters Kluwer, Milano, 2017, S. $51 \mathrm{ff}$. und $138 \mathrm{ff}$; D. Capelli/F. Ruggieri/F. Bocedi, La tutela dei diritti IP, in: Proprietà industriale, intellettuale e IT, Wolters Kluwer, Milano, 2017, S. 899 ff.; P. Kindler, Italienisches Handels- und Wirtschaftsrecht, Fachmedien Recht und Wirtschaft, Frankfurt am Main, 2. Aufl., 2013, S. 78; D. Aldovrandi, La contraffazione del marchio costituito da lettera dell'alfabeto: osservazioni in merito ai problematici confini della tutela penale del marchio, Rivista di diritto industriale, 2008, S. 306 ff.; A. Alessandri, I marchi nei delitti contro la fede pubblica, in: A. Alessandri (a cura di), Reati in materia economica, in: F. Palazzo/C.E. Paliero, Trattato teorico pratico in materia di diritto penale, Torino, Giappichelli, 2012, S. 485 ff.; F. Basile, Il diritto penale nelle società multiculturali: i reati culturalmente motivati, Politica Criminale, vol. 6, n. 12, 2011, S. 339 ff.; C. Blengino, La tutela penale del marchio, in: N. Bottero/M. Travostino (a cura di), Il diritto dei marchi d'impresa. Profili sostanziali, processuali e contabili, Torino, Utet, 2009; B. Böxler, Markenstrafrecht. Geschikte, Akzessorietät, Legitimation, Perspektiven, Mohr Siebeck, Tübingen, 2013; D. Sangiorgio, Contraffazione di marchi e tutela penale delle proprietà industriale e intellettuale, Cedam, Padova, 2006; F. Cingari, La tutela penale dei marchi e dei segni distintivi, Ipsoa, Milano, 2008; A. Ebert-Weidenfeller, Markenstrafrecht, in: H. Achenbach/A. Ransiech/T. Rönnau (Hrsg.), Handbuch Wirschaftsstrafrecht, C.F. Müller, Heidelberg, 5. Aufl., 2019, S. 1642 ff.; G.L. Gatta, La disciplina della contraffazione del marchio d'impresa nel codice penale (artt. 473 e 474): tutela del consumatore e/o del produttore?, in: L.B. Camaldo (a cura di), La circolazione e il contrabbando di prodotti contraffatti pericolosi. La tutela penale degli interessi dell'Unione Europea e dei consumatori, Giappichelli, Torino, 2013.

${ }^{170}$ Gefängnisstrafe von zwei bis sechs Jahren und Geldstrafe zwischen 5000 und 50.000 Euro.

${ }^{171}$ Strafmilderung um die Hälfte bis zu zwei Dritteln.
} 


\section{6 Übertragung und Lizenzierung der Marke}

\subsection{Abtretung der Marke}

Gemäß Art. 23 CPI iVm Art. 2573 c.c. kann eine Marke sowohl definitiv übertragen (Abtretung) als auch Dritten zur zeitweiligen Nutzung überlassen werden (Lizenz). In jedem Fall muss allerdings gewährleistet sein, dass durch die Übertragung oder die Lizensierung keine Täuschung über die nach der Verkehrsauffassung wesentlichen Eigenschaften der Waren oder Dienstleistungen ausgehen darf.

Eine Markenabtretung (cessione del marchio) liegt vor, wenn der Markeninhaber definitiv auf diese Inhaberschaft zugunsten eines Dritten verzichtet. Von einer Teilabtretung spricht man hingegen, wenn die Abtretung nur für einen Teil der Waren und/oder Dienstleistungen erfolgt, für die die Marke eingetragen ist. ${ }^{172}$

Die ursprüngliche Regelung, wonach die Abtretung der Marke nur zusammen mit der Übertragung des Betriebes oder eines Betriebszweiges erfolgen konnte (sog. gebundene Abtretung), wurde durch das gesetzesvertretende Dekret vom 04.12.1992, Nr. $480^{173}$ aufgehoben und auch durch das Gesetzbuch des gewerblichen Eigentums bestätigt. Bestehen blieb allerdings jene Bestimmung, dass sofern die Marke aus einem Bildzeichen, einer Fantasiebezeichnung oder einer abgeleiteten Firmenbezeichnung besteht, vermutet wird, dass das Recht auf ihre ausschließliche Benutzung mit dem Betrieb mitübertragen worden ist. ${ }^{174}$

\subsection{Markenlizenz}

Gemäß Art. 2573 c.c. und Art. 23 CPI kann die Marke nicht nur definitiv übertragen, sondern auch Dritten ein zeitweiliges Nutzungsrecht (Lizenz) eingeräumt werden. Mit der Lizenz (licenza di marchio) werden jene Verträge bezeichnet, mit denen der

\footnotetext{
${ }^{172}$ Sofern die Teilabtretung heterogene Waren bzw. Dienstleistungen betrifft, also die Abtretung der Waren bzw. Dienstleistungen zum Gegenstand hat, die keine Ähnlichkeit zu den beim Abtretenden verbleibenden Waren bzw. Dienstleistungen aufweisen, erscheint die Teilabtretung unproblematisch. In der Lehre ist hingegen umstritten, ob die Teilabtretung einer Marke im Sinne der Gewährleistung der Herkunftsfunktion auch dann zulässig ist, wenn Ähnlichkeit zwischen jenen Waren bzw. Dienstleistungen, für die das Recht an der Marke abgetreten wurden, und jenen Waren bzw. Dienstleistungen, für die das Recht an der Marke beim Abtretenden verblieben ist, besteht; vgl. A. Vanzetti, Codice della Proprietà industriale, Giuffrè, Milano 2013, S. 483 f.; M. Ricolfi. Trattato dei Marchi. Diritto europeo e nazionale, Giappichelli, Torino, 2015, S. 1566 ff.; A. Vanzetti/V. Di Cataldo, Manuale di diritto industriale, Giuffrè, Milano, 2018, S. 268 ff.; P. Kindler, Italienisches Handels- und Wirtschaftsrecht, Fachmedien Recht und Wirtschaft, Frankfurt am Main, 2. Aufl., 2013, S. 73.

${ }^{173}$ Decreto Legislativo 04.12.1992, n. 480: Attuazione della direttiva n. 89/104/CEE del Consiglio del 21 dicembre 1988, recante ravvicinamento delle legislazioni degli Stati membri in materia di marchi di impresa, in: Gazzetta Ufficiale, 16.12.1992, n. 295.
}

${ }^{174}$ Vgl. Art. 2573, Abs. 2 c.c. 
Markeninhaber zwar seine Inhaberschaft behält, die Benutzung aber Dritten einräumt. ${ }^{175}$

Bei der Lizenz wird zwischen einer exklusiven oder nicht-exklusiven Lizenz, einer Voll- oder Teillizenz sowie einer Lizenz, die für das gesamte Staatsgebiet oder nur für einen Teil desselben eingeräumt wird, unterschieden.

Bei der Exklusivlizenz hat ein einzelner Unternehmer das Recht, diese ausschließlich zu benutzen. Eine Exklusivlizenz kann sowohl für die Gesamtheit der Waren und Dienstleistungen als auch nur für einen bestimmten Teil der Waren bzw. Dienstleistungen eingeräumt werden. Demgegenüber steht die nicht-exklusive Lizenz, deren ausdrückliche Anerkennung in der Vergangenheit mit großem Befremden aufgenommen wurde, zumal zwei oder mehrere Unternehmen mit derselben Marke in Bezug auf dieselben Waren bzw. Dienstleistungen auf dem Markt auftreten können. Es besteht daher die Notwendigkeit, eine vermeintliche Irreführung des Publikums infolge des Bestehens von scheinbar identischen, in Wirklichkeit aber qualitativ unterschiedlichen Waren bzw. Dienstleistungen zu verhindern. Aus diesem Grund ist die Rechtmäßigkeit der nicht exklusiven Lizenzen an die Bedingung gebunden, dass der Lizenznehmer sich ausdrücklich verpflichtet, die Marke zur Kennzeichnung von Waren bzw. Dienstleistungen zu benutzen, die gleich sind wie die entsprechenden Waren bzw. Dienstleistungen, die vom Markeninhaber, oder von anderen Lizenznehmern unter der gleichen Marke, in den Handel gebracht werden. ${ }^{176}$

\subsection{Merchandising- und Franchising-Verträge}

Unter Merchandisingverträgen werden jene Verträge verstanden, mit denen der Inhaber einer bekannten Marke Dritten das Recht einräumt, die Marke für Waren bzw. Dienstleistungen zu verwenden, die sich von seinen eigenen Waren bzw. Dienstleistungen erheblich unterscheiden. Die Rechtfertigung dieser Bestimmung gründet darauf, dass dem Inhaber einer bekannten Marke ein Ausschließlichkeitsrecht zur Benutzung der Marke eingeräumt wird, das nicht mehr auf die ähnlichen Waren und Dienstleistungen beschränkt ist.

Ein Sonderaspekt des Lizenzvertrags ist das sog. Franchising, bei dem der Franchisegeber dem Franchisenehmer im Wege einer dauerhaften Zusammenarbeit zwischen Unternehmern die Nutzung seines Vertriebskonzepts, einschließlich der Nutzung von Know-how, der Lieferung von Waren sowie die Verwendung von

\footnotetext{
${ }^{175}$ Vgl. M. Mostardini, La circolazione del marchio: cessione e licenza, in: N. Bottero/M. Travostino, Il diritto dei marchi d'impresa. Profili sostanziali, processuali e contabili, Utet, Torino, 2009; L. Pahlow, Lizenz und Lizenzvertrag im Recht des Geistigen Eigentums, Mohr Siebeck, Thübingen 2006; P. Kindler, Italienisches Handels- und Wirtschaftsrecht, Fachmedien Recht und Wirtschaft, Frankfurt am Main, 2. Aufl., 2013, S. 74.
}

${ }^{176}$ Vgl. Art. 23, Abs. 2 CPI. 
Unterscheidungszeichen einräumt. Dieser letztgenannte Aspekt drückt sich in koordinierten Lizenzverträgen ohne Exklusivrecht aus.

\subsection{Koexistenzverträge}

Bei Koexistenzverträgen (accordi di coesistenza) handelt es sich um privatrechtliche Verträge und Vergleiche zur vertraglichen Regelung der Überschneidung (Verwechselbarkeit von Zeichen sowie Ähnlichkeit von Waren und Dienstleistungen) und damit der Koexistenz von Marken und Unterscheidungszeichen verschiedener Inhaber. Gleichsam dienen Koexistenzverträge zur Anerkennung der jeweiligen Markenrechte sowie zur Regelung der Modalitäten in Bezug auf die Benutzung ihrer sich potenziell überschneidenden Zeichen bzw. Waren und Dienstleistungen.

\subsection{Umschreibung}

Im Sinne von Art. 138 und 139 CPI gilt für die Umschreibung einer eingetragenen Marke eine ähnliche Regelung wie bei der Umschreibung eingetragener beweglicher Güter. Nach Maßgabe von Art. 138 CPI, der eine gemeinsame Regelung aller gewerblichen Eigentumsrechte vorsieht, müssen (a) Rechtsgeschäfte unter Lebenden, mit denen alle oder einige Rechte an eingetragenen Marken übertragen werden und (b) Rechtsgeschäfte unter Lebenden, mit denen persönliche oder dingliche Nutzungsrechte, Sonderrechte oder Schutzrechte an eingetragenen Marken begründet, geändert oder übertragen werden, beim Italienischen Patent- und Markenamt eingetragen werden.

Die Umschreibung beim Italienischen Patent- und Markenamt ist allerdings keine Voraussetzung für die Gültigkeit des Rechtsüberganges, wohl aber für seine Geltendmachung gegenüber Dritten. Ferner ist die Umschreibung auch ein Präferenzkriterium zwischen zwei Rechtsnachfolgern des gleichen Rechtsvorgängers.

\section{Erlöschen der Marke}

Das Erlöschen des Markenschutzes erfolgt nach Ablauf der zehnjährigen Wirksamkeit der Eintragung (sofern diese Frist nicht verlängert wird), bei Verzicht des Inhabers, infolge der Nichtigkeitserklärung der Marke sowie bei Eintritt bestimmter Verfallsgründe. ${ }^{177}$

\footnotetext{
${ }^{177} \mathrm{Vgl}$. P. Kindler, Italienisches Handels- und Wirtschaftsrecht, Fachmedien Recht und Wirtschaft, Frankfurt am Main, 2. Aufl., 2013, S. 74 ff.
} 


\subsection{Nichtigkeit der Marke}

Das Fehlen absoluter Eintragungshindernisse bedingt die Nichtigkeit der Marke (nullità), wobei Art. 25 CPI die spezifischen Nichtigkeitsgründe festlegt. Nach Maßgabe von Art. 117 CPI stellt die Eintragung der Marke kein Hindernis für die Ausübung der Nichtigkeitsklage dar. Das bedeutet, dass die Marke, selbst wenn sie eingetragen ist, bei Vorliegen der Voraussetzungen vom ordentlichen Gericht für nichtig erklärt werden kann.

Im Sinne von Art. 25 CPI ist eine Marke nichtig, wenn:

- sie nicht den Voraussetzungen nach Art. 7 CPI entspricht und es sich demnach um Zeichen handelt, die nicht dazu geeignet sind, (a) um Waren oder Dienstleistungen eines Unternehmens von denen anderer Unternehmen zu unterscheiden bzw. (b) im Register in einer Weise dargestellt zu werden, dass die zuständigen Behörden und das Publikum den Gegenstand des ihrem Inhaber gewährten Schutzes klar und eindeutig bestimmen können; ${ }^{178}$

- sie nach Art. 12 CPI nicht neu ist;

- sie im Widerspruch zu Art. 9, 10, 11, 11-bis, 13, 14, Abs. 1 CPI steht, also es sich unter anderem um Zeichen handelt, die gegen das Gesetz, die öffentliche Ordnung oder die guten Sitten verstoßen, die beschreibend sind und demnach zu wenig Unterscheidungskraft ${ }^{179}$ besitzen oder Wappen oder andere durch internationale Abkommen geschützte Zeichen beinhalten;

- sie im Sinne von Art. 19, Abs. 2 CPI bösgläubig angemeldet wurden;

- sie im Widerspruch zu Art. 8 CPI stehen und somit Namen bzw. Abbildungen Dritter oder bekannte Zeichen zum Gegenstand haben;

- sie von Seiten eines Nichtberechtigten im Sinne von Art. 118, Abs. 3, Bst. b) CPI eingetragen worden ist.

Es liegt dann eine Teilnichtigkeit der Marke vor, wenn sich der Grund für die Nichtigkeit nur auf einen Teil der Waren oder Dienstleistungen bezieht, für die die Marke eingetragen wurde. ${ }^{180}$ Dies kann beispielsweise der Fall sein, wenn die Marke in Bezug auf einige Waren oder Dienstleistungen beschreibend ist, für andere hingegen nicht.

\footnotetext{
${ }^{178}$ Vgl. Corte di Cassazione, 25.01.2016, Nr. 1277: „Un marchio anche denominativo può essere dunque nullo sia quando i nomi utilizzati non siano idonei a indicare la provenienza del prodotto, non valgano a distinguerlo da altri prodotti simili (Art. 7, lett. B), c.i.p.). “

${ }^{179}$ In Bezug auf Marken, denen es an Unterscheidungskraft fehlt, wird anstatt von Nichtigkeit häufig auch von Ungültigerklärbarkeit gesprochen. In diesen Fällen ist das Zeichen zwar nicht markenfähig, es besteht aber die Möglichkeit, dass es im Laufe der Zeit und durch Benutzung ein secondary meaning erlangt, d. h. eine Unterscheidungsfähigkeit, die ursprünglich fehlte. Dieser Prozess der „Rehabilitierung“ der ursprünglich nichtigen Marke ist meist die Folge einer angemessen langen Zeit der ausschließlichen Benutzung des Zeichens in Verbindung mit einer einzigen Ware und unterstützt von breit angelegter Werbung, die dazu führt, dass in der Wahrnehmung des Publikums zu der ursprünglich allgemeinen Bedeutung eine zweite spezifische Bedeutung (secondary meaning) hinzutritt und somit Unterscheidungskraft erlangt wird.
}

${ }^{180}$ Vgl. Art. 27 CPI. 


\subsection{Verfall der Marke}

Der Verfall (decadenza) ist die vorzeitige Beendigung des rechtmäßig begründeten Markenrechts und kommt bei Nichtbenutzung, Vulgarisierung und nachträglicher Unrechtmäßigkeit in Betracht. ${ }^{181}$

\subsubsection{Nichtbenutzung}

Nach Maßgabe von Art. 26, Bst. c) iVm Art. 24 CPI verfällt die Marke, wenn sie nicht innerhalb von fünf Jahren nach ihrer Eintragung benutzt wird, oder wenn ihre Benutzung ununterbrochen für fünf Jahre ausgesetzt wird (decadenza per non uso). ${ }^{182}$ Zum Zwecke der Vermeidung des Markenverfalls wegen Nichtbenutzung muss die Benutzung der Marke tatsächlich erfolgt sein, was bedeutet, dass sporadische und symbolische Benutzungen oder Benutzungen für lächerliche Warenmengen irrelevant sind. ${ }^{183}$

Der Verfall einer Marke wegen Nichtbenutzung kann nicht geltend gemacht werden, wenn zwischen dem Ablauf der fünfjährigen Nichtbenutzung und der Erhebung der Klage oder Einrede des Verfalls die tatsächliche Benutzung der Marke begonnen hat, beziehungsweise wieder aufgenommen wurde. ${ }^{184}$ Sofern der Markeninhaber die Benutzung allerdings erst dann aufnimmt, nachdem er von der bevorstehenden Klageerhebung betreffend dem Verfall Kenntnis erlangt hat, ist dies hinsichtlich einer etwaigen Verfallserklärung irrelevant, vorausgesetzt, dass die Aufnahme der Benutzung im Zeitraum von drei Monaten vor Klageerhebung erfolgt.

Wie bei der Nichtigkeit ist auch ein teilweiser Verfall möglich, ${ }^{185}$ sofern die Marke nur für einige der Waren oder Dienstleistungen, für die sie eingetragen worden ist, benutzt wird.

Eine Besonderheit im Zusammenhang mit dem Verfall wegen Nichtbenutzung stellen die von der italienischen Rechtsordnung tolerierten Defensivmarken dar. Defensivmarken dienen zur Ausweitung des Schutzbereiches einer Hauptmarke, mit dem Ziel, es zu verhindern, dass sich andere Marken der Hauptmarke in einem ansonsten zulässigen Ausmaß annähern. ${ }^{186}$ Es tritt kein Verfall wegen Nichtbenutzung

\footnotetext{
${ }^{181}$ Siehe dazu Art. 26 CPI.

${ }^{182}$ Der Verfall tritt nicht ein, wenn die Nichtbenutzung durch einen legitimen Grund gerechtfertigt ist. Ein solcher liegt etwa dann vor, wenn die Nichtbenutzung aufgrund einer noch fehlenden $\mathrm{Ge}-$ nehmigung zum Inverkehrbringen eins Arzneimittels geschuldet ist; vgl. A. Vanzetti, Codice della Proprietà industriale, Giuffrè, Milano 2013, S. 508.

${ }^{183}$ Vgl. A. Vanzetti, Codice della Proprietà industriale, Giuffrè, Milano 2013, S. 497 ff.

${ }^{184} \mathrm{Vgl}$. Art. 24, Abs. 3 CPI.

${ }^{185} \mathrm{Vgl}$. Art. $27 \mathrm{CPI}$.

${ }^{186}$ Vgl. G. Cuonzo/B. Marsicola, L'identità dell'impresa: i segni distintivi, in: Proprietà industriale, intellettuale e IT, Wolters Kluwer, Milano, 2017, S. 121 f.; A. Vanzetti/V. Di Cataldo, Manuale di diritto industriale, Giuffrè, Milano, 2018, S. 251 f.
} 
ein, wenn der Inhaber der nicht benutzten Marke gleichzeitig Inhaber einer oder mehrerer ähnlicher, nach wie vor gültigen Marken ist, von denen er mindestens eine Marke tatsächlich benutzt, um die gleichen Waren oder Dienstleistungen zu kennzeichnen. ${ }^{187}$

\subsection{2 „Vulgarisierung“}

Der Verfall kommt im Sinne von Art. 26, Bst. a) iVm Art. 13, Abs. 4 CPI auch dann in Betracht, wenn die Marke im Verkehr zu einer allgemeinen Bezeichnung der gekennzeichneten Waren oder der Dienstleistung geworden ist und damit ihre Unterscheidungskraft eingebüßt hat (volgarizzazione). Bekannte Beispiele sind die einstigen Marken „Aspirin“, „Cellophane“ oder „Nylon“.

Der Verfall der Marke kann jedoch nicht allein wegen des objektiven Umstands eintreten, dass die Marke zu einer allgemeinen Bezeichnung der Waren und Dienstleistungen geworden ist, sondern es kommt vielmehr auf das subjektive Verhalten bzw. die Untätigkeit des Markeninhabers an. Ein solches aktives Verhalten dürfte dann gegeben sein, wenn der Inhaber selbst die Marke als allgemeine Bezeichnung benutzt. Von einer Untätigkeit ist hingegen dann auszugehen, wenn es der Inhaber unterlässt, auf die Benutzung der Marke als allgemeine Bezeichnung seitens Dritter zu reagieren. ${ }^{188}$ Um den Verfall der Marke durch Vulgarisierung zu vermeiden - also bei Anzeichen dafür, dass ein Zeichen im allgemeinen Sprachgebrauch zu einer gebräuchlichen Bezeichnung für eine bestimmte Ware wird - muss der Markeninhaber unterbinden, dass Dritte die Marke als allgemeine Bezeichnung verwenden beziehungsweise die Marke selbst auf eine Weise benutzen, dass sie stets als solche erkennbar ist. ${ }^{189}$

\subsubsection{Nachträgliche Unrechtmäßigkeit}

Ein Verfall tritt im Sinne von Art. 26, Bst. b) iVm Art. 14, Abs. 2, Bst a) auch dann ein, wenn im Laufe der Zeit eine ursprünglich schutzfähige Marke für geeignet erachtet wird, aufgrund der Art und Weise oder des Kontextes, in dem sie benutzt

\footnotetext{
${ }^{187}$ Vgl. Art. 24, Abs. 4 CPI.

${ }^{188}$ Vgl. EuGH, Urteil, 27.04.2006, Rechtssache C-145/05, Levi Strauss \& Co./Casucci SpA., in: ECLI:EU:C:2006:264: „Eine solche Untätigkeit kann auch darin bestehen, dass der Inhaber einer Marke es unterlässt, rechtzeitig auf Artikel 5 dieser Richtlinie [Richtlinie 89/104/EWG] zurückzugreifen, um bei der zuständigen Stelle zu beantragen, betroffenen Dritten die Benutzung des Zeichens zu verbieten, für das eine Verwechslungsgefahr besteht, weil solche Anträge gerade den Zweck haben, die Unterscheidungskraft dieser Marke zu bewahren. “

${ }^{189}$ Konkret bedeutet das, dass der Markeninhaber etwa in der Werbung darauf hinweisen muss, dass es sich um eine eingetragene Marke handelt, um zu vermeiden, dass das Zeichen als allgemeine Bezeichnung wahrgenommen wird.
} 
wird, das Publikum - insbesondere über die Art, Beschaffenheit oder Herkunft der Waren oder Dienstleistungen - zu täuschen (decadenza per decettività). ${ }^{190}$

Während die Eintragung einer an sich irreführenden Marke prinzipiell untersagt ist und deren genetische Nichtigkeit bewirkt, ${ }^{191}$ behandelt Art. 26, Bst. b) CPI den Fall einer ursprünglich schutzfähigen und damit originär nicht irreführenden Marke. Geahndet wird hier also die später eingetretene Irreführung, welche die Beschaffenheit der gekennzeichneten Waren beziehungsweise Dienstleistung betreffen muss. ${ }^{192}$

Zum Verfall kommt es im Sinne von Art. 26, Bst. b) iVm Art. 14, Abs. 2, Bst b) CPI auch dann, sofern die Marke nachträglich - also nach ihrer Eintragung - gegen das Gesetz, gegen die öffentliche Ordnung oder gegen die guten Sitten verstößt.

\subsection{Nichtigkeitsklagen und Klagen auf Verfallserklärung}

Es darf hier auf die Ausführungen unter Punkt 4.3. verwiesen werden.

\section{Die Benutzungsmarke}

\subsection{Die Benutzung als konstitutiver Tatbestand der Benutzungsmarke}

Die Eintragung der Marke ist nicht der einzige konstitutive Tatbestand zur Begründung eines Markenrechts. Die Rechtsordnung schützt auch die nicht-eingetragene Marke, die gemeinhin als Benutzungsmarke (marchio di fatto), oder seltener auch de-facto-Marke, bezeichnet wird. Die Schutzwirkung fällt im Gegensatz zur eingetragenen Marke allerdings deutlich geringer aus.

Nach Maßgabe von Art. 2571 c.c. ist derjenige, der von einer nicht registrierten Marke Gebrauch gemacht hat, trotz einer durch andere erwirkten Markenregistrierung befugt, die Marke weiterhin in dem Umfang zu nutzen, in dem er sich ihrer vorher bedient hat. Demnach basiert der Schutz des Rechts an der nicht eingetragenen Marke auf ihrer tatsächlichen Benutzung, auf dem Umfang der Benutzung sowie auf dem tatsächlichen Grad der erreichten Bekanntheit.

\footnotetext{
${ }^{190}$ Weiterführend dazu vgl. S. Giudici, Il marchio decettivo, Giuffrè, Milano 2012, S. 103 ff.

${ }^{191}$ Vgl. Art. 14, Abs. 1, Bst. b) CPI.

${ }^{192}$ Insbesondere kommt der Verfall dann in Betracht, wenn eine deutliche Qualitätsverschlechterung der Ware gegeben ist, die dem Publikum vom Inhaber nicht mitgeteilt oder sogar verschwiegen wird. Möglich ist der Verfall auch bei einer Änderung der Art und Weise, in der die Marke benutzt wird, sodass der Ware neue Qualitäten zugeschrieben werden, die sie nicht hat und auch von Anfang an nicht hatte. Man denke beispielsweise an eine irreführende Werbekampagne, mit der der Marke neue, irreführende Bedeutungen zugedacht werden.
} 
Dabei werden, je nachdem, ob die Vorbenutzung zu einer generellen Bekanntheit der Marke oder lediglich zu einer lokalen Bekanntheit - oder gar zu überhaupt keiner Bekanntheit - geführt hat, zwei Fälle unterschieden. Im ersten Fall erwirkt der Vorbenutzer, dass eine verwechselbare, später eingetragene Marke mangels der Voraussetzung der Neuheit für nichtig erklärt wird. Die entsprechende Klage muss jedoch innerhalb von fünf Jahren erhoben werden, um zu vermeiden, dass die später eingetragene Marke geheilt wird. ${ }^{193}$ Im zweiten Fall, jenem der lokalen Bekanntheit, ist der Schutz des Vorbenutzers deutlich geringer und der Vorbenutzer kann nicht verhindern, dass ein Wettbewerber die rechtswirksame Eintragung der gleichen Marke erlangt. Allerdings steht es dem Vorbenutzer zu, seine nicht-eingetragene Marke weiterhin in dem Umfang und innerhalb der räumlichen Grenzen zu nutzen, indem er sie vorher genutzt hat.

Die Tatsache, dass der konstitutive Tatbestand des Rechts an der Benutzungsmarke nicht in der Eintragung, sondern in der konkreten Benutzung des Zeichens besteht, führt zu einem besonders relevanten Unterschied auf Prozessebene. Der Inhaber einer Benutzungsmarke kann nicht die Vermutung der Schutzfähigkeit in Anspruch nehmen, die in Art. 121 CPI für eingetragene Marken vorgesehen ist. Vielmehr trägt derjenige, der den Schutz einer Benutzungsmarke begehrt, die Beweislast bezüglich der konstitutiven Tatbestände seines Rechts. Diesbezüglich liegt es somit an ihm, den Nachweis für die aktuelle und tatsächliche Benutzung der Marke und deren Verbreitung aus Sicht der Waren bzw. der Dienstleistungen, wie auch aus territorialer Sicht zu erbringen. Außerdem liegt es am Inhaber nachzuweisen, dass seine Benutzungsmarke alle Voraussetzungen für die Schutzfähigkeit erfüllt. ${ }^{194}$

Ein Teil der für die eingetragene Marke geltenden Grundsätze kommt auch für die Benutzungsmarken in Betracht. Die Benutzungsmarke muss demnach zum Zwecke der Schutzfähigkeit ein zumindest gedanklich von der Ware oder Dienstleistung trennbares Zeichen sein. Ferner muss auch die Benutzungsmarke Unterscheidungskraft besitzen, keine allgemeine Bezeichnung darstellen und keine beschreibende Angabe enthalten. Des Weiteren muss die Benutzungsmarke aus einem Zeichen bestehen, das geeignet ist, vom Publikum als Kennzeichnung der betrieblichen Herkunft der Ware wahrgenommen zu werden. Auch die Benutzungsmarke muss neu sein, sich also von älteren Marken unterscheiden. Schließlich darf sie nicht irreführend sein und nicht gegen das Gesetz, die öffentliche Ordnung oder die guten Sitten verstoßen.

\footnotetext{
${ }^{193} \mathrm{Vgl}$. Art. 28 CPI.

${ }^{194} \mathrm{Vgl}$. A. Sirotti Gaudenzi, Preuso di marchi di fatto: la prova deve essere rigorosa anche nel caso di patronimico, in: Quotidiano Giuridico, 2016.
} 


\subsection{Benutzungsmarke und unlauterer Wettbewerb}

Im Gesetzbuch des geistigen Eigentums finden sich hinsichtlich der Benutzungsmarke lediglich Bestimmungen im Hinblick auf das Verhältnis der Benutzungsmarke zur später eingetragenen Marke. Keine Regelungen gibt es hingegen in Bezug auf die Rechtsmittel, die dem Inhaber der Benutzungsmarke (also dem Vorbenutzer) gegenüber Dritten zustehen. Diesbezüglich ist Art. 2598, Ziff. 1) c.c. maßgeblich, wonach es untersagt ist, Namen oder Kennzeichen zu verwenden, die geeignet sind, eine Verwechslung mit den rechtmäßig durch andere verwendeten Namen oder Kennzeichen zu verursachen. Für den Fall, dass Dritte im Bekanntheitsbereich der Benutzungsmarke Waren oder Dienstleistungen in den Verkehr bringen, die identisch oder ähnlich sind wie Waren oder Dienstleistungen des Inhabers der Benutzungsmarke und diese mit einem mit dieser identischen oder ähnlichen Zeichen versehen sind, steht dem Inhaber der Benutzungsmarke ein Klageanspruch wegen unlauteren Wettbewerbs zu. Nach Maßgabe der Art. 2599 und 2600 c.c. kann damit die richterliche Untersagung, Schadenersatz und die öffentliche Bekanntmachung des Urteils begehrt werden.

\section{Internationales Markenrecht und Unionsmarkenrecht}

In Folge der Globalisierung und des internationalen Handels besteht die Notwendigkeit eines über die Staatsgrenzen hinausreichenden Markenschutzes. Allerdings begrenzen die modernen Rechtsordnungen dem Grundsatz der Territorialität folgend die Wirksamkeit des Markenschutzes auf das eigene Hoheitsgebiet. Demzufolge müssten jene Rechtssubjekte, die mit ein und derselben Marke sowohl national als auch internationale tätig sein möchten, die Marke bei den jeweiligen Markenämtern eines jeden Staates einzeln anmelden (Mehrfachanmeldungen), wobei das Recht an der jeweiligen Marke dem jeweiligen Regelwerk dieses Staates unterliegen würde. Um diesen Problemen Abhilfe zu schaffen, wurden zwei internationale Abkommen, nämlich die Pariser Verbandsübereinkunft (PVÜ) und das Madrider Markenabkommen (MMA), geschlossen.

\subsection{Die Pariser Verbandsübereinkunft}

Die Pariser Verbandsübereinkunft zum Schutz des gewerblichen Eigentums ${ }^{195}$ wurde am 20. März 1883 unterzeichnet und stellt eines der ersten internationalen Abkommen im Bereich des gewerblichen Rechtsschutzes dar. Italien trat der Pariser

\footnotetext{
${ }^{195}$ Italienisch: Convenzione di Parigi per la protezione della proprietà industriale; Englisch: Paris Convention for the Protection of Industrial Property.
} 
Verbandsübereinkunft am 07.07.1884 ${ }^{196}$ bei und hat die heute geltende Stockholmer Fassung vom 14.07.1967 mit Gesetz vom 28.04.1976, Nr. $424{ }^{197}$ ratifiziert.

$\mathrm{Zu}$ den wesentlichen Bestimmungen dieser Übereinkunft zählen der Grundsatz der Gleichstellung und die sogenannte Unionspriorität. Nach Maßgabe von Art. 2 der Übereinkunft (Inländerbehandlung für Angehörige der Verbandsländer) sind die Angehörigen eines jeden Verbandslandes den Staatsangehörigen in den anderen Verbandsländern in Bezug auf den Schutz des gewerblichen Eigentums gleichgestellt.

Zur Erleichterung von Mehrfachanmeldungen bestimmt Art. 4 der Übereinkunft, dass demjenigen, der in einem der Verbandsländer eine Marke angemeldet hat, innerhalb von sechs Monaten eine Anmeldung für das gleiche Zeichen in den anderen Verbandsländern vornehmen kann, wobei die Anmeldung rückwirkend ab dem Datum der ersten Anmeldung wirksam ist. Man spricht hier von der Unionspriorität.

\subsection{Die internationale Marke: Madrider Abkommen und Madrider Protokoll}

Die sogenannte internationale Marke (marchio internazionale) ist von zwei internationalen Übereinkünften, dem Madrider Markenabkommen sowie dem Madrider Markenprotokoll, geregelt.

Das Madrider Abkommen über die internationale Registrierung von Marken ${ }^{198}$ vom 14.04.1891 ${ }^{199}$ stellt einen Verband für die internationale Markenregistrierung dar. Aufgrund dieses Abkommens können die Angehörigen der Verbandsländer eine Marke in den gewünschten Verbandsländern auf der Grundlage der im Ursprungsland hinterlegten Markenanmeldung, oder der dort eingetragenen Marke durch Hinterlegung bei der Weltorganisation für geistiges Eigentum (WIPO) ${ }^{200}$ schützen lassen. Die Vereinfachung besteht nicht in der Gewährung eines einzigen Markenrechtes, sondern in einem vereinfachten Verfahren zur Ausdehnung des Markenschutzes auf andere Verbandsländer. Die Einreichung des Antrags auf internationale Eintragung entspricht somit der Anmeldung der Marke bei jedem bezeichneten Staat, wobei der Antrag in nur einer Sprache (Englisch, Französisch oder Spanisch)

\footnotetext{
${ }^{196} \mathrm{https}$ ///www.wipo.int/export/sites/www/treaties/en/documents/pdf/paris.pdf (zugegriffen am 15.04.2020).

${ }^{197}$ Legge 28.04.1976, n. 424: Ratifica ed esecuzione di accordi internazionali in materia di proprietà intellettuale, adottati a Stoccolma il 14 luglio 1967, in: Gazzetta Ufficiale, 19.06.1976, n. 160.

${ }^{198}$ Italienisch: Accordo di Madrid per la registrazione internazionale dei marchi; Englisch: Madrid Agreement Concerning the International Registration of Marks.

${ }^{199}$ In Italien mit Legge 28.04.1976, n. 424 in der Stockholmer Fassung ratifiziert.

${ }^{200}$ Italienisch: Organizzazione mondiale per la proprietà intellettuale (OMPI); Englisch: World Intellectual Property Organization (WIPO). Sitz in 1211 Genf (Schweiz), Chemin des Colombettes 20 - https://www.wipo.int/portal/en/index.html (zugegriffen am 20.04.2020).
} 
und bei einer zentralen Stelle hinterlegt werden kann, ohne dass die Anmeldung bei jedem nationalen Markenamt getrennt erfolgen muss.

$\mathrm{Ab}$ dem Tag der internationalen Registrierung genießt die Marke in den jeweiligen Ländern den gleichen Schutz, den sie genießen würde, wenn die Marke unmittelbar dort hinterlegt worden wäre. Daraus folgt, dass die internationale Registrierung unter der Bedingung gewährt werden kann, dass die Marke bereits im Ursprungsland des Inhabers angemeldet worden ist. Die internationale Registrierung ist in den ersten fünf Jahren ab dem Registrierungsdatum an die nationale Basisregistrierung gebunden. Das bedeutet, dass, sofern in diesem Zeitraum die nationale Marke aus irgendeinem Grund (z. B. infolge einer vor Ablauf der Fünfjahresfrist erhobenen Nichtigkeits- oder Verfallsklage) für ungültig erklärt wird, auch die entsprechende internationale Registrierung ihre Gültigkeit verliert. Erst nach Ablauf dieser fünf Jahre erlangt die internationale Registrierung eine Unabhängigkeit von der nationalen Basisregistrierung.

Das Madrider Markenabkommen wurde durch das sog. Madrider Markenprotokoll vom 27.06.1989 ${ }^{201}$ ergänzt, wobei es ein davon unabhängiges internationales Abkommen darstellt.

In Abweichung vom Madrider Abkommen wurde mit dem Madrider Protokoll vorgesehen, dass bereits die im Ursprungsland hinterlegte Markenanmeldung die Grundlage für die internationale Ausdehnung darstellen kann. Ferner kann auch eine Unionsmarke die Basismarke für die internationale Registrierung darstellen beziehungsweise im Zuge der internationalen Registrierung auch eine Unionsmarke eingeschlossen werden. ${ }^{202}$

\subsection{Das europäische Markenrecht und die Unionsmarke}

Das nationale Markenrecht, das dem Markeninhaber ein auf das nationale Hoheitsgebiet beschränktes Ausschließlichkeitsrecht gewährt, steht potenziell in Konflikt mit dem Unionsrecht, dessen Hauptziel die Schaffung eines gemeinsamen Binnenmarktes ist. Im Laufe der Jahre haben die Unionsorgane mit der Harmonisierung ${ }^{203}$

\footnotetext{
${ }^{201}$ Italienisch: Intesa di Madrid concernente la registrazione internazionale dei marchi. Englisch: Madrid protocol concerning the international registration of marks. In Italien ratifiziert mit Legge 12.03.1996, n. 169: Ratifica ed esecuzione del protocollo relativo alla intesa di Madrid concernente la registrazione internazionale dei marchi, firmato a Madrid il 27 giugno 1989, in: Gazzetta Ufficiale, 30.03.1996, n. 76.

${ }^{202}$ Vgl. A.G. Micara, Tutela del marchio e competitività nell'Unione Europea. Giappichelli, Torino, 2018, S. 196.

${ }^{203}$ Gestützt auf Art. 114, Abs. 1 des Vertrag über die Arbeitsweise der Europäischen Union (vormals Art. 95 EGV) wurde die Richtlinie (EU) 2015/2436 des Europäischen Parlaments und des Rates vom 16. Dezember 2015 zur Angleichung der Rechtsvorschriften der Mitgliedstaaten über die Marken, in: Amtsblatt der Europäischen Union, 23.12.2015, L 336/1 erlassen; vgl. G. Sena/S. Giudici, Il civilista: La nuova disciplina di marchi e brevetti, Giuffrè, Milano, 2019.
} 
des nationalen Markenrechtes einerseits sowie mit der Schaffung der Unionsmarke (vormals: Gemeinschaftsmarke) ${ }^{204}$ andererseits zur Herausbildung eines europäischen Markenrechtes beigetragen.

Die Unionsmarke (marchio dell'Unione Europea) verleiht dem Inhaber ein Schutzrecht, das in allen Mitgliedstaaten der Europäischen Union seine Wirkung entfaltet. Dieses Schutzrecht wird durch die Registrierung der Marke in einem eigens hierfür vorgesehenen Register des Amtes der Europäischen Union für geistiges Eigentum (EUIPO) ${ }^{205}$ mit Sitz in Alicante erworben.

Eine Unionsmarke folgt aufgrund der Bestimmungen der Verordnung (EU) 2017/1001 igF den Grundsätzen der Einheitlichkeit und Autonomie. Nach dem Grundsatz der Einheitlichkeit wird dem Inhaber der Unionsmarke ein Ausschließlichkeitsrecht zuerkannt, dessen Wirkung für das gesamte Gebiet der Europäischen Union gilt, ohne dass die geografische Tragweite des Schutzes auf einzelne Mitgliedsstaaten beschränkt werden kann. Demzufolge kann die Unionsmarke nur für die Europäische Union insgesamt eingetragen und übertragen werden, Gegenstand eines Verzichts sein und für nichtig oder verfallen erklärt werden. Selbiges gilt auch für das Verbot ihrer Benutzung. Im Unterschied zur internationalen Marke ist die Unionsmarke daher kein „Bündel“ verschiedener und eigenständiger nationaler Rechte, sondern ein supranationaler gewerblicher Eigentumstitel, also ein Titel, der auch nach der Eintragung einen einheitlichen Charakter aufweist. Im Falle der Erweiterung der Europäischen Union wird jede eingetragene Unionsmarke automatisch auf die neuen Mitgliedstaaten ausgedehnt, ohne dass es weiterer Formalitäten bedarf.

Nach dem Grundsatz der Autonomie unterliegt die Regelung der Unionsmarke ausschließlich der unionsrechtlichen Verordnung, wobei die Bestimmungen des nationalen Markenrechtes nur dann Anwendung finden, wenn in der Verordnung ausdrücklich darauf verwiesen wird.

Das materielle Unionsmarkenrecht entspricht weitgehend den markenrechtlichen Bestimmungen des italienischen Gesetzbuches für geistiges Eigentum.

Die vormals geltenden Richtlinien wurden außer Kraft gesetzt: Richtlinie 2008/95/EG des Europäischen Parlaments und des Rates vom 22. Oktober 2008 zur Angleichung der Rechtsvorschriften der Mitgliedstaaten über die Marken, in: Amtsblatt der Europäischen Union, 08.11.2008, L 299/25; Erste Richtlinie 89/104/EWG des Rates vom 21. Dezember 1988 zur Angleichung der Rechtsvorschriften der Mitgliedstaaten über die Marken, in: Amtsblatt, 11.02.1989, L 040.

${ }^{204}$ Die Gemeinschaftsmarke wurde mit der Verordnung (EG) Nr. 40/94 des Rates vom 20. Dezember 1993 über die Gemeinschaftsmarke, in: Amtsblatt, 14.01.1994, Nr. L 011 eingeführt, welche durch die Verordnung (EG) Nr. 207/2009 des Rates vom 26. Februar 2009 über die Gemeinschaftsmarke (kodifizierte Fassung), in: Amtsblatt der Europäischen Union, 24.03.2009, L 78/1 ersetzt worden ist. Heute wird die Unionsmarke mit der Verordnung (EU) 2017/1001 des Europäischen Parlaments und des Rates vom 14. Juni 2017 über die Unionsmarke (Text von Bedeutung für den EWR), in: Amtsblatt der Europäischen Union, 16.06.2017, L 154/1 normiert.

${ }^{205}$ Italienisch: Ufficio dell'Unione europea per la proprietà intellettuale; Englisch: European Union Intellectual Property Office. Sitz in 03008 Alicante (Spanien), Avenida de Europa, 4 -https:// euipo.europa.eu/ohimportal/de (zugegriffen am 20.04.2020). 
Demnach können Gegenstand der Unionsmarkenanmeldung dieselben Zeichen sein, die auch in Art. 7 CPI beschrieben sind. ${ }^{206}$

Auch die Voraussetzungen für die Markenfähigkeit, nämlich die Rechtmäßigkeit, die Unterscheidungskraft sowie die Neuheit, spiegeln die Bestimmungen des italienischen Gesetzbuches für geistiges Eigentum wider. In der Unionsmarkenverordnung werden diese Voraussetzungen allerdings als „Hindernisse“ bezeichnet und in absolute und relative Eintragungshindernisse unterschieden.

Die Registrierung der Unionsmarke erfolgt beim Amt der Europäischen Union für geistiges Eigentum (EUIPO), wobei dem Inhaber ein ausschließliches Recht eingeräumt wird, das mit jenem der Eintragung einer italienischen Marke gleichwertig ist, jedoch mit der Ausdehnung auf das gesamte Gebiet der Europäischen Union. Die Eintragung der Unionsmarke hat eine Gültigkeit von zehn Jahren ab dem Datum der Anmeldung und kann um jeweils weitere zehn Jahre erneuert werden.

Der Markeninhaber kann im Falle von Verstößen gegen das Ausschließlichkeitsrecht jene Mittel in Anspruch nehmen, die ausdrücklich für den Fall von Streitigkeiten in Sachen Nachahmung und Schutz der Unionsmarken vorgesehen sind.

Dazu gehört einerseits die Einleitung eines Verfahrens vor einem nach Maßgabe des Art. 123 der Verordnung (EU) 2017/1001 benannten Unionsmarkengericht. ${ }^{207}$ Die Unionsmarkengerichte sind im Sinne von Art. 124 Verordnung (EU) 2017/1001 ausschließlich zuständig für alle (a) Klagen wegen Verletzung und - falls das nationale Recht dies zulässt - wegen drohender Verletzung einer Unionsmarke, (b) Klagen auf Feststellung der Nichtverletzung, ${ }^{208}$ falls das nationale Recht diese zulässt, (c) Klagen hinsichtlich Entschädigungsansprüchen im Sinne von Art. 11, Abs. 2 Verordnung (EU) 2017/1001 sowie (d) Klagen betreffend die Erklärung des Verfalls oder der Nichtigkeit der Unionsmarke.

\footnotetext{
${ }^{206}$ Art. 4 (Markenformen): „Unionsmarken können Zeichen aller Art sein, insbesondere Wörter, einschließlich Personennamen, oder Abbildungen, Buchstaben, Zahlen, Farben, die Form oder Verpackung der Ware oder Klänge, soweit solche Zeichen geeignet sind,
}

a) Waren oder Dienstleistungen eines Unternehmens von denjenigen anderer Unternehmen zu unterscheiden und

b) in dem Register der Unionsmarken (im Folgenden „Register") in einer Weise dargestellt zu werden, dass die zuständigen Behörden und das Publikum den Gegenstand des dem Inhaber einer solchen Marke gewährten Schutzes klar und eindeutig bestimmen können. "

${ }^{207}$ Nach Maßgabe von Art. 123 Verordnung (EU) 2017/1001 haben die Mitgliedstaaten für ihr Gebiet eine möglichst geringe Anzahl nationaler Gerichte erster und zweiter Instanz zu benennen, die die ihnen durch diese Verordnung zugewiesenen Aufgaben wahrnehmen. In Bezug auf Italien liegt diese Zuständigkeit bei den Fachkammern für Unternehmensfragen, welche nach Maßgabe von Art. 1 Decreto Legislativo 27.06.2003, n. 168 bei den Landesgerichten und Oberlandesgerichten mit Sitz in den Hauptstädten der Regionen eingerichtet worden sind. Eine Ausnahme davon bildet die Autonome Region Trentino-Südtirol. Im Sinne von Art. 1, Abs. 1-bis Decreto Legislativo 27.06.2003, n. 168 ist eine Fachkammer für Unternehmensfragen auch beim Landesgericht Bozen sowie bei der Außenabteilung Bozen des Oberlandesgerichtes Trient eingerichtet.

${ }^{208}$ Vgl. G. Felloni, La tutela d'urgenza rispetto all'accertamento negativo: effetti anticipabili ed irreparabilità del pregiudizio, in: Giurisprudenza italiana, 2018, fasc. 3, S. 637 ff. 
Andererseits kann der Markeninhaber Maßnahmen bei den Zollbehörden der Europäischen Union im Sinne der Verordnung (EU) Nr. 608/2013209 beantragen. Mit diesem administrativen Verfahren können die Inhaber einer Unionsmarke die EU-Zollbehörden ersuchen, im Zuge ihrer Kontrollen Waren zu beschlagnahmen, bei denen der Verdacht der Nachahmung besteht.

\footnotetext{
${ }^{209}$ Verordnung (EU) Nr. 608/2013 des Europäischen Parlaments und des Rates vom 12. Juni 2013 zur Durchsetzung der Rechte geistigen Eigentums durch die Zollbehörden und zur Aufhebung der Verordnung (EG) Nr. 1383/2003, in: Amtsblatt der Europäischen Union, 29.06.2013, L 181/15.
}

Open Access Dieses Kapitel wird unter der Creative Commons Namensnennung 4.0 International Lizenz (http://creativecommons.org/licenses/by/4.0/deed.de) veröffentlicht, welche die Nutzung, Vervielfältigung, Bearbeitung, Verbreitung und Wiedergabe in jeglichem Medium und Format erlaubt, sofern Sie den/die ursprünglichen Autor(en) und die Quelle ordnungsgemäß nennen, einen Link zur Creative Commons Lizenz beifügen und angeben, ob Änderungen vorgenommen wurden.

Die in diesem Kapitel enthaltenen Bilder und sonstiges Drittmaterial unterliegen ebenfalls der genannten Creative Commons Lizenz, sofern sich aus der Abbildungslegende nichts anderes ergibt. Sofern das betreffende Material nicht unter der genannten Creative Commons Lizenz steht und die betreffende Handlung nicht nach gesetzlichen Vorschriften erlaubt ist, ist für die oben aufgeführten Weiterverwendungen des Materials die Einwilligung des jeweiligen Rechteinhabers einzuholen. 